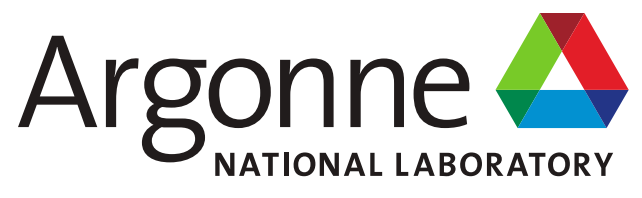

ANL/RTR/TM-18/12

\title{
Alternate Design Concepts for the High Flux Isotope Reactor using Low-Enriched Uranium Fuel Systems
}

Scoping Analysis

Nuclear Science and Engineering Division 
About Argonne National Laboratory

Argonne is a U.S. Department of Energy laboratory managed by UChicago Argonne, LLC under contract DE-AC02-06CH11357. The Laboratory's main facility is outside Chicago, at 9700 South Cass Avenue, Argonne, Illinois 60439. For information about Argonne and its pioneering science and technology programs, see www.anl.gov.

\section{DOCUMENT AVAILABILITY}

Online Access: U.S. Department of Energy (DOE) reports produced after 1991 and a growing number of pre-1991 documents are available free via DOE's SciTech Connect (http://www.osti.gov/scitech/)

Reports not in digital format may be purchased by the public from the National Technical Information Service (NTIS):

U.S. Department of Commerce

National Technical Information Service 5301 Shawnee Rd

Alexandria, VA 22312

www.ntis.gov

Phone: (800) 553-NTIS (6847) or (703) 605-6000

Fax: (703) 605-6900

Email: morders@ntis.gov

Reports not in digital format are available to DOE and DOE contractors from the Office of Scientific and Technical Information (OSTI):

U.S. Department of Energy

Office of Scientific and Technical Information

P.O. Box 62

Oak Ridge, TN 37831-0062

www.osti.gov

Phone: (865) 576-8401

Fax: (865) 576-5728

Email: reports@osti.gov

Disclaimer

This report was prepared as an account of work sponsored by an agency of the United States Government. Neither the United States Government nor any agency thereof, nor UChicago Argonne, LLC, nor any of their employees or officers, makes any warranty, express or implied, or assumes any legal liability or responsibility for the accuracy, completeness, or usefulness of any information, apparatus, product, or process disclosed, or represents that its use would not infringe privately owned rights. Reference herein to any specific commercial product, process, or service by trade name, trademark, manufacturer, or otherwise, does not necessarily constitute or imply its endorsement, recommendation, or favoring by the United States Government or any agency thereof. The views and opinions of document authors expressed herein do not necessarily state or reflect those of the United States Government or any agency thereof, Argonne National Laboratory, or UChicago Argonne, LLC. 


\section{Alternate Design Concepts for the High Flux Isotope Reactor using Low-Enriched Uranium Fuel Systems}

Scoping Analysis

prepared by

Aurelien Bergeron

Nuclear Science and Engineering Division, Argonne National Laboratory

September 2018 
(This page left intentionally blank) 


\section{Abstract}

The Oak Ridge National Laboratory (ORNL) High Flux Isotope Reactor (HFIR) is a multi-mission research reactor dedicated mainly to isotope production, neutron scattering experiments, material irradiation, testing and activation.

In the framework of non-proliferation policies, the international community is currently aiming to reduce or even eliminate, when and where possible, the use of Highly Enriched Uranium (HEU: $235 \mathrm{U} / \mathrm{U} \geq 20 \mathrm{wt} . \%$ ) in civilian applications. In that context, most research reactors worldwide still operating with HEU fuel are actively engaged in an effort to convert to Low Enriched Uranium fuel system (LEU: ${ }^{235} \mathrm{U} / \mathrm{U}<20$ wt. \%). Within the US, the High Performance Research Reactor (USHPRR) fleet (which includes HFIR) is expected to convert to LEU fuel using the UMo "monolithic" fuel system currently under development.

ORNL is responsible for the development of a LEU design for HFIR. In the past years, Argonne National Laboratory (ANL) offered technical assistance to the ORNL LEU design team whenever deemed appropriate.

Due to their complex nature, acceptable HFIR LEU designs identified so far, all based on the UMo monolithic fuel system, would require a substantial fabrication development effort before being proven commercially viable. In order to mitigate technical risks and reduce cost/schedule uncertainties, it appears appropriate to study alternate design solutions and alternate fuel systems as possible backup options for the HFIR conversion to LEU fuel.

In that context, ANL has been exploring alternate design concepts for HFIR. Complementing the ORNL design activities, the goal is to find the best design solution for HFIR in term of cost, performance and safety. The present report summarizes the findings regarding two types of alternate conceptual design: $\mathrm{U}_{3} \mathrm{Si}_{2}$ designs and un-contoured UMo design. Based on available tools and methods, preliminary analysis show that both concepts could probably meet performance and steady-state safety requirements but element fabrication would remain complex and would require a non-trivial fabrication development effort. 


\section{Table of Contents}

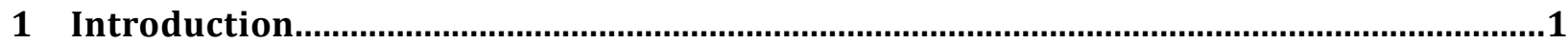

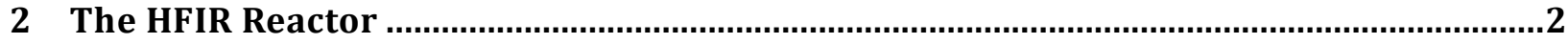

2.1 Brief Description of the HFIR Reactor .......................................................................................... 2

2.2 The HEU Fuel Elements........................................................................................................... 6

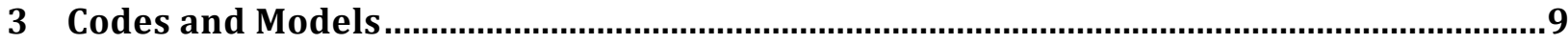

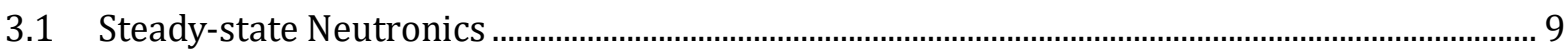

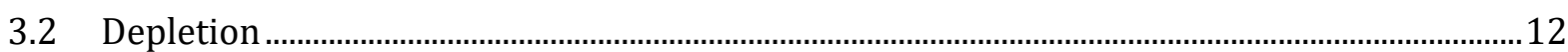

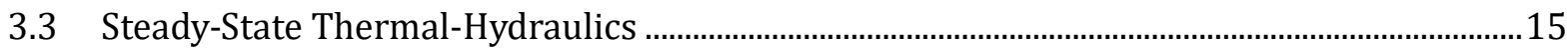

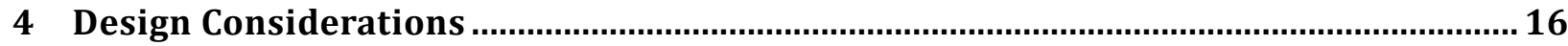

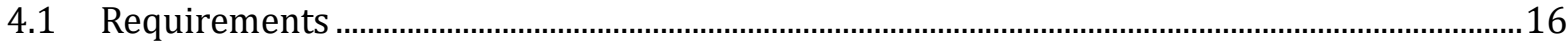

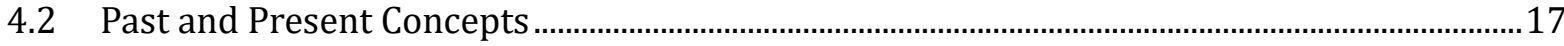

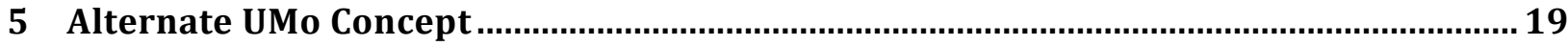

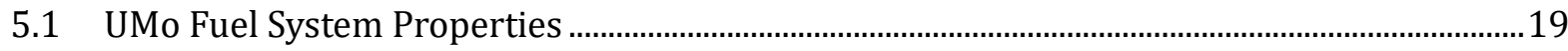

5.2 UMo Design Space Exploration Strategy …..................................................................................20

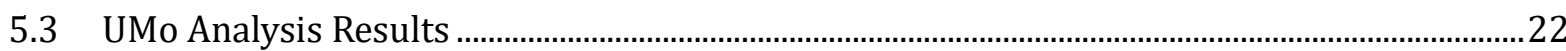

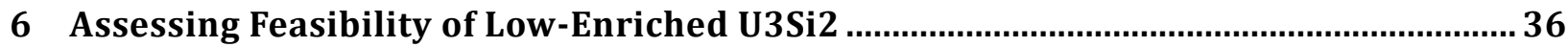

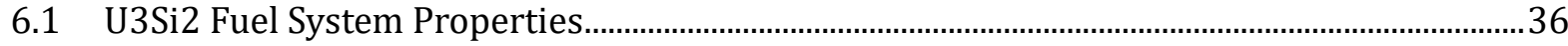

6.2 U3Si2 Design Space Exploration Strategy.................................................................................. 41

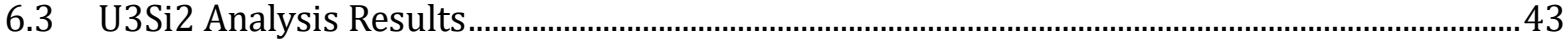

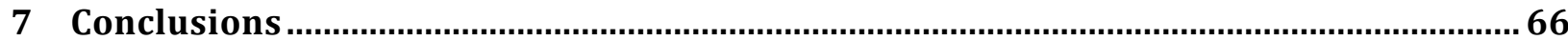

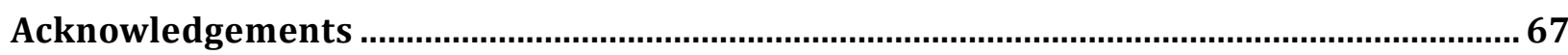

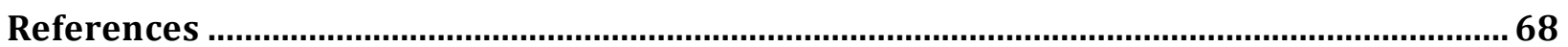

Alternate Design Concepts for the High Flux Isotope Reactor using Low-Enriched Uranium Fuel Systems - Scoping Analysis ii 


\section{List of Figures}

Figure 2-1 - Aerial view of the HFIR site [ORNL, 2017] ……………………............................................. 2

Figure 2-2 - Axial cross sectional view of the HFIR reactor [ORNL, 2017] ................................................... 4

Figure 2-3 - Plan view of the HFIR core assembly [ORNL, 2017] …………………................................... 5

Figure 2-4 - Schematic representation of the position of the control elements during the cycle - Not

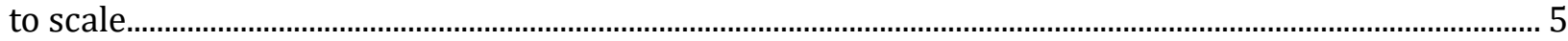

Figure 2-5 - View of a mockup of the inner and outer elements [Ilas, 2011] ............................................ 6

Figure 2-6 - Illustration of the HEU IFE and OFE fuel distributions [Cheverton, 1971]. The fuel meat is shown in gray, the filler in black. Not to scale. ...................................................................................... 7

Figure 2-7 - Thickness of the fuel and filler along the fuel plate width in both HEU IFE (top) and OFE

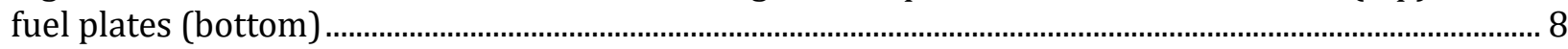

Figure 3-1 - Cross-section view of the HFIR MCNP Model: reactor core (top) and details of the fuel

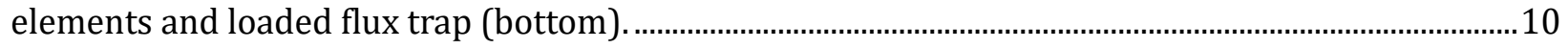

Figure 3-2 - Steady-state/depletion coupling scheme used to perform neutronic calculations..........13

Figure 5-1 - Top cross-section schematic of HFIR side-plate and options to insert wires .....................24

Figure 5-2 - Schematic top and profile cross-section of HFIR fuel elements: current design (left) and sleeve concept (right). Gray represents side-plates; light blue represents fuel plates; red represents fuel; yellow represents sleeve containing cadmium wires (cadmium wires not represented) ............29

Figure 5-3 - Critical position of the control elements versus time for configuration 23-6.5-9.5-S166 depleted at 95MW and HEU depleted at $85 \mathrm{MW}$.

Figure 5-4 - Evolution of HEU representative core and LEU UMo configuration 23-6.5-9.5-S166 thermal neutron flux in the cold source in beam tube HB4..

Figure 5-5 - Evolution of HEU representative core and LEU UMo configuration 23-6.5-9.5-S166 ratio fast/thermal neutron flux in the cold source in beam tube HB4 ................................................................33

Figure 5-6 - Evolution of HEU representative core and LEU UMo configuration 23-6.5-9.5-S166 ${ }^{252} \mathrm{Cf}$

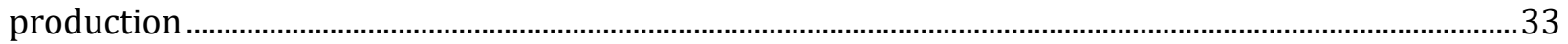

Figure 5-7 - Evolution of HEU representative core and LEU UMo configuration 23-6.5-9.5-S166 238Pu

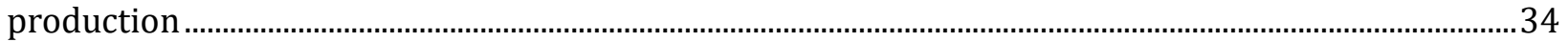

Figure 5-8 - Evolution of HEU representative core and LEU UMo configuration 23-6.5-9.5-S166 limiting power based on the critical heat flux (CHF) and flow excursion (FE) criteria...........................34

Figure 6-1 - Thermal conductivities of uranium silicide, $\mathrm{U}_{3} \mathrm{O}_{8}$ and UAlx-aluminum dispersion fuels as a function of volume fraction of fuel particles plus voids (porosity). Source: [IAEA, 1992] pp.18......39

Figure 6-2 - Calculated U18-20 uncertainty factors for silicide fuel using the methodology described in [Hilvety, 1967] and tools described in [Jaluvka, 2016]..

Figure 6-3 - Meat thickness increase induced by fuel swelling for $\mathrm{U}_{3} \mathrm{Si}_{2} 4.8 \mathrm{gU} / \mathrm{cc}$ and U10Mo monolithic LEU fuel....

Figure 6-4 - Schematic IFE (top) and OFE (bottom) fuel plate cross-section of un-contoured (flat) fuel with Al-B layer in IFE plates. . .48

Figure 6-5 - Power required to match average HEU neutron flux in most limiting location for uncontoured fuel configuration with and without Al-B layer in IFE plates. Results are for 21 (top), 22

Alternate Design Concepts for the High Flux Isotope Reactor using Low-Enriched Uranium Fuel Systems - Scoping Analysis 
(middle), 23 (bottom) inch long fuel configuration. Al-B layer thickness is equal to 26 mil minus the IFE fuel thickness (mil). OFE fuel thickness is always 26 mil. 50

Figure 6-6 - Cycle length at required power for un-contoured fuel configuration with and without AlB layer in IFE plates. Results are for 21 (top), 22 (middle), 23 (bottom) inch long fuel configuration. $\mathrm{Al}-\mathrm{B}$ layer thickness is equal to 26 mil minus the IFE fuel thickness (mil). OFE fuel thickness is always 26 mil. 51

Figure 6-7 - ratio LEU vs. HEU ${ }^{252} \mathrm{Cf}$ production for configuration with and without Al-B layer in IFE plates. Results are for 21 (top), 22 (middle), 23 (bottom) inch long fuel configuration. Al-B layer thickness is equal to 26 mil minus the IFE fuel thickness (mil). OFE fuel thickness is always 26 mil52

Figure 6-8 - ratio LEU vs. HEU ${ }^{238} \mathrm{Pu}$ production for configuration with and without Al-B layer in IFE plates. Results are for 21 (top), 22 (middle), 23 (bottom) inch long fuel configuration. Al-B layer thickness is equal to 26 mil minus the IFE fuel thickness (mil). OFE fuel thickness is always 26 mil53

Figure 6-9 - margin to CHF in IFE plates for configuration with and without Al-B layer in IFE plates. Results are for 21 (top), 22 (middle), 23 (bottom) inch long fuel configuration. Al-B layer thickness is equal to 26 mil minus the IFE fuel thickness (mil). OFE fuel thickness is always 26 mil..... .54

Figure 6-10 - margin to FE in IFE plates for configuration with and without Al-B layer in IFE plates. Results are for 21 (top), 22 (middle), 23 (bottom) inch long fuel configuration. Al-B layer thickness is equal to 26 mil minus the IFE fuel thickness (mil). OFE fuel thickness is always 26 mil .55

Figure 6-11 - margin to CHF in OFE plates for configuration with and without Al-B layer in IFE plates. Results are for 21 (top), 22 (middle), 23 (bottom) inch long fuel configuration. Al-B layer thickness is equal to 26 mil minus the IFE fuel thickness (mikl). OFE fuel thickness is always 26 mil. 56

Figure 6-12 - margin to FE in OFE plates for configuration with and without Al-B layer in IFE plates. Results are for 21 (top), 22 (middle), 23 (bottom) inch long fuel configuration. Al-B layer thickness is equal to 26 mil minus the IFE fuel thickness (mil). OFE fuel thickness is always 26 mil . .57

Figure 6-13 - IFE fuel shape A (top), B (middle) and C (bottom) used to study the impact of the fuel reduction on IFE margins and other metrics of interest. 59

Figure 6-14 - Minimum TH margin in IFE plates at BOC per IFE lateral fuel region obtained with three different IFE fuel shapes (labeled A, B and C, depicted in figure 8). OFE fuel thickness is 26 mil, fuel length in both elements is 22 inch long and no absorbers are present. The blue dashed line represents the minimum required value (1.0) 60

Figure 6-15 - Configuration 22-NH10-26_AlB IFE fuel profile with Al-B filler ... .61

Figure 6-16 - Critical position of the control elements versus time for configuration 22-NH10-26_AlB depleted at 92MW and HEU depleted at $85 \mathrm{MW}$.

Figure 6-17 - Thermal neutron flux in cold source (limiting location) for configuration 22-NH1026_AlB depleted at 92MW and HEU depleted at 85MW..

Figure 6-18 - Ratio of fast / thermal neutron flux in cold source (limiting location) for configuration 22-NH10-26_AlB depleted at 92 MW and HEU depleted at 85MW ... 63

Figure 6-19 - Evolution of the ${ }^{252} \mathrm{Cf}$ atomic density in targets for configuration 22-NH10-26_AlB depleted at 92MW and HEU depleted at $85 \mathrm{MW}$ 63

Figure 6-20 - Evolution of the ${ }^{238} \mathrm{Pu}$ mass in targets for configuration 22-NH10-26_AlB depleted at 92MW and HEU depleted at 85MW . .64

Figure 6-21 - Evolution of the power leading to CHF and OFI for configuration 22-NH10-26_AlB depleted at 92MW and compared to the nominal and safety limit power. 64 


\section{List of Tables}

Table 3-1 - Lateral node size, along the plate, used in design analysis. 11

Table 3-2 - Axial node size used in design analysis 11

Table 3-3 - Time step duration used in depletion analysis 14

Table 4-1 - HFIR design features (fuel and absorber) combination investigated with UMo fuel monolithic fuel (20 inch long fuel) 18

Table 5-1 - UMo "monolithic" composition used in neutronic calculations 19

Table 5-2 - Energy produced in one cycle for various UMo designs having no absorber. Color scale goes from orange (smallest number) to red (largest number). If color is black, value is below threshold value of 2650 MWdays .23

Table 5-3 - Performance of LEU UMo configuration 23-6.5-9.5 with various vertical cadmium wires located in the IFE inner side-plate. Metrics that do no not meet requirements are colored in pink. .26

Table 5-4 - IFE inner edge, OFE outer edge margin evolution. From top to bottom, margin to: CHF, IFE inner edge; CHF OFE outer edge; FE, IFE inner edge; FE, OFE outer edge. Color scale goes from gray (smaller value) to green (highest value). Cells colored in black do not meet safety criteria (margin < 1.0). Axial position 1 is top of the fuel, 25 is bottom 27

Table 5-5 - Selected dimensions for the absorbing sleeve concept used in MCNP 29

Table 5-6 - Geometric information for wire \#1 to \#84 30

Table 5-7 - Geometric information for wire \#85 to \#166. 31

Table 5-8 - Characteristics of the LEU UMo 23-6.5-9.5-S166 design and current HEU core. 35

Table 6-1- Silicide composition description .37

Table 6-2 - Proposed fuel composition for silicide fuel to be used in neutronic calculations 37

Table 6-3 - design space discretized for fuel length and IFE, OFE fuel thicknesses: energy produced during the cycle (left); required reactor power to match neutron flux metrics (middle); cycle length calculated as the ratio between energy and required power (right). Cells are blacken if excluded from design space or below a specific value (2210MWday for energy and 26 days for cycle length) ..........44

Table 6-4 - design space discretized for fuel length and IFE, OFE fuel thicknesses: LEU versus HEU ${ }^{252} \mathrm{Cf}$ production (left); LEU versus HEU ${ }^{238} \mathrm{Pu}$ production (middle); configuration meeting performance requirements (equal 1 if satisfy performance requirements: cycle length at required power, ${ }^{252} \mathrm{Cf} \&{ }^{238} \mathrm{Pu}$ production equal or exceed HEU equivalent, else equal 0) (right). Cells are blacken if excluded from design space or below a specific value. 45

Table 6-5 - design space discretized for fuel length and IFE, OFE fuel thicknesses: margin to CHF in the IFE (left); margin to FE in the IFE (middle); configuration meeting IFE TH margin requirements (equal 1 if CHF and FE margins exceed 1.0, else equal 0) (right). Cells are blacken if excluded from design space or below a specific value (1.0 for the three figures) 46

Table 6-6 - design space discretized for fuel length and IFE, OFE fuel thicknesses: margin to CHF in the OFE (left); margin to FE in the OFE (middle); configuration meeting OFE TH margin requirements (equal 1 if CHF and FE margins exceed 1.0, else equal 0) (right). Cells are blacken if excluded from design space or below a specific value (1.0 for the three figures)

Alternate Design Concepts for the High Flux Isotope Reactor using Low-Enriched Uranium Fuel Systems - Scoping Analysis 
Table 6-7 - Key results obtained for IFE shaped fuel configuration (labeled A, B and C, depicted in Figure 6-13) of fuel length 21, 22 and 23 inch. Cell is black if value does not meet requirement.......60

Table 6-8 - characteristics of the silicide 22-NH10-26_AlB design and current HEU core......................65 


\section{Introduction}

The Oak Ridge National Laboratory (ORNL) High Flux Isotope Reactor (HFIR) is a multi-mission research reactor dedicated mainly to isotope production, neutron scattering experiments, material irradiation, testing and activation.

The international community currently aims to reduce or even eliminate, when and where possible, the use of Highly Enriched Uranium (HEU: ${ }^{235} \mathrm{U} / \mathrm{U} \geq 20 \mathrm{wt}$. \%) in civilian applications. In that context, most research reactor worldwide still operating with HEU fuel are actively engaged in an effort to convert to Low Enriched Uranium fuel system (LEU: ${ }^{235} \mathrm{U} / \mathrm{U}<20 \mathrm{wt}$. \%). Within the US, the High Performance Research Reactor (USHPRR) fleet (which includes HFIR) is expected to convert to LEU fuel using the UMo "monolithic" fuel system currently under development.

All HFIR LEU design concepts presented so far ([Ilas, 2010], [Renfro, 2014]) were based on the constraint that key fuel element geometric dimensions (i.e. fuel length, number of plates...) have to be identical to the current HEU design. In this study, alternate design concepts are investigated based on the assumption that geometric constraints can be relaxed. There is, at this time, no guarantee or basis to justify that such a constraint relaxation is possible, but considering the technical difficulties and cost associated with the current HFIR LEU conversion project, it is useful to understand what unconstrained geometries could offer in term of design possibilities. This report summarizes the key finding of this investigation, and is strucutured as follows:

- The second (next) section provides a brief description of the HFIR reactor

- The third section describes the tools and methods used to perform the design analysis

- The fourth section present the design requirements used to perform the analysis as well as design features considered in the past and their functions

- The fifth section presents an alternate HFIR design concept that makes use of UMo monolithic fuel, cadmium wires as absorber and un-contoured (flat) fuel

- The sixth - and last technical - section assesses the feasibility of using the LEU U3Si2 (silicide) fuel system for HFIR 


\section{The HFIR Reactor}

The following provides a brief description of the HFIR reactor and its fuel elements. This section is largely inspired from [Bergeron, 2012].

\subsection{Brief Description of the HFIR Reactor}

The High Flux Isotope Reactor (HFIR), located at Oak Ridge National Laboratory (ORNL), achieved first criticality August 25 1965. Even though the reactor fulfills a wide range of missions, it has been primarily designed for trans-plutonium isotope production [Cheverton, 1971]. Following a 2-year long survey on flux trap reactors and their potential application for heavy isotope production [Lane, 1958], the U.S. Atomic Energy Commission (forerunner to the U.S. DOE) decided to build HFIR in November 1958 [Lane, 1959]. The first HFIR physics report was issued in 1960 [Cheverton, 1960], immediately followed by the first critical experiments employing prototype HFIR fuel elements and control rods [Cheverton, 1962]. The construction of the reactor was completed in 1964. Low-power operation was completed in January 1966 and full power (100MW thermal) was achieved in September 1966 [Cheverton, 1971]. The reactor operated without any notable incident until November 1986 when it was discovered that, due to neutron-induced-radiation, the reactor vessel suffered embrittlement at a faster rate than expected. After a long shutdown and modification made to the operating pressure of the primary coolant, the reactor was re-started in April 1989 and reached its new full power, 85MW thermal, in May 1990. HFIR underwent another long shutdown in 2006 to refurbish the facility. Significant upgrading of the neutron scattering experiment equipment was carried out during this period. The refurbishment was completed in 2007 [ORNL, 2017].

Today, HFIR continues to fulfill its two main missions: isotope production and neutron scattering experimentation. HFIR has approximately 600 users each year for both neutron scattering and incore research [ORNL, 2017]. An aerial view of the facility is given in Figure 2-1.

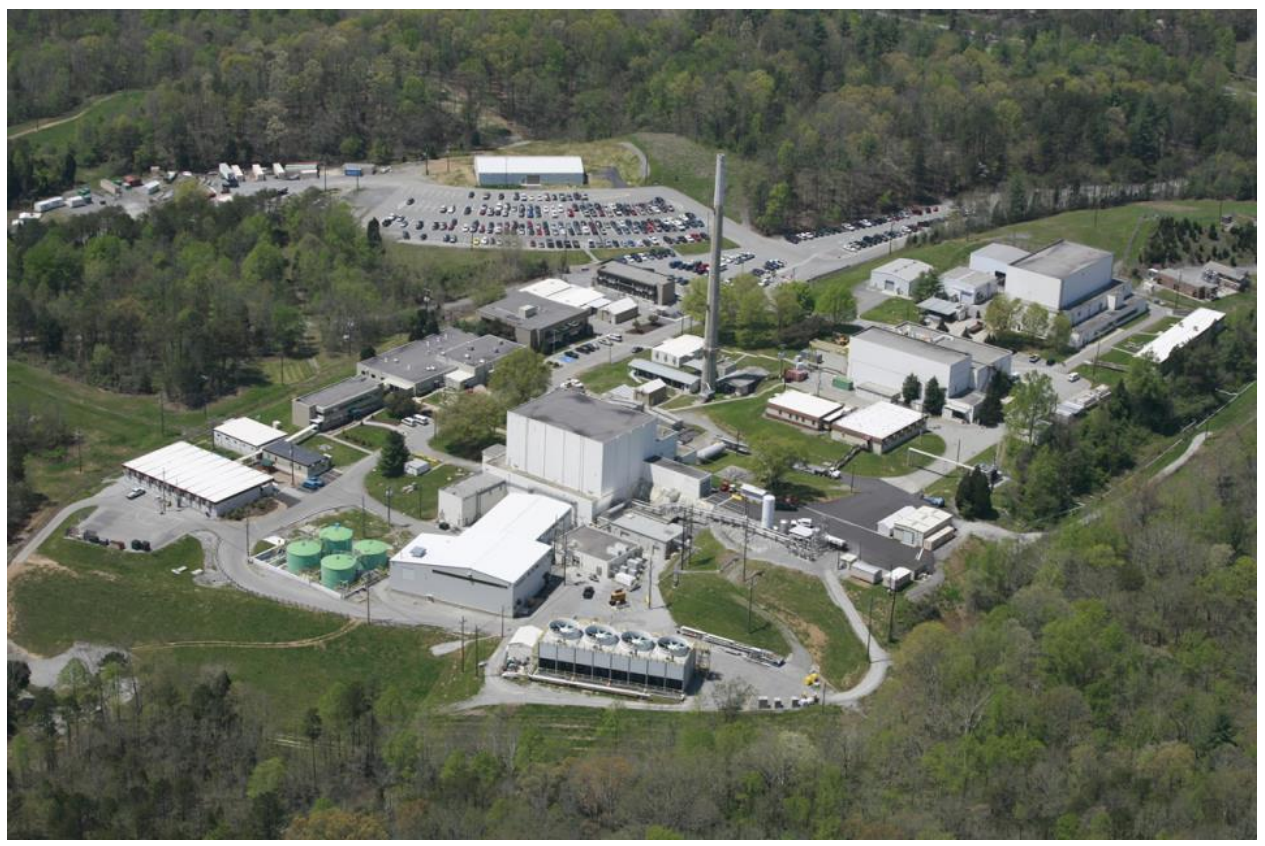

Figure 2-1 - Aerial view of the HFIR site [ORNL, 2017]

Alternate Design Concepts for the High Flux Isotope Reactor using Low-Enriched Uranium Fuel Systems - Scoping Analysis 
HFIR is a light water moderated and cooled, beryllium reflected, flux-trap type reactor. The reactor core is contained in a pressure vessel located in a light water pool. The external diameter of the vessel is about $244 \mathrm{~cm}$ and its height is approximately $500 \mathrm{~cm}$. The reactor core is cylindrical, approximately $61 \mathrm{~cm}$ high and has a diameter of $114 \mathrm{~cm}$. A cross-sectional view of the reactor and a plan view of the core are given in Figure 2-2 and Figure 2-3, respectively. At the center of the core, a hole of $12.7 \mathrm{~cm}$ diameter forms the Flux Trap Target region (FTT). The flux trap is surrounded by two concentric annular fuel elements. Each consists of sandwich-type fuel plate (fuel surrounded by cladding) curved as a circle involute. The involute shape allows the coolant gap between the plates to have a constant thickness. More details on the fuel elements are given in Sections 2.2.

Surrounding the fuel elements is an annular region containing the control elements (CEs). They consist of two $1 \mathrm{~cm}$-thick concentric cylinders. Light water circulates between the CEs to insure proper cooling. The inner cylinder (ICE) is used for both shim control and regulation and is moved downward during the cycle. The outer cylinder (OCE) is made of four plates that can be moved independently to trip the reactor at any time and are referred to as the shim-safety plates. They are moved upward during the cycle. The typical position of the CEs at different times during the cycle is illustrated in Figure 2-4. To reduce axial variations in the power distributions, the control elements are divided into three axial sections. Each of them incorporates different materials that have different neutron absorbing characteristics. The so-called white material (lower section of the OCE, upper section of the ICE) is made of aluminum and is low neutron absorbing. The so-called gray material (central section of both the OCE and ICE) is made of tantalum dispersed in aluminum and is moderately neutron absorbing. The so-called black material (upper section of the OCE, lower section of the ICE) is made of $\mathrm{Eu}_{2} \mathrm{O}_{3}$ dispersed in aluminum and is highly neutron absorbing. In addition, due to the high cross-sections of its daughter products, the efficiency of the black region tends to increase with time [ORNL, 2009].

A $30 \mathrm{~cm}$-thick beryllium annular reflector surrounds the control element region. It suffers irradiation damage during operation. To minimize the amount of beryllium requiring replacement over the long term, the reflector is divided into three regions. The three first cylinders $(\sim 5 \mathrm{~cm}$-thick $)$ are replaced every 40 cycles and constitute the first part of the reflector and are called the Removable Beryllium reflector (RB). The fourth one ( $5 \mathrm{~cm}$-thick), the second part of the reflector, is replaced every 80 cycles and is called the Semi-permanent Beryllium reflector (SB). The last part and outermost section of the reflector $(\sim 20 \mathrm{~cm}$-thick), called the Permanent Beryllium Reflector (PB), is replaced every 135 cycles. The three regions of the reflector contain a significant number of experiment facilities such as the four beam tubes, the engineering facilities and the large and small vertical experiment facilities. The entire core is surrounded by light water in order to prevent significant radiation damage and heating in the pressure vessel. The water enters the pressure vessel through two $41 \mathrm{~cm}$-diameter pipes located above the core (one of them is visible in Figure 2-2). The coolant passes downward through the core and exits through a $\sim 46 \mathrm{~cm}$-diameter pipe located just below the core. The inlet flow rate is $1.01 \mathrm{~m}^{3} / \mathrm{s}$. Through the fuel elements, the flow rate is $0.82 \mathrm{~m}^{3} / \mathrm{s}$ and the coolant velocity between the plates is $15.5 \mathrm{~m} / \mathrm{s}$. The rest of the flow cools down the other regions of the core: reflector, flux trap, control elements. The nominal inlet pressure is $3.33 \mathrm{MPa}$. The core outlet pressure is $2.585 \mathrm{MPa}$ (pressure drop through the core is $0.745 \mathrm{MPa}$ ). The inlet temperature is $322 \mathrm{~K}$ and the outlet temperature is $342 \mathrm{~K}$ [ORNL, 2009]. 


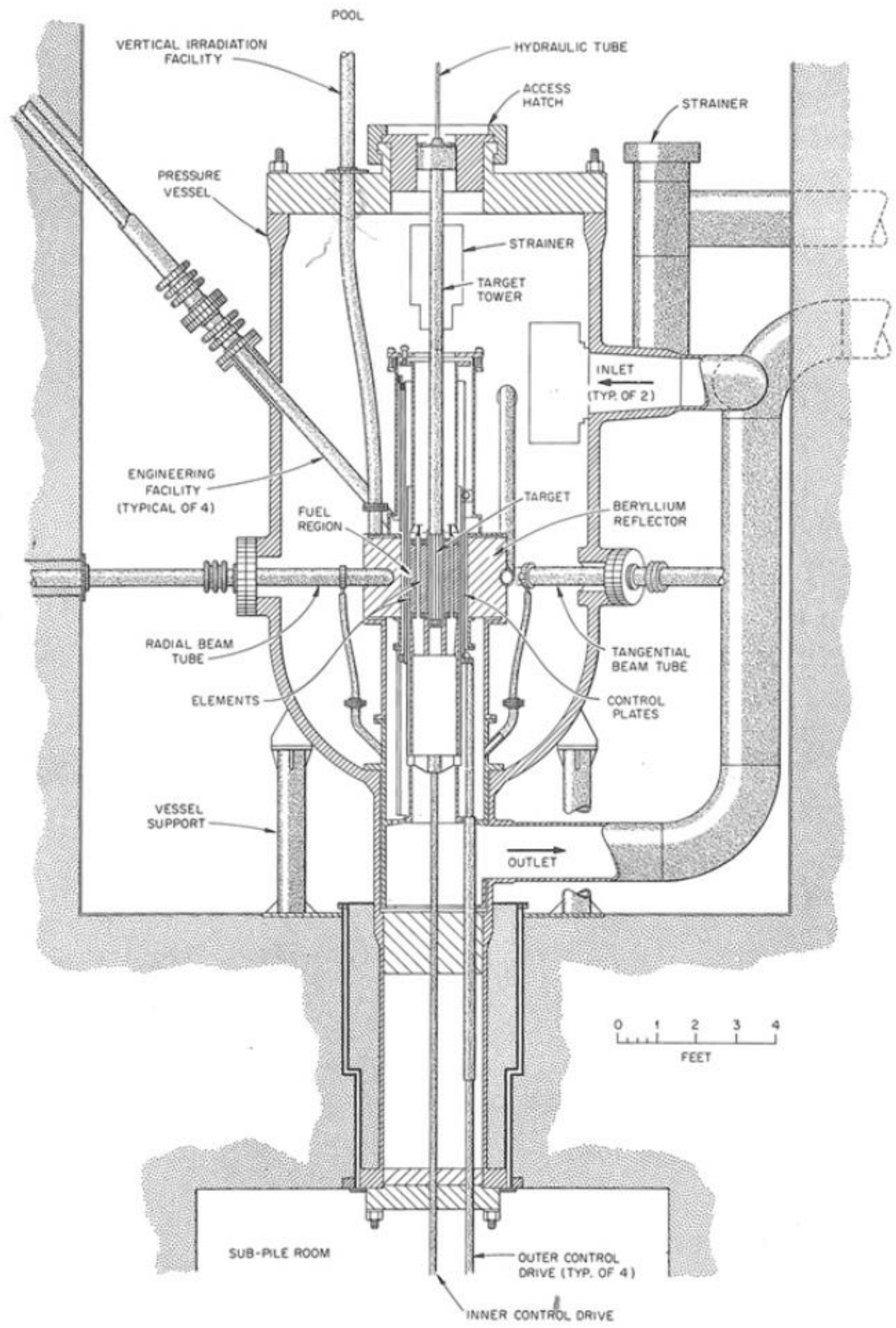

Figure 2-2 - Axial cross sectional view of the HFIR reactor [ORNL, 2017]

Alternate Design Concepts for the High Flux Isotope Reactor using Low-Enriched Uranium Fuel Systems - Scoping Analysis 


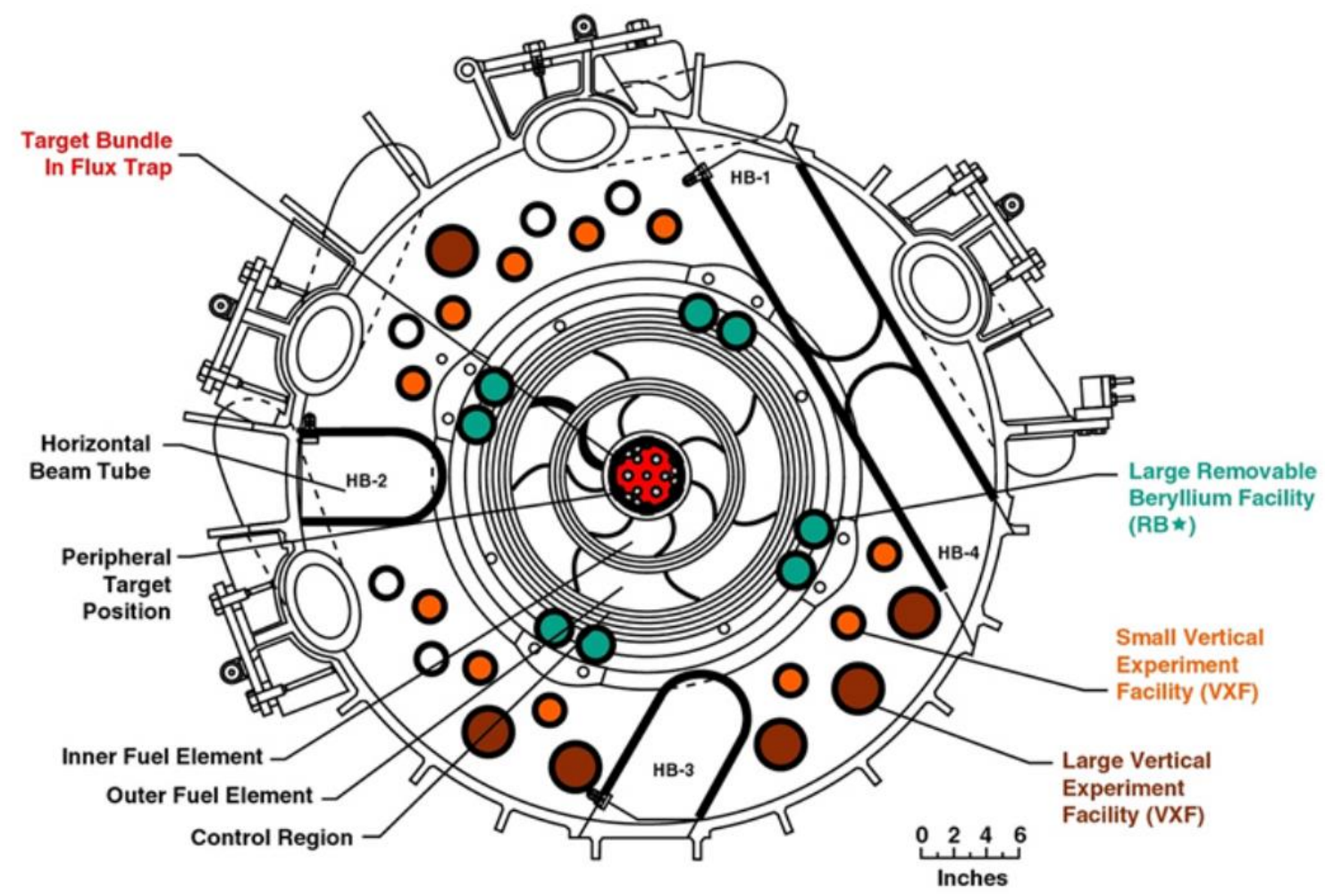

Figure 2-3 - Plan view of the HFIR core assembly [ORNL, 2017]

White region

Grey Region

Black region

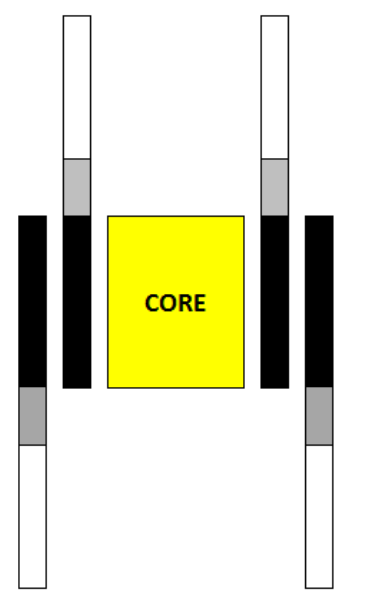

SHUTDOWN

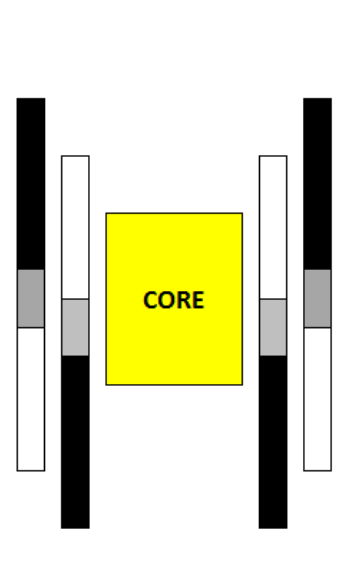

COLD CLEAN CRITICAL

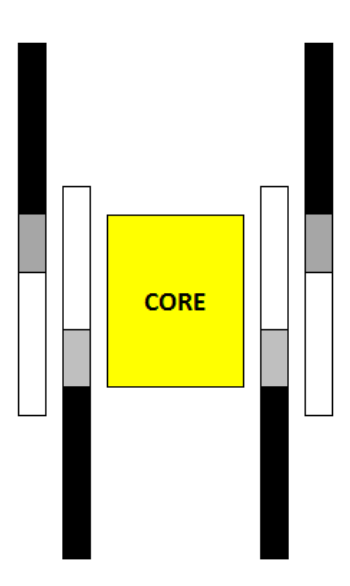

MID CYCLE

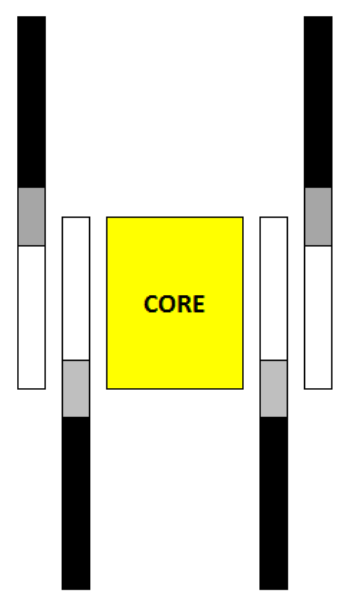

END OF CYCLE

Figure 2-4 - Schematic representation of the position of the control elements during the cycle - Not to scale. 


\subsection{The HEU Fuel Elements}

The HEU core is made of two concentric annular fuel elements separated by a $0.84 \mathrm{~cm}$-thick water gap. Both elements are made of sandwich-type fuel plates (two cladding plates surrounding a thin layer of fuel). A picture of a mockup of the fuel elements is given in Figure 2-5. The plate thickness is $0.127 \mathrm{~cm}(50 \mathrm{mil})$ and the coolant gap between the plates is also $0.127 \mathrm{~cm}$-thick $(50 \mathrm{mil})$. The plates are $60.96 \mathrm{~cm}$ high (24 inches) and the length of the fuel is $50.80 \mathrm{~cm}$ (20 inches). The width of the inner and outer element plates is 9.21 and $8.10 \mathrm{~cm}$, respectively. The width of the inner and outer element fuel along the involute arc length is 7.79 and $7.02 \mathrm{~cm}$, respectively. The cladding is made of 6061 aluminum alloy and its thickness is $0.0254 \mathrm{~cm}$ (10 mil). In order to keep a constant coolant gap thickness, the plates are curved as circle involutes. The inner fuel element (IFE) incorporates 171 plates whereas the outer fuel element (OFE) has 369 plates (a total of 540 plates). Both inner and outer element fuel plates are contained between two $0.635 \mathrm{~cm}$-thick cylindrical aluminum side-plates. The inner and outer radii of the IFE are 6.44 and $13.44 \mathrm{~cm}$, respectively. The inner and outer radii of the OFE are 14.27 and $21.77 \mathrm{~cm}$, respectively. In order to reduce the maximum-to-average power density ratio, the fuel is radially graded (fuel thickness varies from the inner to the outer edge). The fuel grading is different in the inner and outer elements. Figure 2-6 shows a view of the fuel distribution in both elements and Figure 2-7 shows the fuel thickness variation along the plate's width in both elements.

The fuel is made of highly enriched $\mathrm{U}_{3} \mathrm{O}_{8}$ fuel $(235 \mathrm{U} / \mathrm{U}=93 \mathrm{wt}$. \%) dispersed in an aluminum matrix. The fuel density is different in the inner and outer elements. The two elements contain a total of $9.4 \mathrm{~kg}$ of ${ }^{235} \mathrm{U}$ (2.6kg in the IFE and 6.8kg in the OFE). In addition, a burnable absorber, boron in the form of $\mathrm{B}_{4} \mathrm{C}$, is present in the inner fuel plates, as shown in Figure 2-6. In particular, $2.8 \mathrm{~g}$ of ${ }^{10} \mathrm{~B}$ are present in the whole IFE $(0.0164 \mathrm{~g} / \mathrm{plate})$. It is used to shift the power to the outer fuel element and reduce the core reactivity $(\sim 5000 \mathrm{pcm})$ at Beginning of Life (BOL).

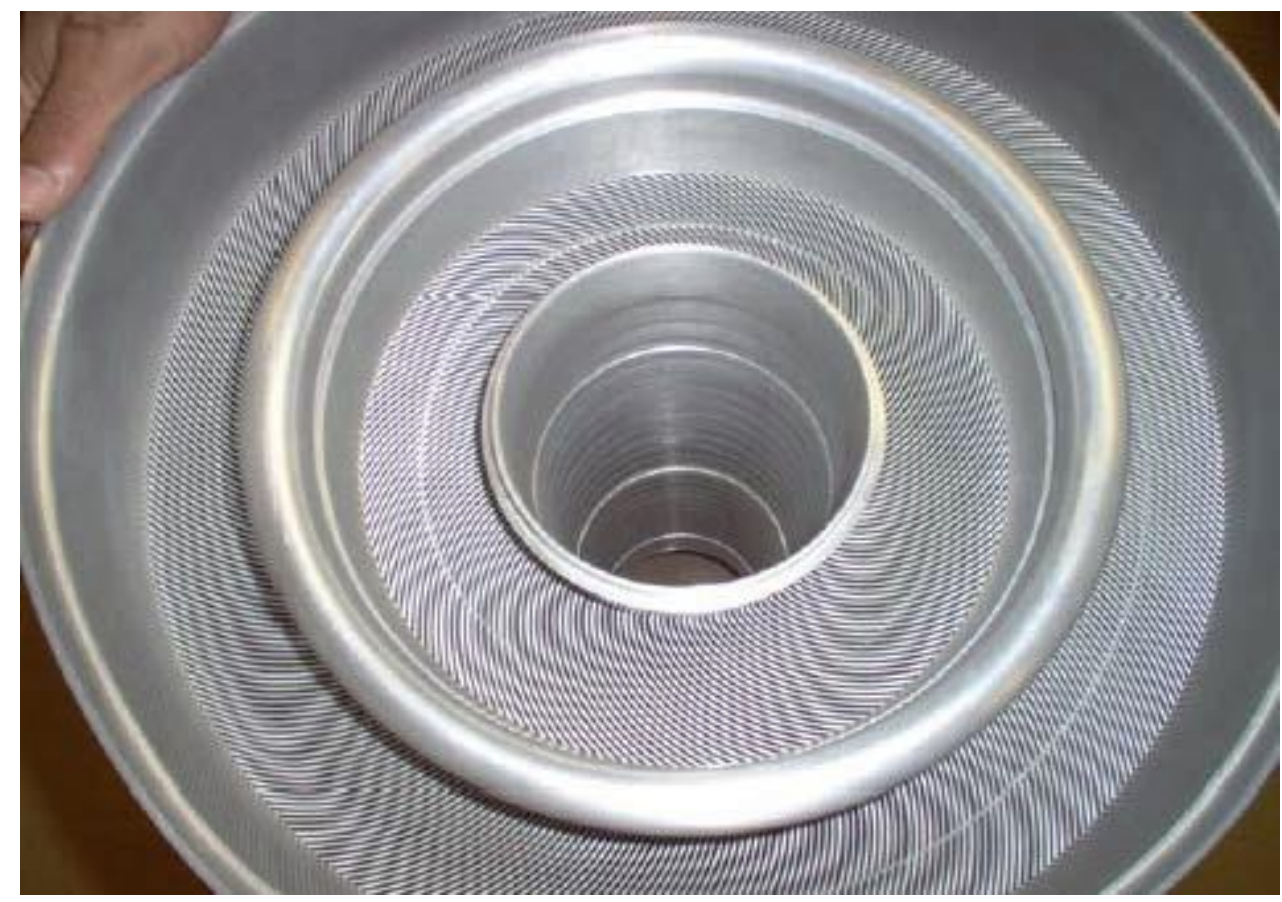

Figure 2-5 - View of a mockup of the inner and outer elements [Ilas, 2011] 


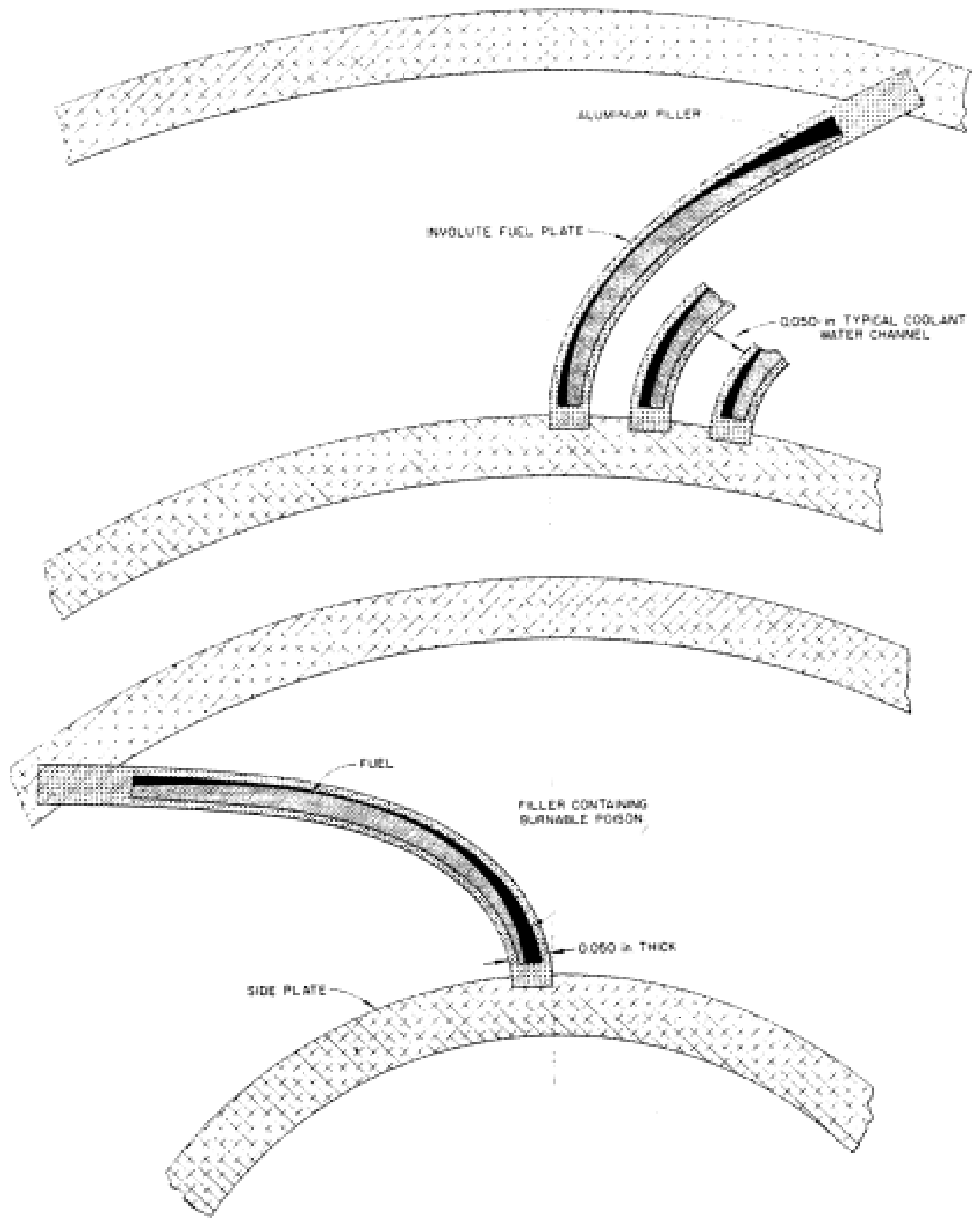

Figure 2-6 - Illustration of the HEU IFE and OFE fuel distributions [Cheverton, 1971]. The fuel meat is shown in gray, the filler in black. Not to scale.

Alternate Design Concepts for the High Flux Isotope Reactor using Low-Enriched Uranium Fuel Systems - Scoping Analysis 

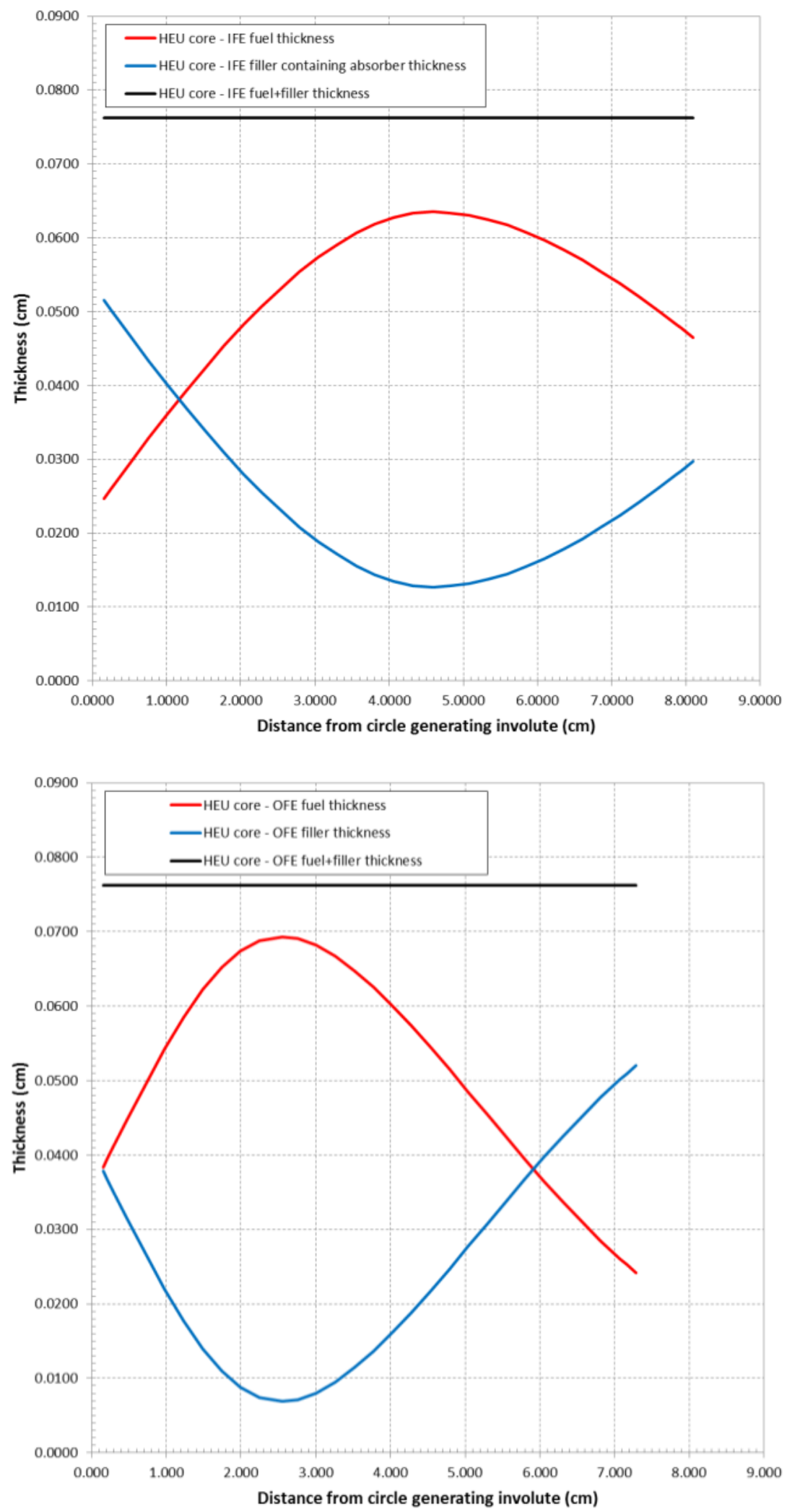

Figure 2-7 - Thickness of the fuel and filler along the fuel plate width in both HEU IFE (top) and OFE fuel plates (bottom)

Alternate Design Concepts for the High Flux Isotope Reactor using Low-Enriched Uranium Fuel Systems - Scoping Analysis 


\section{Codes and Models}

The goal of this work is to evaluate HFIR LEU designs that could satisfy both performance and safety criteria. This work is limited to neutronic and steady-state thermal-hydraulic analyses but does not cover accident analysis. The main tools, models and methods used to carry these analysis are briefly describred below.

\subsection{Steady-state Neutronics}

The Monte Carlo N Particles (MCNP) computer code has been selected to perform the neutronic steady state calculations. This software package is developed by Los Alamos National Laboratory (LANL) [LANL, 2005]. It is used primarily for the simulation of nuclear processes and particle interactions such as neutrons, photons and electrons. Its range of application is very large and covers, among other things, medical physics, fission and fusion reactor design, criticality safety and radiation protection. Its ability to model complex geometries in three-dimensions (3D) and calculate a wide variety of parameters (eigenvalues, neutron flux, spectrum...) make the code an excellent tool for the study of complex systems such as HFIR. However, MCNP is not able to model explicitly the involute shape. In late 2010, ANL developed a methodology to model an approximation of the involute almost as accurately as desired (see [Bergeron, 2012]). The version 51.60 of MCNP has been used through this study.

The neutronic model used is based on the ORNL HEU representative core established in 2015 [Chandler, 2015]. Model is used "as is" except of course for the fuel elements. Screenshots taken from the HFIR MCNP model are shown in Figure 3-1. The density of the coolant between the plates is modified over time to simulate the coolant-displacement effect of fuel swelling (see section 3.2). In addition, 15 IFE plates and 15 OFE plates are explicitly misaligned in order to simulate the effect of plate's axial misalignment due to normal fabrication tolerances (taken into account in the HFIR safety basis [Bergeron, 2015]).

Neutronic calculations are performed using 100,000 particles per cycle, skipping the first 20 cycles and using 50 active cycles for a total of 5 million active histories. These settings lead to an accuracy of about $40 \mathrm{pcm}$ at one standard deviation and ensure Shannon entropy convergence test is satisfied

In order to capture adequately the strong power (and burnup) gradients occurring in a fuel plate, the fuel regions need to be discretized. The grid used in this analysis is based on considerations described in [Bojanowski, 2018]. The lateral and axial discretization used is described in Table 3-1 and Table 3-2, respectively.

Power distributions have been calculated with the MCNP tally F7. Based on previous results [Bergeron, 2012], It has been conservatively assumed that the power generated in the fuel elements was $97.5 \%$ of the total nuclear power.

Alternate Design Concepts for the High Flux Isotope Reactor using Low-Enriched Uranium Fuel Systems - Scoping Analysis 

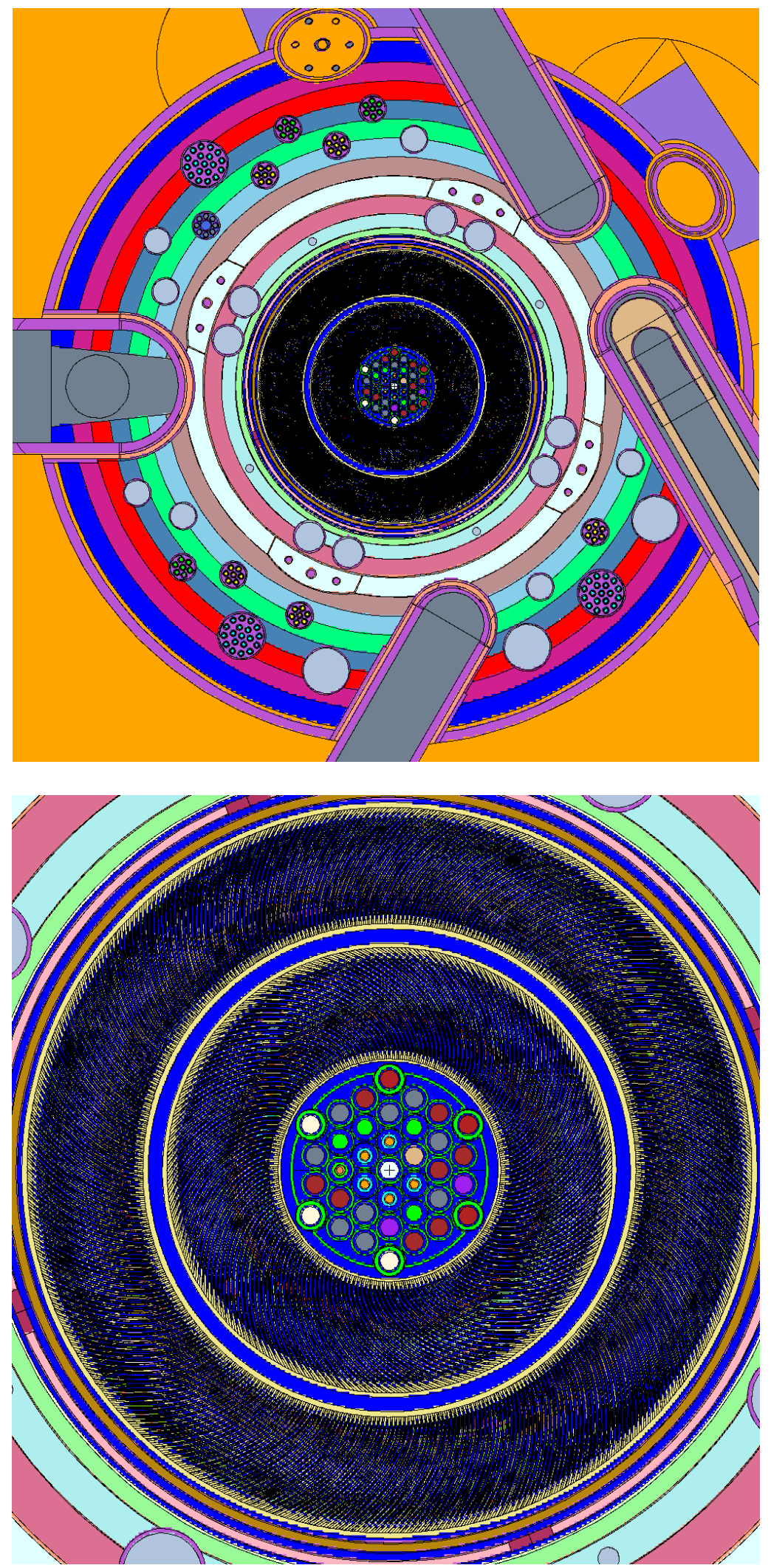

Figure 3-1 - Cross-section view of the HFIR MCNP Model: reactor core (top) and details of the fuel elements and loaded flux trap (bottom).

Alternate Design Concepts for the High Flux Isotope Reactor using Low-Enriched Uranium Fuel Systems - Scoping Analysis 
Table 3-1 - Lateral node size, along the plate, used in design analysis

\begin{tabular}{|c|c|c|c|c|c|c|c|c|c|c|c|c|c|}
\hline $\begin{array}{c}\text { lateral } \\
\text { region \# } \\
(\mathbf{1} \text { is inner } \\
\text { edge) }\end{array}$ & $\mathbf{1}$ & $\mathbf{2}$ & $\mathbf{3}$ & $\mathbf{4}$ & $\mathbf{5}$ & $\mathbf{6}$ & $\mathbf{7}$ & $\mathbf{8}$ & $\mathbf{9}$ & $\mathbf{1 0}$ & $\mathbf{1 1}$ & $\mathbf{1 2}$ & $\begin{array}{c}\text { sum } \\
\mathbf{( c m )}\end{array}$ \\
\hline IFE & 0.5 & 0.25 & 0.35 & 0.35 & 1.05 & 1.05 & 1.05 & 1.05 & 0.7 & 0.7 & 0.25 & 0.5 & 7.8 \\
\hline OFE & 0.5 & 0.2 & 0.3 & 0.3 & 0.9 & 0.9 & 0.9 & 0.9 & 0.6 & 0.6 & 0.49 & 0.5 & 7.09 \\
\hline
\end{tabular}

Table 3-2 - Axial node size used in design analysis

\begin{tabular}{|c|c|c|c|c|}
\hline \multirow{2}{*}{$\begin{array}{c}\text { axial region \# } \\
\text { (1 is top) }\end{array}$} & \multicolumn{4}{|c|}{ fuel node height $(\mathrm{cm})$} \\
\hline & 20 inch long fuel & 21 inch long fuel & 22 inch long fuel & 23 inch long fuel \\
\hline 1 & 0.60 & 0.60 & 0.60 & 0.60 \\
\hline 2 & 1.00 & 1.00 & 1.00 & 1.00 \\
\hline 3 & 1.30 & 1.57 & 1.34 & 1.34 \\
\hline 4 & 2.00 & 2.50 & 2.50 & 2.50 \\
\hline 5 & 2.50 & 2.50 & 2.50 & 2.77 \\
\hline 6 & 2.50 & 2.50 & 2.50 & 2.50 \\
\hline 7 & 2.50 & 2.50 & 2.50 & 2.50 \\
\hline 8 & 2.50 & 2.50 & 2.50 & 2.50 \\
\hline 9 & 2.50 & 2.50 & 2.50 & 2.50 \\
\hline 10 & 2.50 & 2.50 & 2.50 & 3.50 \\
\hline 11 & 3.00 & 3.50 & 4.50 & 4.50 \\
\hline 12 & 2.00 & 2.00 & 2.50 & 2.50 \\
\hline 13 & 1.00 & 1.00 & 1.00 & 1.00 \\
\hline 14 & 2.00 & 2.00 & 2.50 & 2.50 \\
\hline 15 & 3.00 & 3.50 & 4.50 & 4.50 \\
\hline 16 & 2.50 & 2.50 & 2.50 & 3.50 \\
\hline 17 & 2.50 & 2.50 & 2.50 & 2.50 \\
\hline 18 & 2.50 & 2.50 & 2.50 & 2.50 \\
\hline 19 & 2.50 & 2.50 & 2.50 & 2.50 \\
\hline 20 & 2.50 & 2.50 & 2.50 & 2.50 \\
\hline 21 & 2.50 & 2.50 & 2.50 & 2.77 \\
\hline 22 & 2.00 & 2.50 & 2.50 & 2.50 \\
\hline 23 & 1.30 & 1.57 & 1.34 & 1.34 \\
\hline 24 & 1.00 & 1.00 & 1.00 & 1.00 \\
\hline 25 & 0.60 & 0.60 & 0.60 & 0.60 \\
\hline $\operatorname{sum}(\mathrm{cm})=$ & 50.80 & 53.34 & 55.88 & 58.42 \\
\hline sum (inch) = & 20 & 21 & 22 & 23 \\
\hline
\end{tabular}

Alternate Design Concepts for the High Flux Isotope Reactor using Low-Enriched Uranium Fuel Systems - Scoping Analysis 


\subsection{Depletion}

Studying the evolution of a complex reactor like HFIR requires having a detailed time-discretization of the cycle from multi-step depletion calculations.

A so-called Monte-Carlo depletion code has been used to couple the steady state calculation (performed by MCNP) with the depletion function performed by ORIGEN (see below). Among the codes available (MCODE, MONTEBURNS...), the code VESTA, developed by the Institut de Radioprotection et de Sûreté Nucléaire (IRSN) has been selected mainly because it uses the Multigroup Binning Approach (MBA) [Haeck, 2007]. It has been shown that for coupled coreevolution calculations, a significant part of the computational time is due to the calculation of the reaction rates performed during the steady state calculation. The MBA method does not require the calculation of the reaction rates directly from the steady state calculation but only the calculation of the very fine-group flux, which is far less time consuming. Pre-generated very fine-group crosssections are then weighted with the fine-group flux and collapsed to generate one-group crosssections. These cross-sections can then be used by the depletion module (ORIGEN).

ORIGEN is a versatile tool that has been developed by ORNL for calculating the buildup, decay and processing of radioactive materials [Croff, 1980]. ORIGEN uses the matrix exponential method to solve a large system of coupled, linear differential equations. ORIGEN v2.2 has been used as the depletion module for the HFIR analyses but not directly: t has been coupled with MCNP5 via VESTA.

Nuclear fuels tends to swell during irradiation due solid and gaseous fission products buildup and other microstructural changes. With plate-type geometry there is little to no room available to accommodate the fuel swelling which in turn can cause local plate deformation that reduces coolant channel space. This reduction in coolant volume can lead to a reduction in reactivity and affect thermal-hydraulic performance.

Explicit modeling of time- and space-dependent fuel deformation in neutronic modeling remains a difficult task as it requires frequent redefinition of the fuel, plate and coolant geometry. To go around this difficulty, we account for the swelling effect by adjusting the coolant density and ignoring explicit geometric changes. The more the fuel swells, the more the coolant density is reduced. The coolant density reduction in the fixed geometry is proportional to the coolant volume change that would be caused by the fuel swelling. It remains to be proven that this methodology is an accurate equivalent to an explicit geometric change but it is believed to capture an essential physical effect: the reduced neutron moderation caused by the reduced amount of coolant between the plates.

The complete calculation scheme (steady-state, depletion and coupling) is illustrated in Figure 3-2. Coolant density adjustment is performed outside VESTA, when it is possible to calculate updated fission densities, via a script that also insure that control elements are at critical position.

The cycle is discretized in several time steps of relatively short duration (see Table 3-3 for more details). These steps are about a half day long at beginning of cycle to insure proper modeling of the xenon buildup and can be as long as three days in the remainder of the cycle. These longer steps are justified by the moderate change of the neutron flux. 


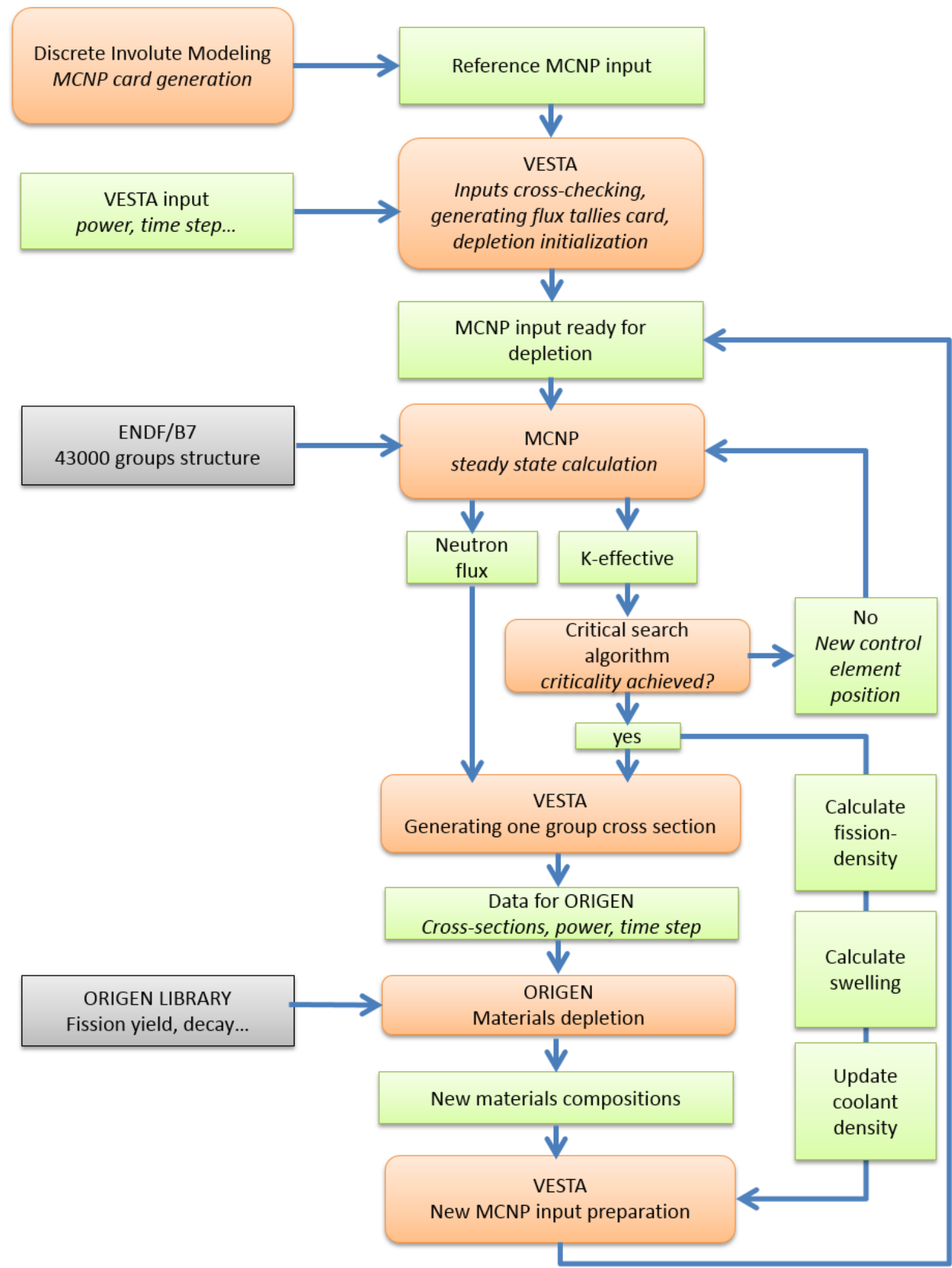

Figure 3-2 - Steady-state/depletion coupling scheme used to perform neutronic calculations

Alternate Design Concepts for the High Flux Isotope Reactor using Low-Enriched Uranium Fuel Systems - Scoping Analysis 
Table 3-3 - Time step duration used in depletion analysis

\begin{tabular}{|c|c|c|}
\hline time step \# & $\begin{array}{l}\text { time step duration } \\
\text { (days) }\end{array}$ & $\begin{array}{l}\text { time at beginning of } \\
\text { time step (days) }\end{array}$ \\
\hline 0 & 0.5 & 0 \\
\hline 1 & 0.5 & 0.5 \\
\hline 2 & 0.5 & 1 \\
\hline 3 & 0.5 & 1.5 \\
\hline 4 & 1 & 2 \\
\hline 5 & 1 & 3 \\
\hline 6 & 1 & 4 \\
\hline 7 & 3 & 5 \\
\hline 8 & 2 & 8 \\
\hline 9 & 3 & 10 \\
\hline 10 & 2 & 13 \\
\hline 11 & 3 & 15 \\
\hline 12 & 2 & 18 \\
\hline 13 & 2 & 20 \\
\hline 14 & 2 & 22 \\
\hline 15 & 2 & 24 \\
\hline 16 & 2 & 26 \\
\hline 17 & 2 & 28 \\
\hline 18 & 2 & 30 \\
\hline 19 & 2 & 32 \\
\hline 20 & 2 & 34 \\
\hline 21 & 2 & 36 \\
\hline 22 & 2 & 38 \\
\hline
\end{tabular}

Alternate Design Concepts for the High Flux Isotope Reactor using Low-Enriched Uranium Fuel 


\subsection{Steady-State Thermal-Hydraulics}

Steady-state thermal-hydraulic calculations are performed at ORNL using the code HSSHTC [Hilvety, 1967]. This code is currently being adapted by ORNL to LEU fuel systems. HSSHTC calculates margins to Onset of Nucleate Boiling (ONB), Critical Heat Flux (CHF) and Flow Excursion (FE). Details on how these margins are calculated and under which conditions can be found in the following references: [Rothrock, 2008] and [ORNL, 2009].

Because HSSHTC is not available at ANL, a scoping model has been developed instead that we will refer to as ASM (Argonne Scoping Model). ASM has not been designed to replicate the entire HSSHTC calculation procedure; it ignores, for instance, mechanical deformation. Only the effects deemed relevant for the safety margin evaluation have been implemented similarly to HSSHTC: heat transfer coefficient calculations, uncertainty factors, ONB, CHF and FE correlations, and margin evaluation.

Limited cross-comparisons between ASM and HSSHTC have shown that, when using identical dataset and fuel discretization, it appears that ASM calculated margins are reasonably close to the one obtained with HSSHTC, with variations of $+/-5 \%$. However, because the ORNL design team is performing calculations on a different spatial grid (smaller node size on the plate edges compared to what has been used in this analysis), for a given design, HSSHTC margins are expected to be systemically lower than the ones calculated by ASM. Therefore, a design considered feasible by ANL may not necessarily be acceptable by the ORNL design team.

ASM thermal-hydraulic solution is calculated at each time-step and for four plates: IFE, OFE and IFE, OFE explicitly misaligned. Power fraction deposited in the fuel is assumed to be $97.5 \%$ (like for HEU); heat flux to flow safety limit ratio is 1.36 (the Safety Limit - SL - value), inlet temperature is $135^{\circ} \mathrm{F}$ (Limited Control Settings - LCS - value), inlet pressure is 350 psia (LCS value), pressure drop is 108 psi. Reactor nominal power corresponds to minimum power required to match HEU core average flux at the most limiting location (typically the cold source).

HFIR safety basis makes use of 25 uncertainty factors [Hilvety, 1967]. Some of them are derived directly or indirectly from fuel specifications and fabrication tolerances. Because the LEU UMo monolithic fuel system is still under development, specifications and fabrication tolerances are assumed values that have been discussed with fabrication experts. The basis for the selected numbers has been reported previously [Bergeron, 2015]. For silicide fuel designs, fabrication tolerances have been assumed to be similar to the current HEU fuel system. As fabrication development progresses, assumed fabrication tolerances will need to be re-evaluated and it will be necessary to reassess selected designs with respect to safety margins. 


\section{Design Considerations}

\subsection{Requirements}

The engineering problem to be solved is to find HFIR design(s) that:

1) Meet or exceed performance requirements

- Cycle length shall equal or exceed 26 days, which is the cycle length obtained with the HEU representative core model [Chandler, 2015]. In the calculations, fuel swelling is modeled to account for the likely penalty it will induce on cycle length.

- Thermal neutron flux in the beam tubes, fast flux in the flux trap and fast flux in the reflector of the LEU core shall equal or exceed their HEU core equivalents.

- Flux trap's ${ }^{252} \mathrm{Cf}$ production shall equal or exceed the HEU core (reference HEU metrics obtained with representative core model).

- Reflector's ${ }^{238} \mathrm{Pu}$ production shall equal or exceed the HEU core (reference HEU metrics obtained with representative core model).

2) Meet or exceed steady-state safety requirements

- Design must provide sufficient margins to Critical Heat Flux (CHF, using the modified Gambill correlation described in HFIR SAR [ORNL, 2009, chap. 4-4]) and Flow Excursion (FE, using the modified Saha-Zuber correlation [Rothrock, 2008]) from beginning to end of cycle in both the inner and the outer fuel element (later simply referred as IFE and OFE).

3) Minimize plant modifications

- Avoid flow area / flow resistance changes (for instance by changing number of plates, or fuel element external dimensions) to avoid adding additional pumps or other costly plant modifications.

4) Minimize conversion-related cost as well as operational cost

- Minimize uranium inventory.

- $\quad$ Minimize power uprate.

- $\quad$ Reduce fuel element complexity.

Alternate Design Concepts for the High Flux Isotope Reactor using Low-Enriched Uranium Fuel 


\subsection{Past and Present Concepts}

The current HFIR fuel elements have complex design features serving specific purposes:

- The inner fuel element plates contain a neutron absorber in form of B4C. This is to provide a reactivity reserve at beginning of cycle and also better balance the inner and outer element plate power,especially at beginning of cycle).

- The inner and outer fuel is contoured (fuel thickness varies along the fuel width and is thinner on the edges than in the middle). This is to reduce lateral edge power peaking.

These features are necessary to meet the safety criteria. The need for complex features as described above is exacerbated with LEU fuel for two reasons:

- Higher fuel density tends to aggravate lateral edge power peaking (especially in the IFE inner edge, facing the flux trap, and the OFE outer edge, facing the reflector).

- Higher ${ }^{238} \mathrm{U}$ parasitic capture requires the reactor to operate at a higher power level to maintain current experimental flux levels. Since cooling conditions (pressure, flow rate) cannot be changed, safety margins decrease with higher power.

Over the past years, signifcant numbers of UMo monolithic designs have been proposed (see Table 4-1 below) that would meet performance and safety criteria (not all have been documented but some are described in [Ilas, 2010] and [Renfro, 2014]).

Unfortunately, to date, all proposed designs present complex features for which fabrication feasibility remains largely unproven. It is therefore difficult to assess if a proposed design is more feasible than another. The different challenges and potential solutions proposed so far are briefly discussed below:

- Reduce axial power peaking: Higher uranium density and higher operating power tends to aggravate substantially the power peaking at the very bottom of the fuel compared to HEU. Lateral fuel contouring becomes unsufficient to satisfy safety criteria. Two solutions are suggested:

1) Reduce the fuel thickness at the bottom of the fuel. The last 1 to $3 \mathrm{~cm}$ of the fuel sees a gradual thickness reduction to reach a value of $75 \mu \mathrm{m}$ (3 mils) for UMo [Ilas, 2010]

2) Add a neutron absorber region below the fuel region. For UMo fuel, adding a hafnium region below has been shown to be an efficient way to reduce axial power peaking [Renfro, 2014].

- Reduce lateral power peaking:

1) Vary the fuel thickness along the fuel width (thinner on the edges), similar to the current HEU design [Ilas, 2010], [Renfro, 2014].

- Better balance of inner/outer plate power at beginning of life:

1) IFE plates filler containing neutron absorber, similar to the current HEU design [Ilas, 2010].

2) IFE side-plates containing neutron absorber [Renfro, 2014]

Alternate Design Concepts for the High Flux Isotope Reactor using Low-Enriched Uranium Fuel 
- Increase overall safety margins:

1) Centering the fuel to balance the heat flux across the two sides of the plates. Currently, the fuel is not centered and one side of the plate (Figure 2-6) exhibits larger heat fluxes than the other side, which reduces margins.

Table 4-1 - HFIR design features (fuel and absorber) combination investigated with UMo fuel monolithic fuel (20 inch long fuel)

\begin{tabular}{|c|c|c|c|c|}
\hline $\begin{array}{l}\text { Neutron } \\
\text { absorber }\end{array}$ & no contouring & $\begin{array}{l}\text { lateral } \\
\text { contouring } \\
\text { only }\end{array}$ & $\begin{array}{l}\text { axial } \\
\text { contouring } \\
\text { only }\end{array}$ & $\begin{array}{l}\text { lateral and axial } \\
\text { contouring }\end{array}$ \\
\hline None & NOT POSSIBLE* & NOT POSSIBLE* & NOT POSSIBLE* & NOT POSSIBLE ${ }^{*}$ \\
\hline $\begin{array}{l}\text { Neutron absorber in IFE } \\
\text { filler }\end{array}$ & $\begin{array}{l}\text { NOT POSSIBLE } \\
\text { [Renfro, 2014] }\end{array}$ & NOT POSSIBLE* & NOT POSSIBLE ${ }^{*}$ & $\begin{array}{l}\text { POSSIBLE, with and } \\
\text { without centered \& } \\
\text { symmetric fuel [llas, } \\
2010] \\
\text { [Renfro, 2014] }\end{array}$ \\
\hline $\begin{array}{l}\text { Neutron absorber in IFE } \\
\text { side plates }\end{array}$ & NOT POSSIBLE* & NOT POSSIBLE* & NOT POSSIBLE* & $\begin{array}{l}\text { POSSIBLE, with and } \\
\text { without centered \& } \\
\text { symmetric fuel [llas, } \\
2010] \\
\text { [Renfro, 2014] }\end{array}$ \\
\hline $\begin{array}{l}\text { Neutron absorber in IFE } \\
\text { filler + poison region at } \\
\text { bottom }\end{array}$ & NOT POSSIBLE* & $\begin{array}{l}\text { POSSIBLE } \\
\text { [Renfro, 2014] }\end{array}$ & NOT POSSIBLE ${ }^{*}$ & \multirow{2}{*}{$\begin{array}{l}\text { LIKELY POSSIBLE BUT } \\
\text { NOT TESTED AS } \\
\text { POISON REGION } \\
\text { BELOW FUEL IS } \\
\text { SURROGATE } \\
\text { SOLUTION TO AXIAL } \\
\text { CONTOURING }\end{array}$} \\
\hline $\begin{array}{l}\text { Neutron absorber in IFE } \\
\text { side plates + poison } \\
\text { region at bottom }\end{array}$ & NOT POSSIBLE* & LIKELY* & NOT POSSIBLE* & \\
\hline
\end{tabular}

* Design feasibility is deduced from feasbibility/non-feasibility of other designs, some of which have not been documented. 


\section{Alternate UMo Concept}

As explained previously and unlike past HFIR design studies, the analytical work presented here is based on the assumption that fuel geometric constraints can be relaxed, in particular the fuel length. Currently, HFIR fuel is 20 inches long $(50.8 \mathrm{~cm})$. For a given fuel mass and assuming that the fuel width remains unchanged, increasing the fuel length by a certain factor means that the fuel thickness can be reduced by the same factor. This fuel thickness reduction would have the effects of lowering the local edge power peaking. This will tend to increase safety margins while having a moderate effect on performance (the neutron flux distribution would not be expected to change drastically). The work presented in this section investigates the possibility of having a design that does not require contouring the fuel, which would represent a major simplification of the fabrication process

\subsection{UMo Fuel System Properties}

To perform neutronic calculations, the following fuel properties need to be defined

\subsubsection{UMo Composition and Density}

The fuel composition used in the MCNP model is defined in Table 5-1 below.

Table 5-1 - UMo "monolithic" composition used in neutronic calculations

\begin{tabular}{|c|c|c|}
\hline isotope & $\begin{array}{l}\text { atomic density } \\
\text { (at/barn.cm) }\end{array}$ & density (g/cc) \\
\hline${ }^{92} \mathrm{Mo}$ & $1.58536 \mathrm{E}-03$ & 2.41949E-01 \\
\hline${ }^{94} \mathrm{Mo}$ & $9.88178 \mathrm{E}-04$ & $1.54090 \mathrm{E}-01$ \\
\hline 95 Mo & 1.70073E-03 & $2.68026 \mathrm{E}-01$ \\
\hline 96 Mo & 1.78192E-03 & 2.83777E-01 \\
\hline${ }^{97} \mathrm{Mo}$ & $1.02023 \mathrm{E}-03$ & 1.64172E-01 \\
\hline${ }^{98} \mathrm{Mo}$ & $2.57781 \mathrm{E}-03$ & 4.19089E-01 \\
\hline $100 \mathrm{Mo}$ & 1.02877E-03 & $1.70673 \mathrm{E}-01$ \\
\hline $234 \mathrm{U}$ & $1.02480 \mathrm{E}-04$ & $3.98272 \mathrm{E}-02$ \\
\hline $235 \mathrm{U}$ & 7.75120E-03 & $3.02529 E+00$ \\
\hline $236 \mathrm{U}$ & 1.79770E-04 & $7.04632 E-02$ \\
\hline $238 \mathrm{U}$ & 3.08190E-02 & $1.21825 \mathrm{E}+01$ \\
\hline sum $=$ & 4.95354E-02 & 1.70199E+01 \\
\hline
\end{tabular}

Alternate Design Concepts for the High Flux Isotope Reactor using Low-Enriched Uranium Fuel 


\subsubsection{UMo Swelling}

One can expect fuel swelling to negatively impact the core performance (cycle length reduction due to loss of reactivity induced by less favorable metal to coolant ratio) and thermal-hydraulics margin (channel reduction). Fuel swelling must therefore be taken into account in the analysis. Only the irradiation-induced fuel swelling must be adapted from the current HEU tools and models. Other swelling sources such as cladding thermal expansion and oxide growth - both modeled in HFIR analysis - are unlikely to be impacted by switching from $\mathrm{HEU} \mathrm{U}_{3} \mathrm{O}_{8}$ to LEU fuel.

The swelling rate for UMo monolithic fuel is provided by:

$$
\% \text { Swelling }=5.69957 \times 10^{-43} \mathrm{fd}^{2}+4.30015 \times 10^{-21} \mathrm{fd}
$$

(fd: fission density in fissions $/ \mathrm{cm}^{3}$ ) - from [Meyer, 2017] eq. 52, P176

\subsection{UMo Design Space Exploration Strategy}

In order to perform the design analysis, the following parameters have been considered design variables:

1) Fuel meat length:

- The fuel length can vary in the range 20 to 23 inches.

- $\quad$ The fuel length should be the same in both elements, to avoid excessive axial power peaking.

2) Inner, outer fuel element meat thickness:

- The thickness can be different between the two fuel elements but should not exceed 26 mil (plate thickness is 50 mil and cladding thickness is 12 mil). No minimum is explicitly defined

3) IFE, OFE fuel shape:

- Unlike the HEU core, the fuel is not contoured, i.e., the fuel thickness is constant from the inner to the outer edge of each plate.

4) Neutron absorber:

- Unlike the HEU core, no poison is allowed in the fuel plate; only poison in the IFE inner side-plate is considered.

- Only cadmium wires are considered in this analysis because they have been used successfully in other reactors [Kalcheva, 2012] and shown to be very efficient and could eliminate the need for the development and qualification of a special Al-B alloy as currently proposed [Renfro, 2014]

Alternate Design Concepts for the High Flux Isotope Reactor using Low-Enriched Uranium Fuel 
5) Power level:

- To compensate for the flux losses, the reactor power can be increased.

In order to explore the entire design space as efficiently as possible while identifying the less complex solution, the following strategy has been followed:

1) Start with simple shapes:

- No fuel contouring and no absorber, with fuel plates oriented on radii from the flux trap center.

- Vary fuel length, meat thickness and study the response on performance.

- Identify most favorable design space.

2) No fuel contouring and uniform vertical cadmium wires:

- Based on most favorable design space identified in step 1, compare performance and margins evolution on configuration with and without vertical wires.

- $\quad$ Deduce if acceptable designs are possible. If not go to step 3.

3) Fuel contouring and non-uniform cadmium wires:

- Based on most favorable design space identified in step 1 and 2, compare performance and margins evolution on configuration with non-uniform wires.

- Deduce if acceptable designs are possible. 


\subsection{UMo Analysis Results}

\subsubsection{Un-contoured UMo Design without Absorber}

In this first step, the influence of fuel length and fuel thickness on cycle length is analyzed in order to identify the most favorable design space. A large number of depletion models have been prepared where the fuel length varies from 20 to 23 inch by increment of one inch and the IFE and OFE fuel thickness is varied from three to twelve mil by increment of one mil.

Results are presented in Table 5-2 below and are expressed in term of energy produced during a cycle (MWdays). The cycle length of the HEU core obtained with the representative core model [Chandler, 2015] is 26days at $85 \mathrm{MW}$ and therefore represents $26 \times 85=2210 \mathrm{MWdays}$. Due to the neutron flux penalty induced by the LEU UMo fuel larger ${ }^{238} \mathrm{U}$ and molybdenum parasitic capture, it seems reasonable to target a number of MWdays 20\% larger with the LEU UMo fuel than with the HEU core to achieve similar performance.

A threshold value of $2210 \times 1.20 \approx 2650$ MWdays is therefore used to identify the most favorable configurations. In addition, in order to increase the likelihood of satisfying the safety criteria, the fuel needs to be as thin as possible, especially in the IFE plates. On the other hand, the OFE fuel thickness should not depart too strongly from the IFE fuel thickness, as it will tend to create strong inner and outer edge peaking in the OFE plates. With these considerations in mind and based on the results presented in Table 5-2, a 23-inch long fuel configuration with an IFE and OFE fuel thickness of respectively 6.5 and $9.5 \mathrm{mil}$ is selected for further analysis. For convenience, this configuration will now be simply refer as configuration 23-6.5-9.5.

Such configuration leads to satisfying performances (cycle length, isotope production...) but also to a significant lack of safety thermal-hydraulic margins in the inner edge of the IFE plates, as expected.

Insertion of burnable absorbers in the inner element is therefore required to increase margins in the IFE plates. To simplify plate manufacturing, absorber are not allowed in the fuel plates. Therefore, only solution with absorber in the inner side plate of the IFE are considered. 
Table 5-2 - Energy produced in one cycle for various UMo designs having no absorber. Color scale goes from orange (smallest number) to red (largest number). If color is black, value is below threshold value of 2650 MWdays

\begin{tabular}{|c|c|c|c|c|c|c|c|c|c|c|c|}
\hline \multicolumn{12}{|c|}{20 inch long fuel - Energy produced in one cycle (MWdays) } \\
\hline \multirow{6}{*}{ 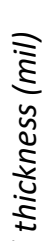 } & 12 & 1094 & 1526 & 1923 & 2189 & 2454 & 2637 & 2759 & 2901 & 2930 & 3046 \\
\hline & 11 & 1011 & 1439 & 1781 & 2068 & 2281 & 2466 & 2613 & 2741 & 2833 & 2907 \\
\hline & 10 & 910 & 1306 & 1650 & 1921 & 2141 & 2304 & 2485 & 2560 & 2675 & 2722 \\
\hline & 9 & 819 & 1202 & 1498 & 1748 & 1957 & 2123 & 2187 & 2318 & 2453 & 2545 \\
\hline & 8 & 699 & 1031 & 1312 & 1554 & 1734 & 1884 & 2018 & 2101 & 2168 & 2250 \\
\hline & 7 & 582 & 862 & 1098 & 1300 & 1477 & 1597 & 1700 & 1822 & 1902 & 1985 \\
\hline \multirow{4}{*}{ 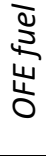 } & 6 & 446 & 683 & 882 & 1075 & 1215 & 1309 & 1401 & 1517 & 1591 & 1640 \\
\hline & 5 & 309 & 490 & 645 & 787 & 896 & 1012 & 1078 & 1165 & 1207 & 1241 \\
\hline & 4 & 185 & 303 & 410 & 504 & 602 & 661 & 718 & 777 & 829 & 864 \\
\hline & 3 & 79 & 137 & 197 & 251 & 301 & 344 & 386 & 408 & 441 & 464 \\
\hline & & 3 & 4 & 5 & 6 & 7 & 8 & 9 & 10 & 11 & 12 \\
\hline & & \multicolumn{10}{|c|}{ IFE foil thickness (mil) } \\
\hline
\end{tabular}

\begin{tabular}{|c|c|c|c|c|c|c|c|c|c|c|c|}
\hline \multicolumn{12}{|c|}{21 inch long fuel - Energy produced in one cycle (MWdays) } \\
\hline \multirow{10}{*}{ 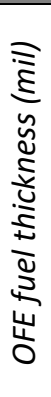 } & 12 & 1296 & 1791 & 2212 & 2506 & 2738 & 2956 & 3117 & 3176 & 3308 & 3377 \\
\hline & 11 & 1177 & 1657 & 2029 & 2370 & 2589 & 2780 & 2954 & 3095 & 3140 & 3213 \\
\hline & 10 & 1066 & 1537 & 1887 & 2159 & 2440 & 2612 & 2760 & 2857 & 3007 & 3074 \\
\hline & 9 & 965 & 1367 & 1721 & 1986 & 2205 & 2412 & 2515 & 2625 & 2739 & 2790 \\
\hline & 8 & 831 & 1232 & 1531 & 1790 & 1987 & 2161 & 2304 & 2414 & 2452 & 2534 \\
\hline & 7 & 708 & 1037 & 1305 & 1533 & 1729 & 1871 & 1981 & 2093 & 2179 & 2229 \\
\hline & 6 & 553 & 815 & 1061 & 1252 & 1410 & 1560 & 1657 & 1767 & 1835 & 1869 \\
\hline & 5 & 394 & 601 & 799 & 941 & 1074 & 1196 & 1296 & 1351 & 1405 & 1452 \\
\hline & 4 & 234 & 383 & 511 & 634 & 718 & 808 & 885 & 933 & 989 & 1035 \\
\hline & 3 & 105 & 179 & 251 & 312 & 371 & 427 & 473 & 513 & 550 & 569 \\
\hline & & 3 & 4 & 5 & 6 & 7 & 8 & 9 & 10 & 11 & 12 \\
\hline & & & & & & il th & hess & & & & \\
\hline
\end{tabular}

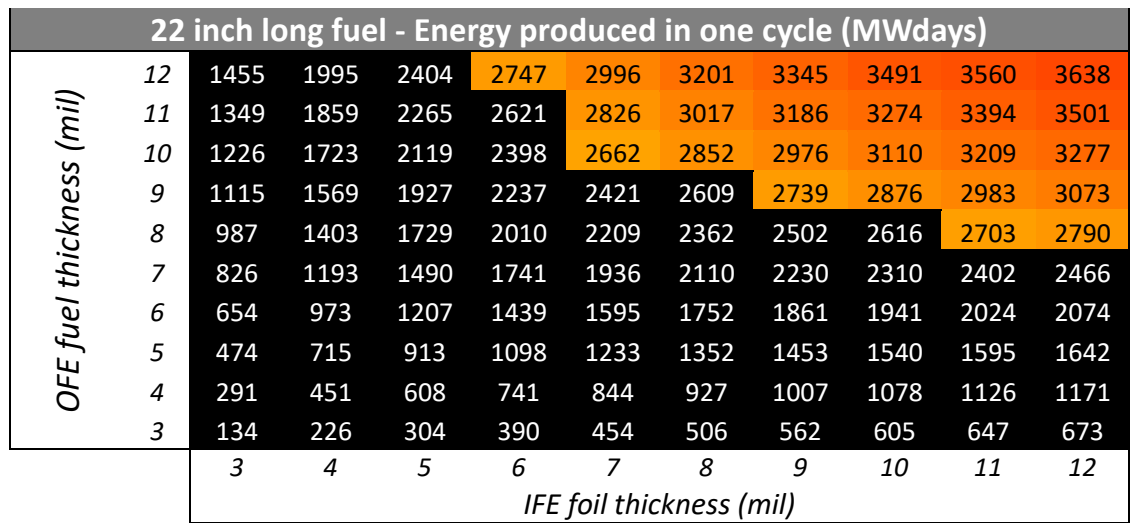

23 inch long fuel - Energy produced in one cycle (MWdays)

\begin{tabular}{|c|c|c|c|c|c|c|c|c|c|c|c|}
\hline \multirow{10}{*}{ 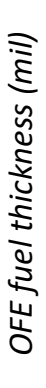 } & 12 & 1467 & 2118 & 2694 & 3144 & 3410 & 3802 & 4043 & 4114 & 4298 & 4389 \\
\hline & 11 & 1362 & 1991 & 2531 & 2963 & 3242 & 3567 & 3786 & 3877 & 4050 & 4148 \\
\hline & 10 & 1213 & 1799 & 2314 & 2691 & 3029 & 3225 & 3448 & 3606 & 3767 & 3854 \\
\hline & 9 & 1079 & 1616 & 2049 & 2468 & 2771 & 2994 & 3185 & 3312 & 3474 & 3543 \\
\hline & 8 & 923 & 1405 & 1817 & 2137 & 2431 & 2644 & 2800 & 3006 & 3145 & 3236 \\
\hline & 7 & 750 & 1157 & 1531 & 1815 & 2074 & 2296 & 2434 & 2575 & 2650 & 2778 \\
\hline & 6 & 572 & 901 & 1186 & 1448 & 1663 & 1832 & 1978 & 2080 & 2208 & 2284 \\
\hline & 5 & 392 & 634 & 868 & 1051 & 1211 & 1372 & 1482 & 1571 & 1662 & 1725 \\
\hline & 4 & 221 & 374 & 517 & 660 & 756 & 888 & 957 & 1017 & 1081 & 1144 \\
\hline & 3 & 86 & 160 & 229 & 303 & 373 & 424 & 474 & 522 & 558 & 585 \\
\hline & & 3 & 4 & 5 & $\begin{array}{l}6 \\
I F\end{array}$ & $\begin{array}{c}7 \\
\text { il th }\end{array}$ & 8 & & 10 & 11 & 12 \\
\hline
\end{tabular}

Alternate Design Concepts for the High Flux Isotope Reactor using Low-Enriched Uranium Fuel Systems - Scoping Analysis 


\subsubsection{Un-contoured UMo Design with Uniform Cadmium Wires}

As explained before, cadmium wires located in the inner side-plate of the inner element are investigated as potential burnable absorber because they will eliminate the need to develop and qualify a new Al-B alloy material for the side-plate (see [Renfro, 2014]) and because they have been successfully tested in the past in other reactors [Kalcheva, 2012]. Conceptually, one can imagine various ways to insert wires in an annular-shaped HFIR side-plate as illustrated in Figure 5-1 below.

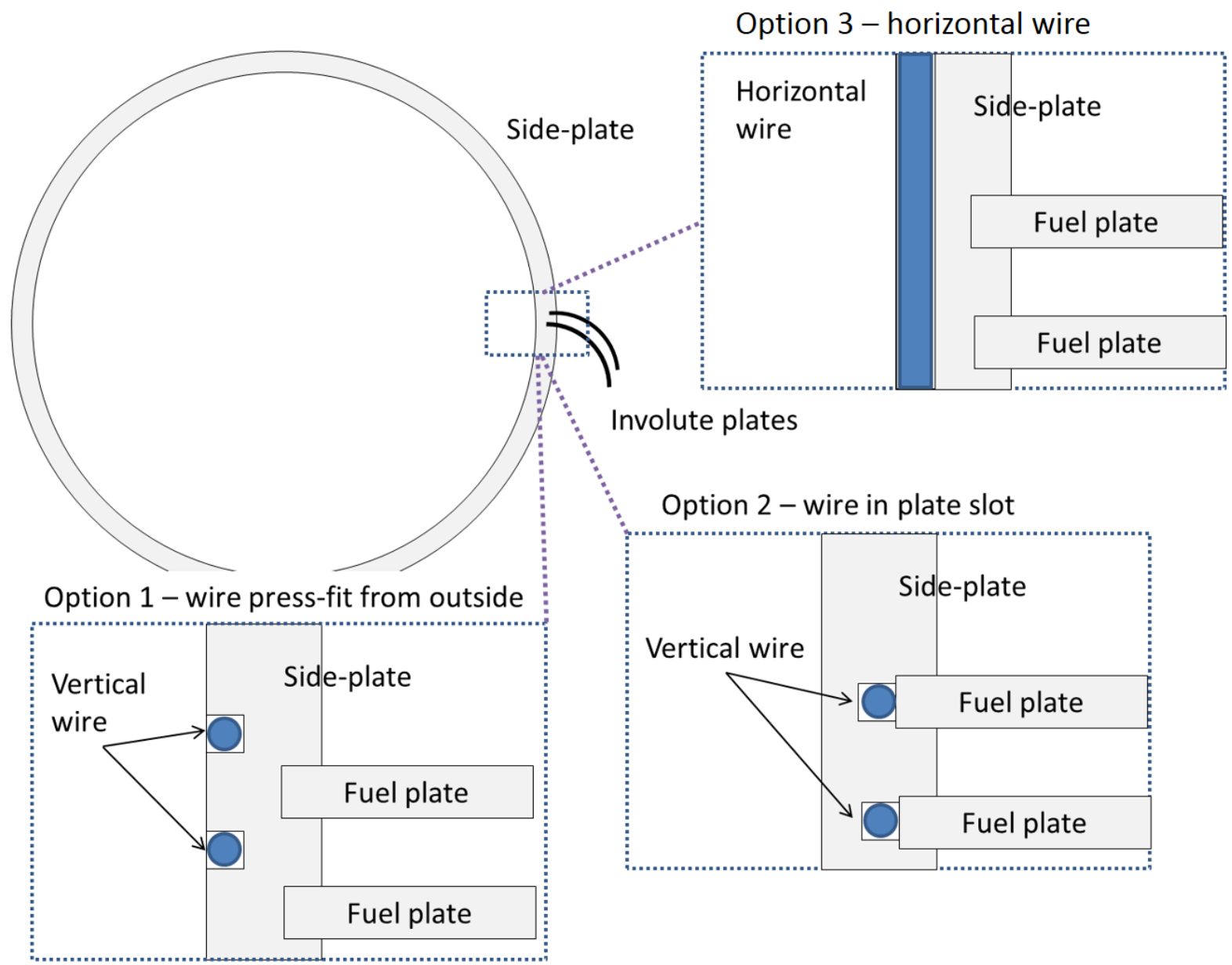

Figure 5-1 - Top cross-section schematic of HFIR side-plate and options to insert wires

First, only uniform vertical wires are considered (option 1 and 2 in Figure 5-1). Uniform here means that all wires are identical in length and thickness. For neutronics, the exact wire location has little importance (virtually no differences have been observed on fuel power distributions between option 1 and 2). The number of wires is fixed and is equal to the number of plates (one wire per IFE plate). With these constraints, only the wire length and diameter are variables.

To study the impact of cadmium wires on margins and performance, 16 configurations are analyzed were the wire length and wire diameter are changed as described in Table 5-3. Wire length is varied from a quarter of the fuel length to full fuel length with the bottom of the wire always coinciding with the bottom of the fuel (where the minimum margin typically occurs). Wire diameter is varied from 250 to $1000 \mu \mathrm{m}$. 
Performance metrics have been evaluated $\left(238 \mathrm{Pu},{ }^{252} \mathrm{Cf}\right.$ isotope production) for these 16 configurations and the minimum operating power required to achieve HEU equivalent neutron flux has been calculated. Dividing the number of MWdays obtained during the cycle by the calculated minimum operating power gives the cycle length. Safety margins (margins to CHF and FE) are also evaluated and the limiting reactor power (maximum power for which safety criteria can still be met) is compared to the operating power. For a given configuration, if performance requirements are met and the limiting power is greater than the operating power, the design is considered acceptable.

The safety and performance metrics for the 16 configurations studied are presented in Table 5-3. For convenience, metrics that do not meet requirements are colored in light red. It can be seen immediately that not a single configuration is acceptable. Most of them meet the performance requirements but none of them meets the safety criteria. Several observations can be made from the data presented in Table 5-3:

- Having a too thick wire (1000 $\mu$ m diameter) of a certain length (from half to full length) is detrimental to performance by either affecting the ${ }^{252} \mathrm{Cf}$ production (flux trap) or the cycle length or a combination of both. This indicates a limit on the mass of cadmium that can be tolerated in the core.

- Variation in operating power, cycle length and isotope production is relatively small for configurations meeting the performance requirements:

○ Operating power varies from 93.3 to $97.2 \mathrm{MW}$

○ Cycle length varies from 26.8 to 28.4 days

- LEU vs HEU ${ }^{252}$ Cf production varies from 1.02 to 1.12

- LEU vs HEU ${ }^{238} \mathrm{Pu}$ production varies from 1.07 to 1.16

- Variation in limiting power is however significant:

○ Delta between operating and limiting power goes from 4.57 to $25.1 \mathrm{MW}$

- Evolution of safety margins do not necessarily follow a monotonic behavior with wire size and/or length indicating a displacement of the limiting location(s) which is not necessarily beneficial:

$\circ$ Configuration with the minimum delta between operating and limiting power (wire length is half the fuel length, $750 \mu \mathrm{m}$ diameter wire,) experiences margin degradation with a reduction or increase in wire diameter or length

To better understand the safety margin issues, the evolution of the IFE inner edge, OFE outer edge margins to CHF and FE obtained for the best configuration $(750 \mu \mathrm{m}$ diameter wire, wire length is half the fuel length) is shown in Table 5-4. Recall that the IFE inner edge and OFE outer edge are typically the most limiting one and this particular configuration is no exception. For convenience, table cells are colored going from gray (lowest value) to green (highest value). Node in which the safety criteria are not met (margin $<1.0$ ) are colored in black. The following observations can be made:

- There is sufficient margins to both CHF and FE in the OFE everywhere, from the beginning to the end of cycle

- $\quad$ The IFE lacks margin to CHF at the very beginning of cycle only and the problematic area is localized just above fuel mid-height, which corresponds to the level just above the top of the wire.

- The IFE lacks margin to FE near the end of cycle, likely when the cadmium wires have been depleted. The lack of margins occurs only at the very bottom of the fuel.

In order to fix the beginning of cycle CHF margin issue, one could imagine increasing the length of the wire. However, Table 5-3 data indicates that increasing the wire length of this diameter from half to three-quarter of the fuel length is detrimental to margins (indication of hot spot relocation). In 
addition, the lack of CHF margin is not significant. One could argue that an additional, small and thinner wire located above the $750 \mu \mathrm{m}$ diameter one might be sufficient to meet the safety requirement.

Regarding the lack of flow excursion margins near the end of cycle, one could imagine that a bigger wire - which could take longer to deplete - located at the very bottom of the fuel could provide enough extra margin to meet the requirements.

These proposed changes would imply having three types of wires on top of each other. Manufacturing such side-plate with non-uniform wires would certainly be challenging. This is why additional configurations with uniform wires have been tested where the wire length and wire diameter have been moderately changed to see if it could be possible to find an acceptable solution. Unfortunately, no single configuration could meet the safety and performance criteria simultaneously. It is therefore concluded that uniform cadmium wires are unlikely to be an acceptable solution for un-contoured UMo fuel designs.

Table 5-3 - Performance of LEU UMo configuration 23-6.5-9.5 with various vertical cadmium wires located in the IFE inner side-plate. Metrics that do no not meet requirements are colored in pink.

\begin{tabular}{|c|c|c|c|c|c|c|c|c|}
\hline $\begin{array}{l}\text { cadmium } \\
\text { wire } \\
\text { length } \\
\text { (fraction } \\
\text { of total } \\
\text { fuel } \\
\text { length) }\end{array}$ & $\begin{array}{c}\text { cadmium } \\
\text { diameter } \\
(\mu \mathrm{m})\end{array}$ & MWdays & $\begin{array}{l}\text { operating } \\
\text { power (to } \\
\text { match HEU } \\
\text { core flux } \\
\text { performance) } \\
\text { (MW) }\end{array}$ & $\begin{array}{c}\text { cycle } \\
\text { length at } \\
\text { operating } \\
\text { (MW) }\end{array}$ & $\begin{array}{l}\text { LEU/HEU } \\
252 \mathrm{Cf} \\
\text { production }\end{array}$ & $\begin{array}{l}\text { LEU/HEU } \\
238 \mathrm{Pu} \\
\text { production }\end{array}$ & $\begin{array}{l}\text { limiting } \\
\text { power } \\
\text { (to } \\
\text { satisfy } \\
\text { TH } \\
\text { margin } \\
\text { criteria) } \\
\text { (MW) }\end{array}$ & $\begin{array}{c}\text { delta } \\
\text { between } \\
\text { operating } \\
\text { power } \\
\text { and } \\
\text { limiting } \\
\text { power } \\
\text { (MW) }\end{array}$ \\
\hline \multirow{4}{*}{0.25} & 250 & 2635 & 97.15 & 27.12 & 1.12 & 1.07 & 72.06 & 25.09 \\
\hline & 500 & 2626.5 & 96.50 & 27.22 & 1.11 & 1.07 & 76.47 & 20.03 \\
\hline & 750 & 2626.5 & 95.55 & 27.49 & 1.09 & 1.08 & 79.41 & 16.14 \\
\hline & 1000 & 2541.5 & 94.97 & 26.76 & 1.05 & 1.05 & 79.41 & 15.56 \\
\hline \multirow{4}{*}{0.5} & 250 & 2635 & 96.42 & 27.33 & 1.11 & 1.07 & 75.74 & 20.68 \\
\hline & 500 & 2635 & 95.28 & 27.65 & 1.09 & 1.09 & 81.62 & 13.67 \\
\hline & 750 & 2652 & 93.54 & 28.35 & 1.08 & 1.11 & 88.97 & 4.57 \\
\hline & 1000 & 2533 & 96.08 & 26.36 & 0.93 & 1.08 & 88.97 & 7.11 \\
\hline \multirow{4}{*}{0.75} & 250 & 2626.5 & 96.25 & 27.29 & 1.10 & 1.07 & 77.94 & 18.31 \\
\hline & 500 & 2660.5 & 93.93 & 28.32 & 1.10 & 1.11 & 80.15 & 13.79 \\
\hline & 750 & 2686 & 96.91 & 27.72 & 1.04 & 1.15 & 86.03 & 10.88 \\
\hline & 1000 & 1411 & 105.83 & 13.33 & 0.27 & 0.58 & 88.97 & 16.86 \\
\hline \multirow{4}{*}{1} & 250 & 2626.5 & 96.15 & 27.32 & 1.09 & 1.07 & 77.21 & 18.95 \\
\hline & 500 & 2635 & 93.31 & 28.24 & 1.07 & 1.10 & 82.35 & 10.96 \\
\hline & 750 & 2677.5 & 97.07 & 27.58 & 1.02 & 1.16 & 86.76 & 10.30 \\
\hline & 1000 & 1054 & 105.33 & 10.01 & 0.12 & 0.41 & 86.03 & 19.30 \\
\hline
\end{tabular}


Table 5-4 - IFE inner edge, OFE outer edge margin evolution. From top to bottom, margin to: CHF, IFE inner edge; CHF OFE outer edge; FE, IFE inner edge; FE, OFE outer edge. Color scale goes from gray (smaller value) to green (highest value). Cells colored in black do not meet safety criteria (margin < 1.0). Axial position 1 is top of the fuel, 25 is bottom

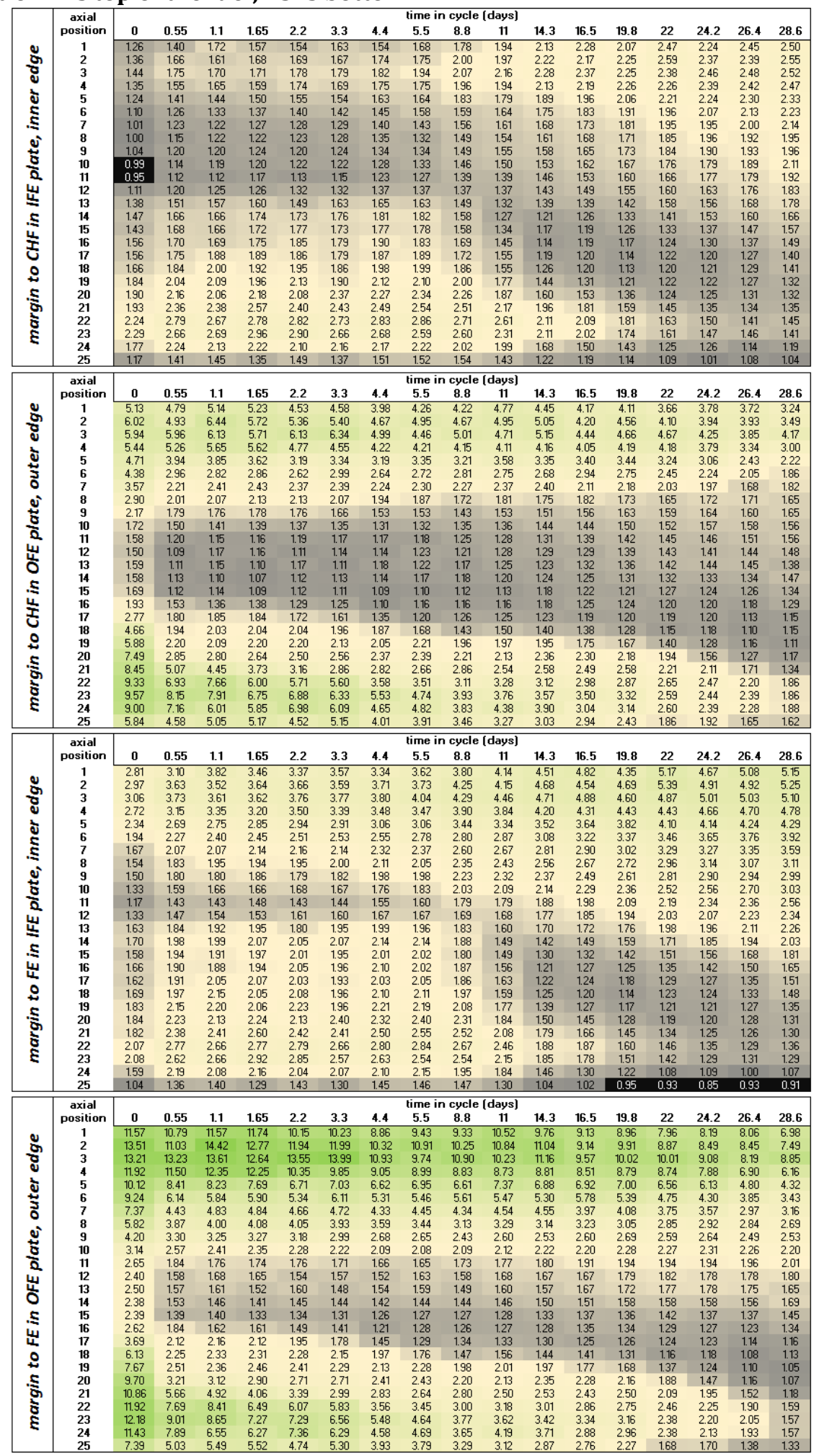

Alternate Design Concepts for the High Flux Isotope Reactor using Low-Enriched Uranium Fuel Systems - Scoping Analysis 


\subsubsection{Un-contoured UMo Design with Non-Uniform Cadmium Wires}

The previous section concluded that it was unlikely to find an acceptable design with only uniform cadmium wires. In this section, we explore designs that include horizontal wires with different thicknesses. Because manufacturing side-plates with non-uniform wires will likely be difficult, a radical concept has been investigated with a modified side-plate design. This new concept, depicted in Figure 5-2, is described below.

The basic idea is to separate the side-plate function (holding the plates together) from the neutron absorber function by separating physically the two. One could imagine a simple sleeve in which horizontal grooves are made on the external side where cadmium wires could be press-fitted inside. This "absorbing" sleeve could then be inserted just inside the inner side-plate so that the external radius of the sleeve would be in contact with the inner radius of the side-plate. Due to geometric constraints, the inner radius of the sleeve has to be identical or slightly larger than the current IFE inner side-plate inner radius. To accommodate the inserted wires and groove machining, it seems reasonable to consider a sleeve thickness of at least three to four times the wire diameter. Such sleeve dimensions would require increasing the IFE side-plate inner and outer radius. This would reduce the flow area and fuel volume in the IFE, which could be recovered by a small reduction in plate thickness and a slight increase in the number of plates. Currently the side-plate is attached to a bottom connector, which insure that the fuel elements sit in the core. With this concept, both the sleeve and side-plate would be attached to the bottom connector.

If this concept represents significant changes in the element design, it has the advantage of not increasing the complexity of the side-plate fabrication itself: the same process, just different dimensions. The sleeve manufacture would obviously represent additional work but this could be done independently from the side-plate and fuel element manufacture.

Based on the constraints mentioned above, a new MCNP model has been generated in which the sleeve concept is introduced. The geometric parameters impacted by these modifications are described in Table 5-5 below.

Based on the results obtained previously and described in the previous section, designs with the sleeve and horizontal cadmium wires have been investigated with the goals of finding a configuration that satisfy performance and safety criteria, and of simplifying manufacture by limiting the number of wires required and limiting the number of wire types. Starting with the configuration 23-6.5-9.5, and after several iterations, a configuration has been obtained that meet all these requirements.

This configuration (later referred as 23-6.5-9.5-S166) requires 92 horizontal cadmium wires having a diameter of $0.03 \mathrm{~cm}$ and 74 wires having a diameter of $0.08 \mathrm{~cm}$ for a total of 166 wires. A more detailed description of the wires is provided in Table 5-6 and Table 5-7. Calculations show that an operating power of $95 \mathrm{MW}$ is required to meet the performance metrics. The cycle length at that power would be 27.5 days (compared to 26 days for the HEU core).

Figure 5-3 to Figure 5-8 illustrate the evolution of the performance and safety criteria for this configuration. Table 5-8 provides additional information on the design. It can be seen from these figures that configuration 23-6.5-9.5-S166 performances are quite similar to the HEU core and that the limiting power would remain at a minimum two MW above the operating power. It is believed that better wire arrangement can be obtained that would increase performance and/or safety criteria but these optimization analysis have not been performed at this point. 
Table 5-5 - Selected dimensions for the absorbing sleeve concept used in MCNP

\begin{tabular}{|l|c|c|}
\hline \multicolumn{1}{|c|}{ parameter } & HEU & LEU \\
\hline sleeve inner radius (cm) & - & 6.43763 \\
sleeve outer radius (cm) & - & 6.78763 \\
sleeve thickness (cm) & - & 0.35 \\
IFE inner sideplate inner radius (cm) & 6.43763 & 6.78763 \\
IFE inner side-plate outer radius (cm) & 6.88886 & 7.23763 \\
inner side-plate thickness (cm) & 0.45123 & 0.45 \\
IFE involute radius (cm) & 6.9126 & 7.3170 \\
IFE, OFE plate thickness (cm / mil) & $0.127 / 50$ & $0.12192 / 48$ \\
IFE, OFE channel thickness (cm / mil) & $0.127 / 50$ & $0.13208 / 52$ \\
number of plates in IFE, OFE, total & $171,369,540$ & $181,369,550$ \\
\hline \multicolumn{2}{|c}{}
\end{tabular}
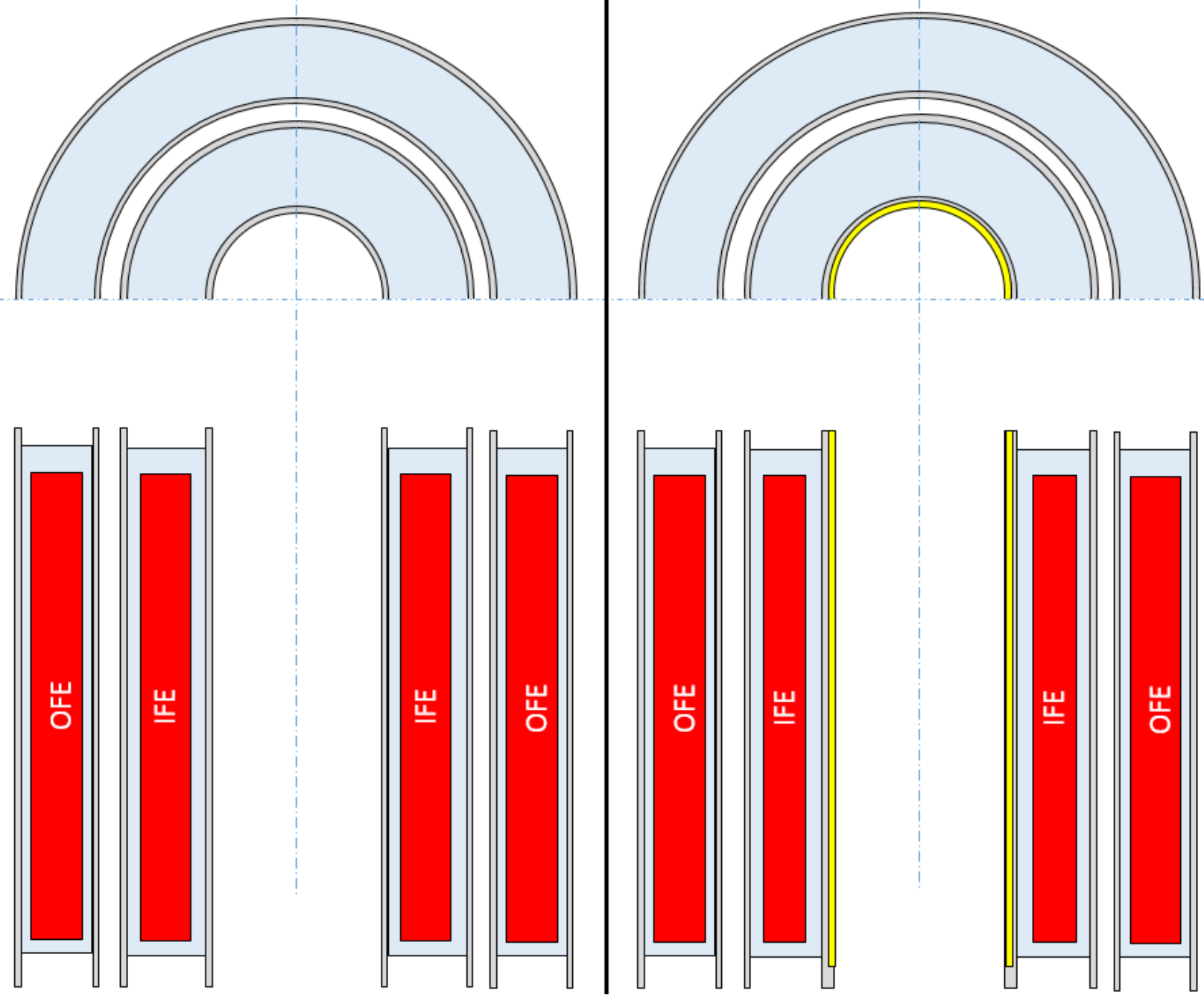

Figure 5-2 - Schematic top and profile cross-section of HFIR fuel elements: current design (left) and sleeve concept (right). Gray represents side-plates; light blue represents fuel plates; red represents fuel; yellow represents sleeve containing cadmium wires (cadmium wires not represented) 
Table 5-6 - Geometric information for wire \#1 to \#84

\begin{tabular}{|c|c|c|c|c|c|c|c|}
\hline $\begin{array}{c}\text { wire } \\
\#\end{array}$ & $\begin{array}{l}\text { position } \\
\text { relative to fuel } \\
\text { midplane }(\mathrm{cm})\end{array}$ & $\begin{array}{c}\text { distance with } \\
\text { wire above } \\
\text { (cm) }\end{array}$ & $\begin{array}{c}\text { wire } \\
\text { radius } \\
(\mathrm{cm})\end{array}$ & $\begin{array}{c}\text { wire } \\
\#\end{array}$ & $\begin{array}{l}\text { position } \\
\text { relative to fuel } \\
\text { midplane }(\mathrm{cm})\end{array}$ & $\begin{array}{l}\text { distance with } \\
\text { wire above } \\
\text { (cm) }\end{array}$ & $\begin{array}{l}\text { wire radius } \\
\text { (cm) }\end{array}$ \\
\hline 1 & 10.775 & - & 0.015 & 43 & 0.695 & 0.24 & 0.015 \\
\hline 2 & 10.535 & 0.24 & 0.015 & 44 & 0.455 & 0.24 & 0.015 \\
\hline 3 & 10.295 & 0.24 & 0.015 & 45 & 0.215 & 0.24 & 0.015 \\
\hline 4 & 10.055 & 0.24 & 0.015 & 46 & -0.025 & 0.24 & 0.015 \\
\hline 5 & 9.815 & 0.24 & 0.015 & 47 & -0.265 & 0.24 & 0.015 \\
\hline 6 & 9.575 & 0.24 & 0.015 & 48 & -0.475 & 0.21 & 0.015 \\
\hline 7 & 9.335 & 0.24 & 0.015 & 49 & -0.745 & 0.27 & 0.015 \\
\hline 8 & 9.095 & 0.24 & 0.015 & 50 & -0.985 & 0.24 & 0.015 \\
\hline 9 & 8.855 & 0.24 & 0.015 & 51 & -1.225 & 0.24 & 0.015 \\
\hline 10 & 8.615 & 0.24 & 0.015 & 52 & -1.465 & 0.24 & 0.015 \\
\hline 11 & 8.375 & 0.24 & 0.015 & 53 & -1.705 & 0.24 & 0.015 \\
\hline 12 & 8.135 & 0.24 & 0.015 & 54 & -1.945 & 0.24 & 0.015 \\
\hline 13 & 7.895 & 0.24 & 0.015 & 55 & -2.185 & 0.24 & 0.015 \\
\hline 14 & 7.655 & 0.24 & 0.015 & 56 & -2.425 & 0.24 & 0.015 \\
\hline 15 & 7.415 & 0.24 & 0.015 & 57 & -2.665 & 0.24 & 0.015 \\
\hline 16 & 7.175 & 0.24 & 0.015 & 58 & -2.905 & 0.24 & 0.015 \\
\hline 17 & 6.935 & 0.24 & 0.015 & 59 & -3.145 & 0.24 & 0.015 \\
\hline 18 & 6.695 & 0.24 & 0.015 & 60 & -3.385 & 0.24 & 0.015 \\
\hline 19 & 6.455 & 0.24 & 0.015 & 61 & -3.625 & 0.24 & 0.015 \\
\hline 20 & 6.215 & 0.24 & 0.015 & 62 & -3.865 & 0.24 & 0.015 \\
\hline 21 & 5.975 & 0.24 & 0.015 & 63 & -4.105 & 0.24 & 0.015 \\
\hline 22 & 5.735 & 0.24 & 0.015 & 64 & -4.345 & 0.24 & 0.015 \\
\hline 23 & 5.495 & 0.24 & 0.015 & 65 & -4.585 & 0.24 & 0.015 \\
\hline 24 & 5.255 & 0.24 & 0.015 & 66 & -4.825 & 0.24 & 0.015 \\
\hline 25 & 5.015 & 0.24 & 0.015 & 67 & -5.065 & 0.24 & 0.015 \\
\hline 26 & 4.775 & 0.24 & 0.015 & 68 & -5.305 & 0.24 & 0.015 \\
\hline 27 & 4.535 & 0.24 & 0.015 & 69 & -5.545 & 0.24 & 0.015 \\
\hline 28 & 4.295 & 0.24 & 0.015 & 70 & -5.785 & 0.24 & 0.015 \\
\hline 29 & 4.055 & 0.24 & 0.015 & 71 & -6.025 & 0.24 & 0.015 \\
\hline 30 & 3.815 & 0.24 & 0.015 & 72 & -6.265 & 0.24 & 0.015 \\
\hline 31 & 3.575 & 0.24 & 0.015 & 73 & -6.505 & 0.24 & 0.015 \\
\hline 32 & 3.335 & 0.24 & 0.015 & 74 & -6.745 & 0.24 & 0.015 \\
\hline 33 & 3.095 & 0.24 & 0.015 & 75 & -6.985 & 0.24 & 0.015 \\
\hline 34 & 2.855 & 0.24 & 0.015 & 76 & -7.225 & 0.24 & 0.015 \\
\hline 35 & 2.615 & 0.24 & 0.015 & 77 & -7.465 & 0.24 & 0.015 \\
\hline 36 & 2.375 & 0.24 & 0.015 & 78 & -7.705 & 0.24 & 0.015 \\
\hline 37 & 2.135 & 0.24 & 0.015 & 79 & -7.945 & 0.24 & 0.015 \\
\hline 38 & 1.895 & 0.24 & 0.015 & 80 & -8.185 & 0.24 & 0.015 \\
\hline 39 & 1.655 & 0.24 & 0.015 & 81 & -8.425 & 0.24 & 0.015 \\
\hline 40 & 1.415 & 0.24 & 0.015 & 82 & -8.665 & 0.24 & 0.015 \\
\hline 41 & 1.175 & 0.24 & 0.015 & 83 & -8.905 & 0.24 & 0.015 \\
\hline 42 & 0.935 & 0.24 & 0.015 & 84 & -9.145 & 0.24 & 0.015 \\
\hline
\end{tabular}

Alternate Design Concepts for the High Flux Isotope Reactor using Low-Enriched Uranium Fuel Systems - Scoping Analysis 
Table 5-7 - Geometric information for wire \#85 to \#166

\begin{tabular}{|c|c|c|c|c|c|c|c|}
\hline $\begin{array}{c}\text { wire } \\
\#\end{array}$ & $\begin{array}{l}\text { position } \\
\text { relative to fuel } \\
\text { midplane }(\mathrm{cm})\end{array}$ & $\begin{array}{l}\text { distance with } \\
\text { wire above } \\
\text { (cm) }\end{array}$ & $\begin{array}{l}\text { wire } \\
\text { radius } \\
\text { (cm) }\end{array}$ & $\begin{array}{c}\text { wire } \\
\#\end{array}$ & $\begin{array}{l}\text { position } \\
\text { relative to fuel } \\
\text { midplane }(\mathrm{cm})\end{array}$ & $\begin{array}{l}\text { distance with } \\
\text { wire above } \\
\text { (cm) }\end{array}$ & $\begin{array}{l}\text { wire } \\
\text { radius } \\
\text { (cm) }\end{array}$ \\
\hline 85 & -9.385 & 0.24 & 0.015 & 127 & -19.805 & 0.25 & 0.040 \\
\hline 86 & -9.625 & 0.24 & 0.015 & 128 & -20.055 & 0.25 & 0.040 \\
\hline 87 & -9.865 & 0.24 & 0.015 & 129 & -20.305 & 0.25 & 0.040 \\
\hline 88 & -10.105 & 0.24 & 0.015 & 130 & -20.555 & 0.25 & 0.040 \\
\hline 89 & -10.345 & 0.24 & 0.015 & 131 & -20.805 & 0.25 & 0.040 \\
\hline 90 & -10.585 & 0.24 & 0.015 & 132 & -21.055 & 0.25 & 0.040 \\
\hline 91 & -10.825 & 0.24 & 0.015 & 133 & -21.305 & 0.25 & 0.040 \\
\hline 92 & -11.065 & 0.24 & 0.015 & 134 & -21.555 & 0.25 & 0.040 \\
\hline 93 & -11.285 & 0.22 & 0.040 & 135 & -21.805 & 0.25 & 0.040 \\
\hline 94 & -11.535 & 0.25 & 0.040 & 136 & -22.055 & 0.25 & 0.040 \\
\hline 95 & -11.785 & 0.25 & 0.040 & 137 & -22.305 & 0.25 & 0.040 \\
\hline 96 & -12.035 & 0.25 & 0.040 & 138 & -22.555 & 0.25 & 0.040 \\
\hline 97 & -12.285 & 0.25 & 0.040 & 139 & -22.805 & 0.25 & 0.040 \\
\hline 98 & -12.535 & 0.25 & 0.040 & 140 & -23.055 & 0.25 & 0.040 \\
\hline 99 & -12.785 & 0.25 & 0.040 & 141 & -23.305 & 0.25 & 0.040 \\
\hline 100 & -13.035 & 0.25 & 0.040 & 142 & -23.555 & 0.25 & 0.040 \\
\hline 101 & -13.285 & 0.25 & 0.040 & 143 & -23.825 & 0.27 & 0.040 \\
\hline 102 & -13.555 & 0.27 & 0.040 & 144 & -24.075 & 0.25 & 0.040 \\
\hline 103 & -13.805 & 0.25 & 0.040 & 145 & -24.325 & 0.25 & 0.040 \\
\hline 104 & -14.055 & 0.25 & 0.040 & 146 & -24.575 & 0.25 & 0.040 \\
\hline 105 & -14.305 & 0.25 & 0.040 & 147 & -24.825 & 0.25 & 0.040 \\
\hline 106 & -14.555 & 0.25 & 0.040 & 148 & -25.075 & 0.25 & 0.040 \\
\hline 107 & -14.805 & 0.25 & 0.040 & 149 & -25.325 & 0.25 & 0.040 \\
\hline 108 & -15.055 & 0.25 & 0.040 & 150 & -25.575 & 0.25 & 0.040 \\
\hline 109 & -15.305 & 0.25 & 0.040 & 151 & -25.825 & 0.25 & 0.040 \\
\hline 110 & -15.555 & 0.25 & 0.040 & 152 & -26.075 & 0.25 & 0.040 \\
\hline 111 & -15.805 & 0.25 & 0.040 & 153 & -26.325 & 0.25 & 0.040 \\
\hline 112 & -16.055 & 0.25 & 0.040 & 154 & -26.575 & 0.25 & 0.040 \\
\hline 113 & -16.305 & 0.25 & 0.040 & 155 & -26.825 & 0.25 & 0.040 \\
\hline 114 & -16.555 & 0.25 & 0.040 & 156 & -27.075 & 0.25 & 0.040 \\
\hline 115 & -16.805 & 0.25 & 0.040 & 157 & -27.325 & 0.25 & 0.040 \\
\hline 116 & -17.055 & 0.25 & 0.040 & 158 & -27.535 & 0.21 & 0.040 \\
\hline 117 & -17.305 & 0.25 & 0.040 & 159 & -27.785 & 0.25 & 0.040 \\
\hline 118 & -17.555 & 0.25 & 0.040 & 160 & -28.035 & 0.25 & 0.040 \\
\hline 119 & -17.805 & 0.25 & 0.040 & 161 & -28.285 & 0.25 & 0.040 \\
\hline 120 & -18.055 & 0.25 & 0.040 & 162 & -28.535 & 0.25 & 0.040 \\
\hline 121 & -18.305 & 0.25 & 0.040 & 163 & -28.785 & 0.25 & 0.040 \\
\hline 122 & -18.555 & 0.25 & 0.040 & 164 & -29.035 & 0.25 & 0.040 \\
\hline 123 & -18.805 & 0.25 & 0.040 & 165 & -29.285 & 0.25 & 0.040 \\
\hline 124 & -19.055 & 0.25 & 0.040 & 166 & -29.535 & 0.25 & 0.040 \\
\hline 125 & -19.305 & 0.25 & 0.040 & & & & \\
\hline 126 & -19.555 & 0.25 & 0.040 & & & & \\
\hline
\end{tabular}

Alternate Design Concepts for the High Flux Isotope Reactor using Low-Enriched Uranium Fuel Systems - Scoping Analysis 


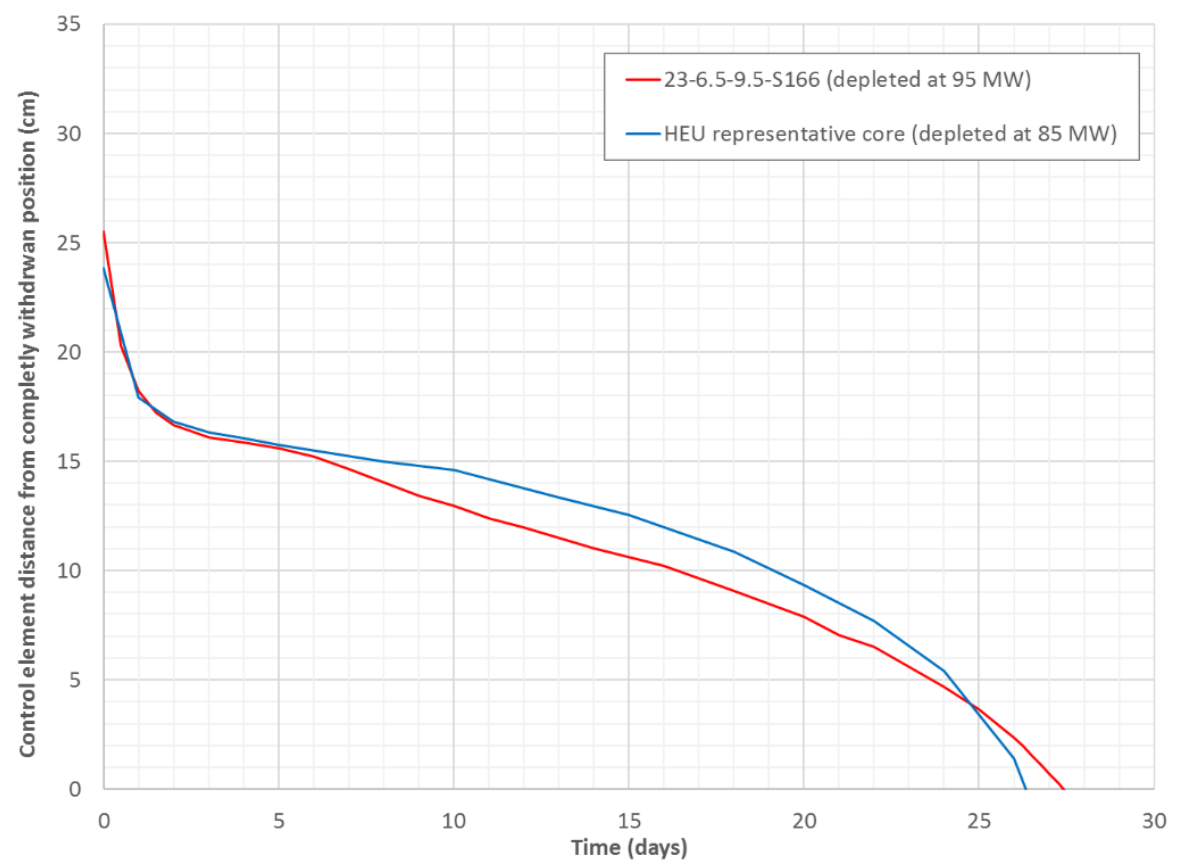

Figure 5-3 - Critical position of the control elements versus time for configuration 23-6.5-9.5-S166 depleted at 95MW and HEU depleted at 85MW

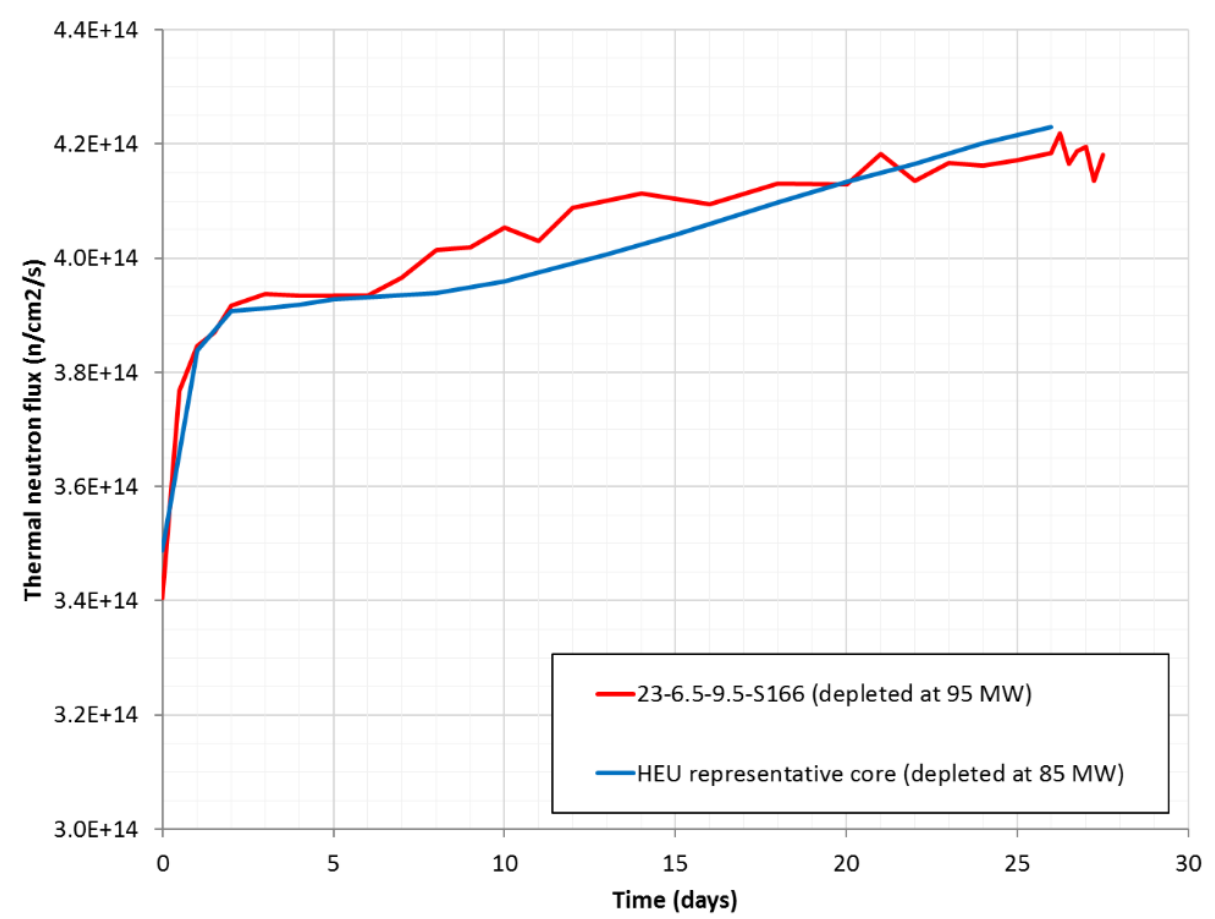

Figure 5-4 - Evolution of HEU representative core and LEU UMo configuration 23-6.5-9.5-S166 thermal neutron flux in the cold source in beam tube HB4

Alternate Design Concepts for the High Flux Isotope Reactor using Low-Enriched Uranium Fuel Systems - Scoping Analysis 


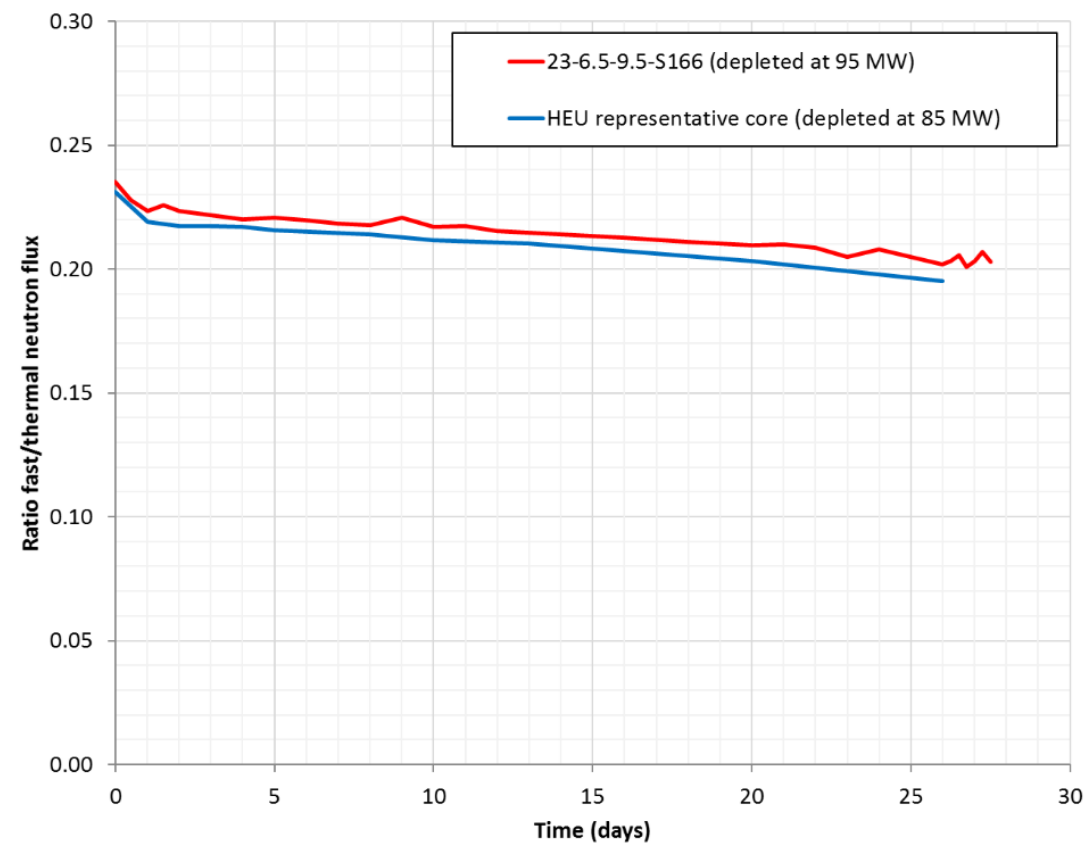

Figure 5-5 - Evolution of HEU representative core and LEU UMo configuration 23-6.5-9.5-S166 ratio fast/thermal neutron flux in the cold source in beam tube HB4

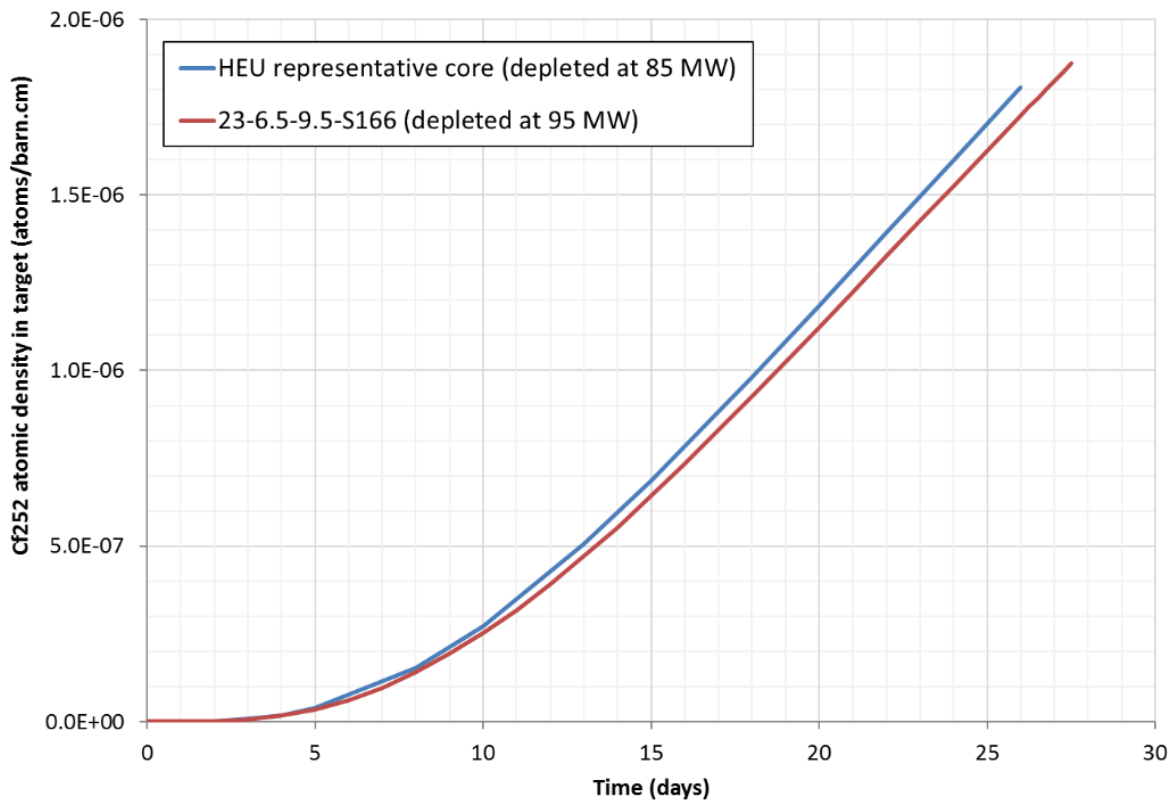

Figure 5-6 - Evolution of HEU representative core and LEU UMo configuration 23-6.5-9.5-S166 ${ }^{252} \mathrm{Cf}$ production

Alternate Design Concepts for the High Flux Isotope Reactor using Low-Enriched Uranium Fuel Systems - Scoping Analysis 


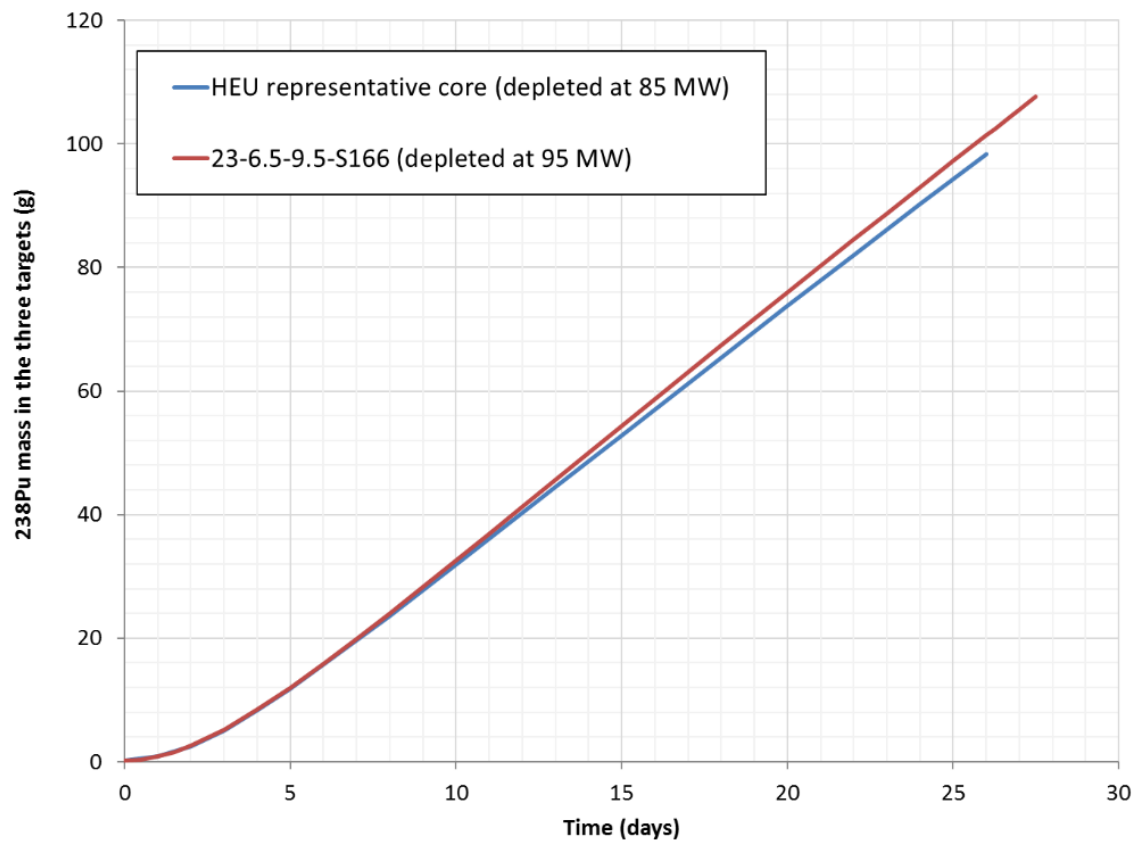

Figure 5-7 - Evolution of HEU representative core and LEU UMo configuration 23-6.5-9.5-S166 ${ }^{238} \mathrm{Pu}$ production

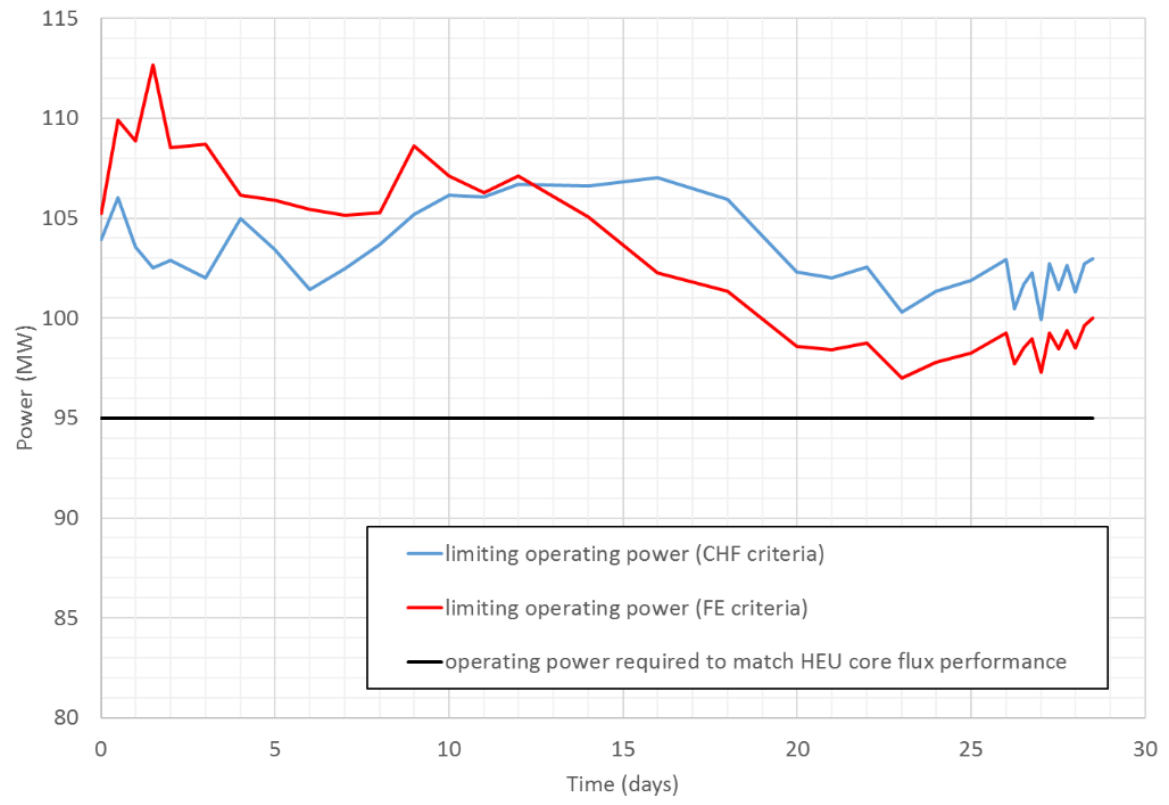

Figure 5-8 - Evolution of HEU representative core and LEU UMo configuration 23-6.5-9.5-S166 limiting power based on the critical heat flux (CHF) and flow excursion (FE) criteria

Alternate Design Concepts for the High Flux Isotope Reactor using Low-Enriched Uranium Fuel Systems - Scoping Analysis 
Table 5-8 - Characteristics of the LEU UMo 23-6.5-9.5-S166 design and current HEU core

\begin{tabular}{|c|c|c|}
\hline Core parameters & HEU core & $23-6.5-9.5-S 166$ \\
\hline Nominal reactor power (MW) & 85 & 95 \\
\hline Number of fuel elements & 2 & 2 \\
\hline Cladding type & Al-6061 & Al-6061 \\
\hline Fuel type & $\mathrm{U} 308-\mathrm{Al}$ & UMo "monolithic" \\
\hline Fuel form & Mixed powder & Alloy \\
\hline 235U enrichment (wt. \%) & 93.10 & 19.75 \\
\hline${ }^{235} \mathrm{U}$ loading (IFE/OFE/total, kg/core) & $2.60 / 6.8 / 9.40$ & $3.68 / 11.16 / 14.83$ \\
\hline Uranium loading (IFE/OFE/total, kg/core) & $2.79 / 7.30 / 10.10$ & $18.61 / 56.49 / 75.10$ \\
\hline Number of plates (IFE / OFE / total) & $171 / 369 / 540$ & $181 / 369 / 550$ \\
\hline Plate length (in) & 24 & 24 \\
\hline Plate thickness (mil) & 50 & 48 \\
\hline Channel thickness (mil) & 50 & 52 \\
\hline Fuel length (in) & 20 & 23 \\
\hline Fuel width (IFE, OFE, in) & $3.07 / 2.79$ & $3.07 / 2.79$ \\
\hline IFE fuel thickness (mil) & Not communicated & 6.5 \\
\hline IFE fuel + filler thickness (mil) & 30 & 6.5 (no filler) \\
\hline IFE fuel volume / plate (cc/plate) & 21.0 & 6.71 \\
\hline OFE fuel thickness (mil) & Not communicated & 9.5 \\
\hline OFE fuel volume (cc/plate) & 18.77 & 9.99 \\
\hline 235U maximum consumption (\%) & Not communicated & 51.5 \\
\hline Estimated peak fission density (f/cc) * & Not communicated & $3.97 \times 10^{21}$ \\
\hline Peak power density (kW/cc meat) & Not communicated & 62.3 \\
\hline Peak heat flux $\left(\mathrm{W} / \mathrm{cm}^{2}\right)$ & Not communicated & 509 \\
\hline
\end{tabular}




\section{Assessing Feasibility of Low-Enriched U3Si2}

Based on NUREG-1313 [NRC, 1988], the silicide fuel system is "suitable and acceptable for use in research and test reactors (...) with uranium densities up to $4.8 \mathrm{~g} / \mathrm{cm}^{3}$ ". In this document, the above statement derived from favorable irradiation behavior observed in the ORNL's ORR reactor. However, two operational limits are defined:

- $\quad$ Maximum fuel meat temperature: $130{ }^{\circ} \mathrm{C}$

- $\quad$ Maximum heat flux: $140 \mathrm{~W} / \mathrm{cm}^{2}$

How would a silicide fuel behave with respect to these limits? While the temperature is very likely to be in the range of interest for HFIR, the mentioned heat flux is however far below what can be expected in HFIR. No limit on burnup is defined. To complicate matters, these limits do not correspond to intrinsic limits of the fuel system; they are the limits of operation of the ORR reactor, where the qualification campaign occurred.

Recently, the French's CEA has carried out the Jules Horowitz Reactor (JHR) fuel element qualification campaign in the BR-2 reactor using a dedicated semi-open loop called EVITA [Koonen, 2009]. The fuel system was silicide enriched at $27 \%$. Even though the post-irradiation data publicly available is very limited, it appears that:

- $\quad$ The maximum meat temperature was above $140{ }^{\circ} \mathrm{C}$ [Gouat, 2011].

- The maximum heat flux was around $516 \mathrm{~W} / \mathrm{cm}^{2}$ [Koonen, 2009].

- $\quad$ The maximum burnup was around 80\% [Anselmet, 2013].

In [Anselmet, 2013] it is concluded that irradiation of silicide fuel at JHR conditions leads to:

- Moderate change in fuel element and plate geometry.

- $\quad$ No particular evolution of the cladding microstructure.

- Satisfactory fuel meat behavior up to high burnups.

If confirmed, the EVITA campaign value for each of the parameters stated above would likely exceed HFIR operating conditions, and therefore support the idea that the silicide fuel system is - from the perspective of fuel performance - suitable for HFIR. Consequently, it appears justified to assess if the LEU silicide fuel system could also meet HFIR performance and safety criteria.

\subsection{U3Si2 Fuel System Properties}

In order to perform HFIR neutronic and thermal-hydraulic analysis the properties described below need to be defined.

\subsubsection{U3Si2 Fuel Composition and Density}

Based on [IAEA, 1992] page 25, the density of $\mathrm{U}_{3} \mathrm{Si}_{2}$ is $12.20 \mathrm{~g} / \mathrm{cm}^{3}$ and the silicon weight fraction is 7.5\%. From there, key characteristics, described in Table 6-1, of the fuel composition can be deduced as follow:

Alternate Design Concepts for the High Flux Isotope Reactor using Low-Enriched Uranium Fuel 
Table 6-1- Silicide composition description

\begin{tabular}{|c|c|c|c|}
\hline Parameter & symbol & value & comments \\
\hline $\mathrm{U}_{3} \mathrm{Si}_{2}$ density $(\mathrm{g} / \mathrm{cc})$ & $\rho$ & 12.200 & From [IAEA, 1992] \\
\hline Aluminum matrix density $(\mathrm{g} / \mathrm{cc}$ ) & $\rho \_$Al & 2.7000 & Typical pure Al density \\
\hline Silicon weight fraction (\%) & Si_w & 7.5 & From [IAEA, 1992] \\
\hline Uranium density in $\mathrm{U}_{3} \mathrm{Si}_{2}(\mathrm{~g} / \mathrm{cc})$ & $\overline{\rho U}$ & 11.285 & $\begin{array}{l}\text { Calculated as: } \\
\rho U=\rho^{*}\left(1-\mathrm{Si}_{-} \mathrm{w}\right)\end{array}$ \\
\hline Uranium density in meat $(\mathrm{g} / \mathrm{cc})$ & $\rho \mathrm{UM}$ & 4.8000 & imposed \\
\hline $235 \mathrm{U}$ enrichment & $\mathrm{e}$ & $19.75 \%$ & Imposed, same as UMo monolithic \\
\hline 235 $\mathrm{U}$ density in meat $(\mathrm{g} / \mathrm{cc})$ & $\rho \mathrm{SUM}$ & 0.94800 & $\begin{array}{l}\text { Calculated as: } \\
\rho \mathrm{U} 5 \mathrm{M}=\rho \mathrm{UM} * \mathrm{e}\end{array}$ \\
\hline $\mathrm{U}_{3} \mathrm{Si}_{2}$ density in meat $(\mathrm{g} / \mathrm{cc})$ & $\rho U S i M$ & 5.1892 & $\begin{array}{l}\text { Calculated as: } \\
\rho U S i M=\rho U M * \rho / \rho U\end{array}$ \\
\hline Silicon density in meat (g/cc) & $\rho \mathrm{SiM}$ & 0.38919 & $\begin{array}{l}\text { Calculated as: } \\
\rho \text { SiM }=\rho U S i M-\rho U M\end{array}$ \\
\hline $\mathrm{U}_{3} \mathrm{Si}_{2}$ volume fraction in meat & Vf & $42.53 \%$ & $\begin{array}{l}\text { Calculated as: } \\
\mathrm{Vf}=\rho \mathrm{USiM} / \rho\end{array}$ \\
\hline As-built porosity volume fraction & $\mathrm{Vp}$ & $8.24 \%$ & $\begin{array}{l}\text { From [IAEA, 1992] p. } 14: \\
\text { Vp }=0.072 \text { Vf }-0.275 \mathrm{Vf}^{\wedge} 2+1.32 \mathrm{Vf}^{\wedge} 3\end{array}$ \\
\hline Matrix volume fraction & $\mathrm{Vm}$ & $49.23 \%$ & $\begin{array}{l}\text { Calculated as: } \\
\mathrm{Vm}=1-\mathrm{Vf}-\mathrm{Vp}\end{array}$ \\
\hline Aluminum matrix density in meat $(\mathrm{g} / \mathrm{cc})$ & $\rho \_$AlM & 1.3291 & $\begin{array}{l}\text { Calculated as: } \\
\rho \_\mathrm{AlM}=\mathrm{Vm} * \rho_{\_} \mathrm{Al}\end{array}$ \\
\hline Meat density (g/cc) & $\rho \_$meat & 6.5183 & $\begin{array}{l}\text { Calculated as: } \\
\rho \_ \text {meat }=\rho \_ \text {AlM }+\rho U \text { SiM }\end{array}$ \\
\hline
\end{tabular}

From Table 6-1 data, the composition presented in Table 6-2 below is proposed for neutronic calculations.

Table 6-2 - Proposed fuel composition for silicide fuel to be used in neutronic calculations

\begin{tabular}{|c|c|c|c|c|c|c|}
\hline Element & $\begin{array}{c}\text { Element } \\
\text { density } \\
\text { (g/cc) }\end{array}$ & Isotope & $\begin{array}{c}\text { Isotope } \\
\text { molar mass } \\
\text { (g/mol) } \\
{[\mathrm{NIST}, 2018]}\end{array}$ & $\begin{array}{l}\text { Isotopic weight } \\
\text { fraction in element } \\
\text { (\%) [NIST,2018 } \\
\text { except for } \\
\text { uranium] }\end{array}$ & $\begin{array}{l}\text { Isotope } \\
\text { density } \\
\text { (g/cc) }\end{array}$ & $\begin{array}{c}\text { Isotope atomic } \\
\text { density } \\
\text { (at/barn.cm) }\end{array}$ \\
\hline $\mathrm{Al}$ & 1.3291 & ${ }^{27} \mathrm{Al}$ & 26.98154 & 100 & $1.32910 \mathrm{E}+00$ & $2.96641 \mathrm{E}-02$ \\
\hline \multirow{3}{*}{$\mathrm{Si}$} & \multirow{3}{*}{0.38919} & ${ }^{28} \mathrm{Si}$ & 27.97693 & 92.223 & 3.58923E-01 & $7.72577 \mathrm{E}-03$ \\
\hline & & ${ }^{29} \mathrm{Si}$ & 28.97649 & 4.685 & $1.82336 \mathrm{E}-02$ & $3.78936 \mathrm{E}-04$ \\
\hline & & ${ }^{30} \mathrm{Si}$ & 29.97377 & 3.092 & $1.20338 \mathrm{E}-02$ & $2.41769 \mathrm{E}-04$ \\
\hline \multirow{4}{*}{$\mathrm{U}$} & \multirow{4}{*}{4.8000} & ${ }^{234} \mathrm{U}$ & 234.04095 & 0.176 & $8.44800 \mathrm{E}-03$ & $2.17372 \mathrm{E}-05$ \\
\hline & & $235 \mathrm{U}$ & 235.04393 & 19.75 & $9.48000 \mathrm{E}-01$ & $2.42885 \mathrm{E}-03$ \\
\hline & & $236 \mathrm{U}$ & 236.04557 & 0.091 & $4.36800 \mathrm{E}-03$ & 1.11437E-05 \\
\hline & & $238 \mathrm{U}$ & 238.05079 & 78.75 & $3.83918 \mathrm{E}+00$ & $9.71203 \mathrm{E}-03$ \\
\hline Sum $=$ & 6.51829 & - & - & - & 6.51829 & 5.01843E-02 \\
\hline
\end{tabular}

Alternate Design Concepts for the High Flux Isotope Reactor using Low-Enriched Uranium Fuel Systems - Scoping Analysis 


\subsubsection{U3Si2 Thermal Conductivity}

The fuel thermal conductivity is a necessary input for the evaluation of the HFIR thermal-hydraulic uncertainty factor U18-U20 used in the thermal-hydraulic safety margin evaluation. U18-U20 reflects the peaking factor caused by the simultaneous presence of local fuel segregation and local fuel/clad non-bond. The historical methodology used to define the HFIR HEU core U18-20 factors is well described in [Hilvety, 1967]. Using modern tools, ANL has recently been able to reproduce relatively well the historical U18-20 results [Jaluvka, 2016]. To perform analysis with a silicide fuel system, the following U18-20 parameters need to be adapted:

- Power ratio between segregated / non-segregated fuel areas (area containing more fuel than nominal but still within fabrication tolerance)

In [Hilvety, 1967], it is explained that the packing fraction of closed sphere cannot exceed $74 \%$. The silicide fuel volume fraction is $42.53 \%$ (see Table 6-1). Following the above assumption, the power ratio between segregated / non-segregated fuel areas is therefore: 74 / $42.53 \approx 1.74$. Conservatively, a ratio of 1.8 is considered in this analysis. Note that historically, for HEU, the power ratio is about 10.3. The origin of this number has never been understood but appears excessively conservative (see [Jaluvka, 2016] for more details).

- Radius of segregated area

Assuming a power ratio between segregated / non-segregated fuel areas of 1.8, assuming a local fuel loading tolerance of $27 \%$ (maximum fuel aerial density compared to nominal tolerated per fuel specification, value similar to current HEU) and using the set of equations provided in [Hilvety, 1967], the radius of the overload region is calculated as $23.24 \mathrm{mil}$ (compared to 8.2mil for HEU).

- Thermal-conductivity of segregated / non-segregated fuel areas

In [IAEA, 1992] pp. 18, the thermal-conductivity of silicide is presented as a function of fuel + porosity volume fraction (see Figure 6-1 below for a reproduction). The dataset has been generated at $333 \mathrm{~K}$. Using this data, the thermal-conductivity in the non-segregated area (nominal condition) is set at $40 \mathrm{~W} / \mathrm{m} . \mathrm{K}$ (fuel volume fraction of $42.53 \%$ + porosity of $8.24 \%$ $=50.77 \%$ ). The thermal-conductivity in the segregated area (fuel volume fraction of $74 \%$ and assuming $26 \%$ void $=100 \%$ ) cannot be evaluated since the data stop at $\sim 70 \%$. Considering the shape of the curve in figure 1 and extrapolating, a value of $5 \mathrm{~W} / \mathrm{m} . \mathrm{K}$ is assumed in the segregated area. In section 3.2.3 of NUREG-1313 [NRC, 1988], the dependence of silicide fuel thermal conductivity with temperature is described as weak but slightly positive $(+0.06$ $\mathrm{W} / \mathrm{m} . \mathrm{K}^{2}$ ). This, combined with the fact that the selected values corresponds to relatively low temperature (333K, well below typical HFIR operation condition) means that the selected thermal-conductivity values are likely conservative.

Using the above assumptions and considering a nominal cladding thickness of $12 \mathrm{mil}$, two cases have been considered:

- Fuel centered

- Fuel not centered

Alternate Design Concepts for the High Flux Isotope Reactor using Low-Enriched Uranium Fuel Systems - Scoping Analysis 
The results obtained for the combined U18-20 are presented in Figure 6-2. The curves are well-fitted using order 2 polynomials. One can clearly see the significant impact of the fuel centering on the magnitude of the uncertainty factors. This information is critical for design: If possible, centered-fuel designs are highly preferable.

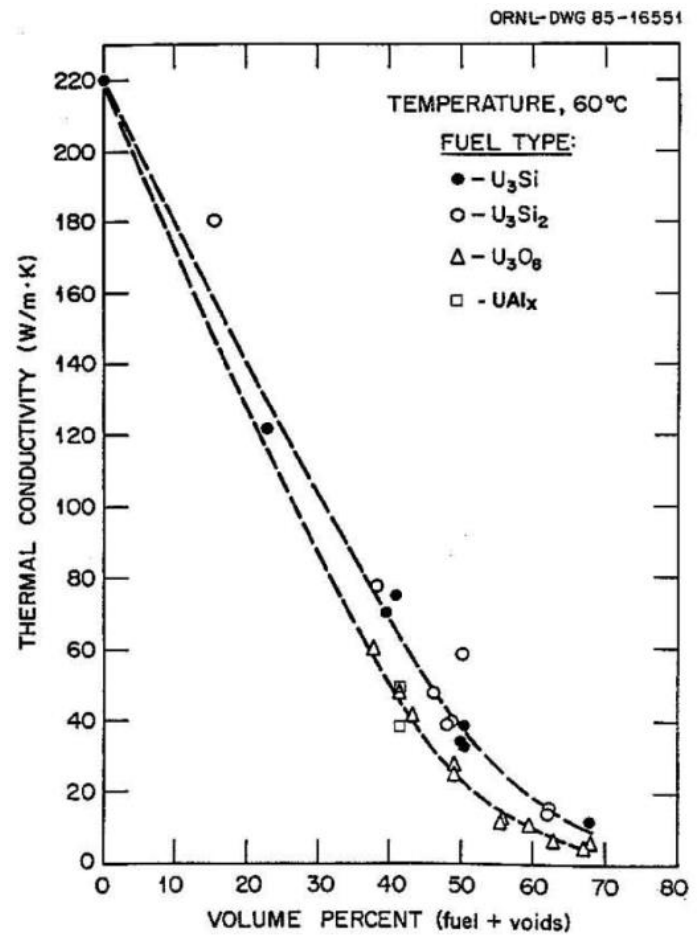

Figure 6-1 - Thermal conductivities of uranium silicide, $\mathrm{U}_{3} \mathrm{O}_{8}$ and UAlx-aluminum dispersion fuels as a function of volume fraction of fuel particles plus voids (porosity). Source: [IAEA, 1992] pp.27

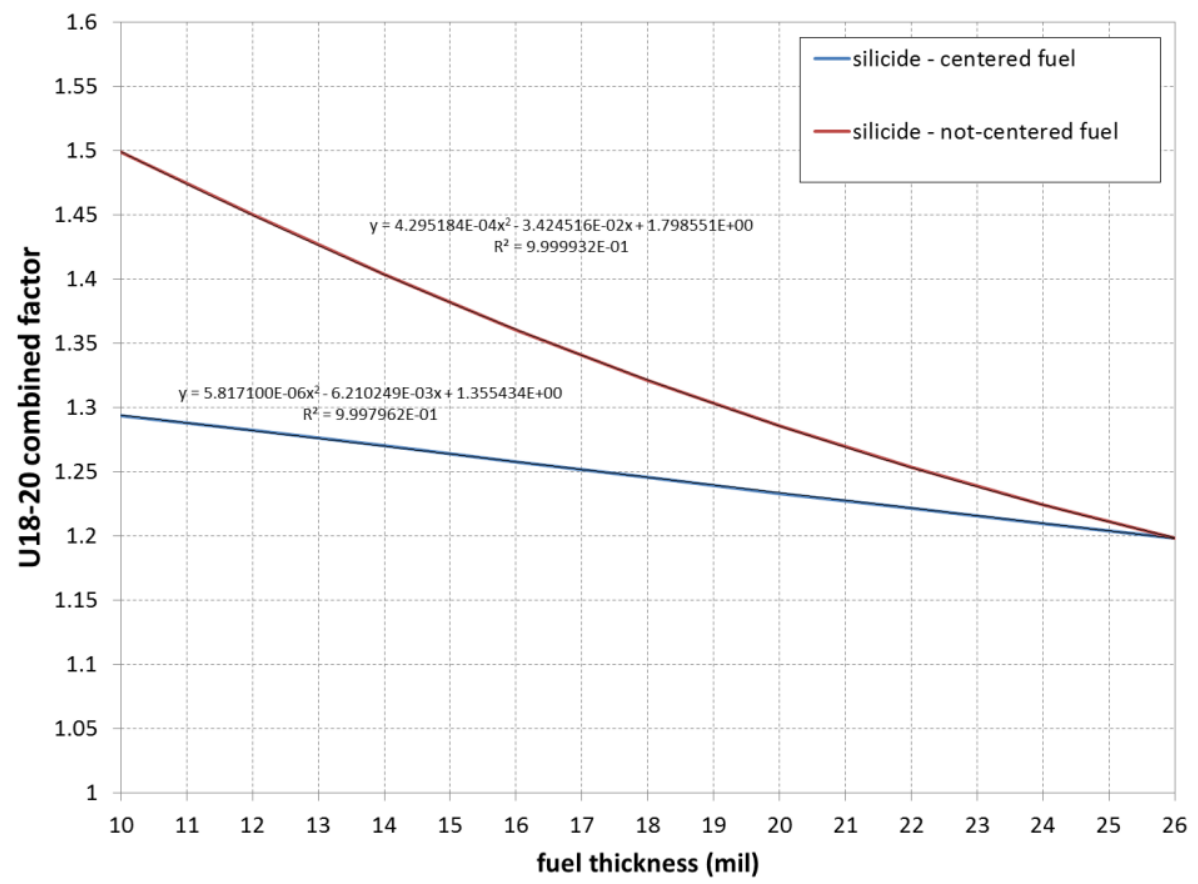

Figure 6-2 - Calculated U18-20 uncertainty factors for silicide fuel using the methodology described in [Hilvety, 1967] and tools described in [Jaluvka, 2016]

Alternate Design Concepts for the High Flux Isotope Reactor using Low-Enriched Uranium Fuel Systems - Scoping Analysis 


\subsubsection{U3Si2 Swelling}

As explained previously, fuel swelling must be modeled because of its adverse effect on core reactivity. In section 3.3.1 of NUREG-1313 [NRC, 1988], the irradiation-induced swelling behavior of silicide fuel is described as linearly dependent with burnup. The slope of the linear silicide fuel particle swelling

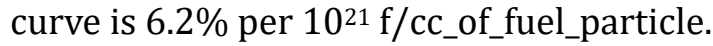

As depicted in Figure 6-3, the silicide fuel swelling is not particularly significant and is not expected to lead to severe swelling in HFIR. It is however expected to decrease cycle length and is therefore modeled in neutronic analyses.

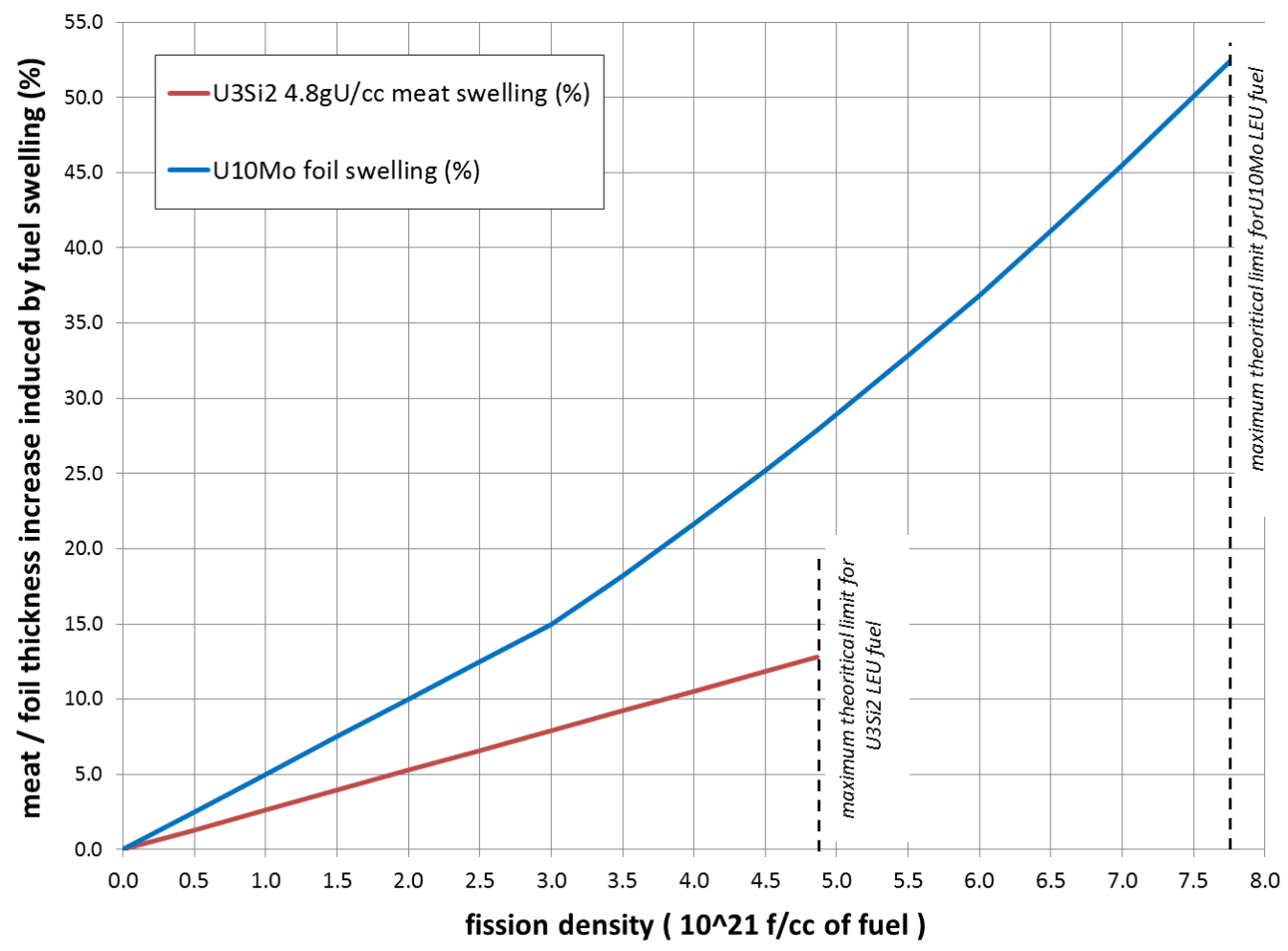

Figure 6-3 - Meat thickness increase induced by fuel swelling for $\mathrm{U}_{3} \mathrm{Si}_{2} 4.8 \mathrm{gU} / \mathrm{cc}$ and $\mathrm{U} 10 \mathrm{Mo}$ monolithic LEU fuel

Alternate Design Concepts for the High Flux Isotope Reactor using Low-Enriched Uranium Fuel 


\subsection{U3Si2 Design Space Exploration Strategy}

In order to perform the design analysis, the following parameters have been considered design variables:

1) Fuel length

- The fuel meat length can vary in the range 20 to $23 \mathrm{inch}$ and fuel length should be the same in both elements

2) Inner, outer fuel element meat thickness

- Meat thickness can be different between the two fuel elements but should not exceed 26 mil (plate thickness is 50 mil and cladding thickness is 12 mil). No minimum is explicitly defined

3) IFE, OFE fuel shape

- $\quad$ Like for the HEU core, fuel contouring is allowed

4) Neutron absorber

- $\quad$ Like for the HEU core, Al-B within the inner fuel element plate is allowed

- ${ }^{10} \mathrm{~B}$ density can be different than the one used in the HEU core but shall not be exceeded

5) Power level

- $\quad$ To compensate for the flux losses, the reactor power can be increased

In order to explore the entire design space with the goal of identifying the less complex solution, the following strategy has been followed step-by-step:

1) Start with simple shape:

- No fuel contouring and no absorber

- Vary fuel length, meat thickness and study the response on performance and margins

- Identify most favorable design space

2) No fuel contouring, but Al-B in IFE plates:

- Based on most favorable design space identified in step 1, compare performance and margins evolution on configuration with and without Al-B layer

- Deduce if acceptable designs are possible

Alternate Design Concepts for the High Flux Isotope Reactor using Low-Enriched Uranium Fuel 
3) Fuel contouring, but no absorber:

- $\quad$ Based on most favorable design space identified in step 1, compare performance and margins evolution on configuration with and without fuel contouring

- Deduce if acceptable designs are possible

4) Both fuel contouring and Al-B in IFE plates:

- $\quad$ Based on most favorable design space identified in step 1 and conclusions drawn on step 2 and 3, compare performance and margins evolution on configuration with and without fuel contouring plus Al-B layer

- Deduce if acceptable designs are possible 


\subsection{U3Si2 Analysis Results}

\subsubsection{No Fuel Contouring, no Absorber}

In a first step, we evaluate the performance and TH safety margins of designs having no absorber and no fuel contouring. Although these configurations are unlikely to satisfy all requirements, they should help identify the most favorable design space. In particular, one can expect to understand how much fissile mass is required to meet or exceed the performance requirements (i.e. cycle length and key isotope production).

By framing the problem that way, only three geometric variables are of interest:

- Fuel length (from 20 to 23 inch long fuel, fuel length being similar in both elements)

- IFE fuel plate thickness (varied from 12 to 26 mil, IFE thickness being lower or equal to the OFE one but not exceeding it)

- $\quad$ OFE fuel plate thickness (varied from 12 to 26 mil)

The following metrics of interest have been calculated:

- Required power (to match the cycle average neutron flux in the most limiting location, typically the cold source)

- Cycle length at required power

- ${ }^{252} \mathrm{Cf}$ production

- ${ }^{238} \mathrm{Pu}$ production

- IFE margin to CHF

- IFE margin to FE

- OFE margin to CHF

- $\quad$ OFE margin to FE

From this analysis, the following conclusions can be drawn:

- IFE and OFE thick fuel configurations can meet performance requirements for all lengths (see Table 6-3 and Table 6-4)

- None of the designs satisfies the safety margin requirements in the IFE (see Table 6-5)

- Designs may present sufficient safety margins in the OFE, even with 26 mil thick fuel (see Table 6-6)

- No viable configuration can be obtained (satisfying simultaneously performance and safety criteria) 
Table 6-3 - design space discretized for fuel length and IFE, OFE fuel thicknesses: energy produced during the cycle (left); required reactor power to match neutron flux metrics (middle); cycle length calculated as the ratio between energy and required power (right). Cells are blacken if excluded from design space or below a specific value (2210MWday for energy and 26 days for cycle length)
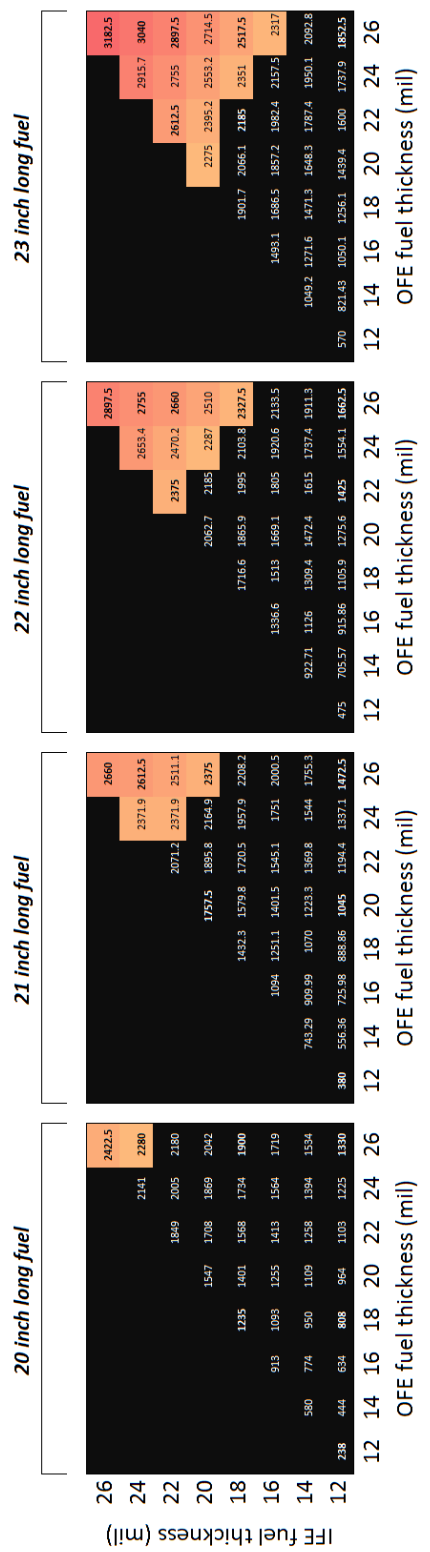

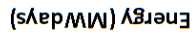
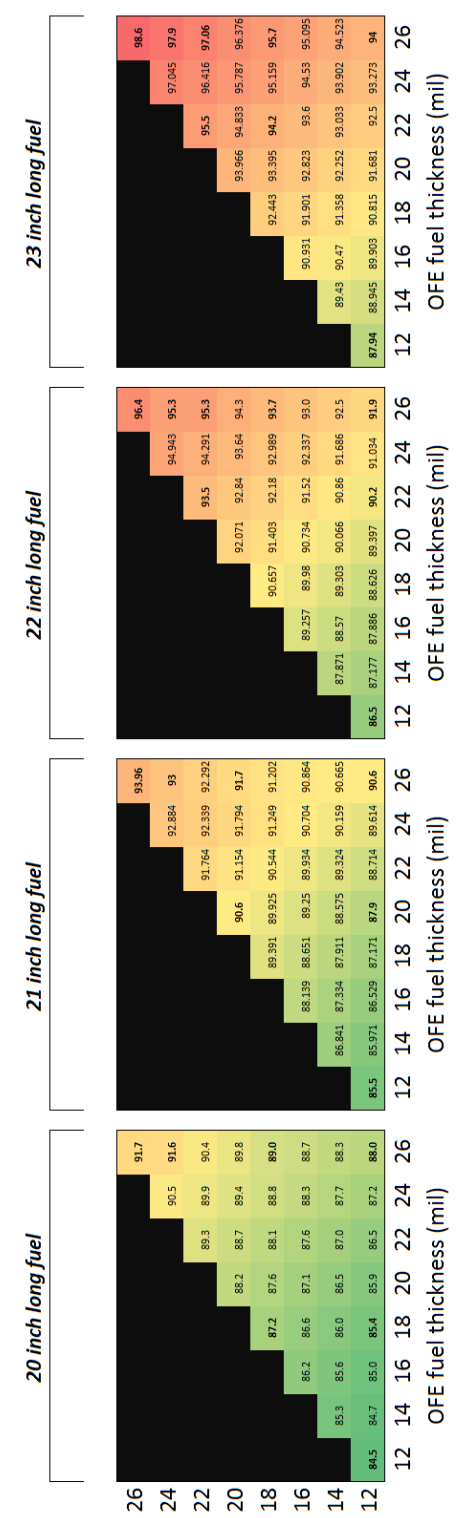

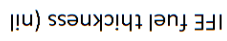

(MW) دamod su!łejado
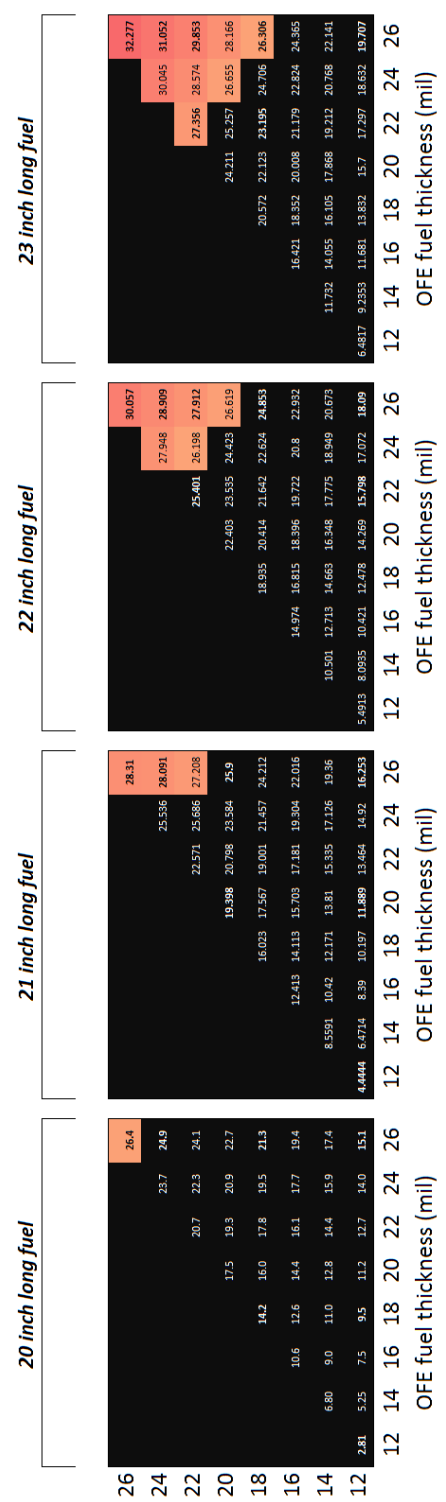

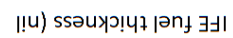

(skep) دәMod

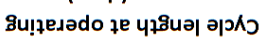


Table 6-4 - design space discretized for fuel length and IFE, OFE fuel thicknesses: LEU versus HEU ${ }^{252} \mathrm{Cf}$ production (left); LEU versus HEU ${ }^{238} \mathrm{Pu}$ production (middle); configuration meeting performance requirements (equal 1 if satisfy performance requirements: cycle length at required power, ${ }^{252} \mathrm{Cf} \&{ }^{238} \mathrm{Pu}$ production equal or exceed HEU equivalent, else equal 0) (right). Cells are blacken if excluded from design space or below a specific value
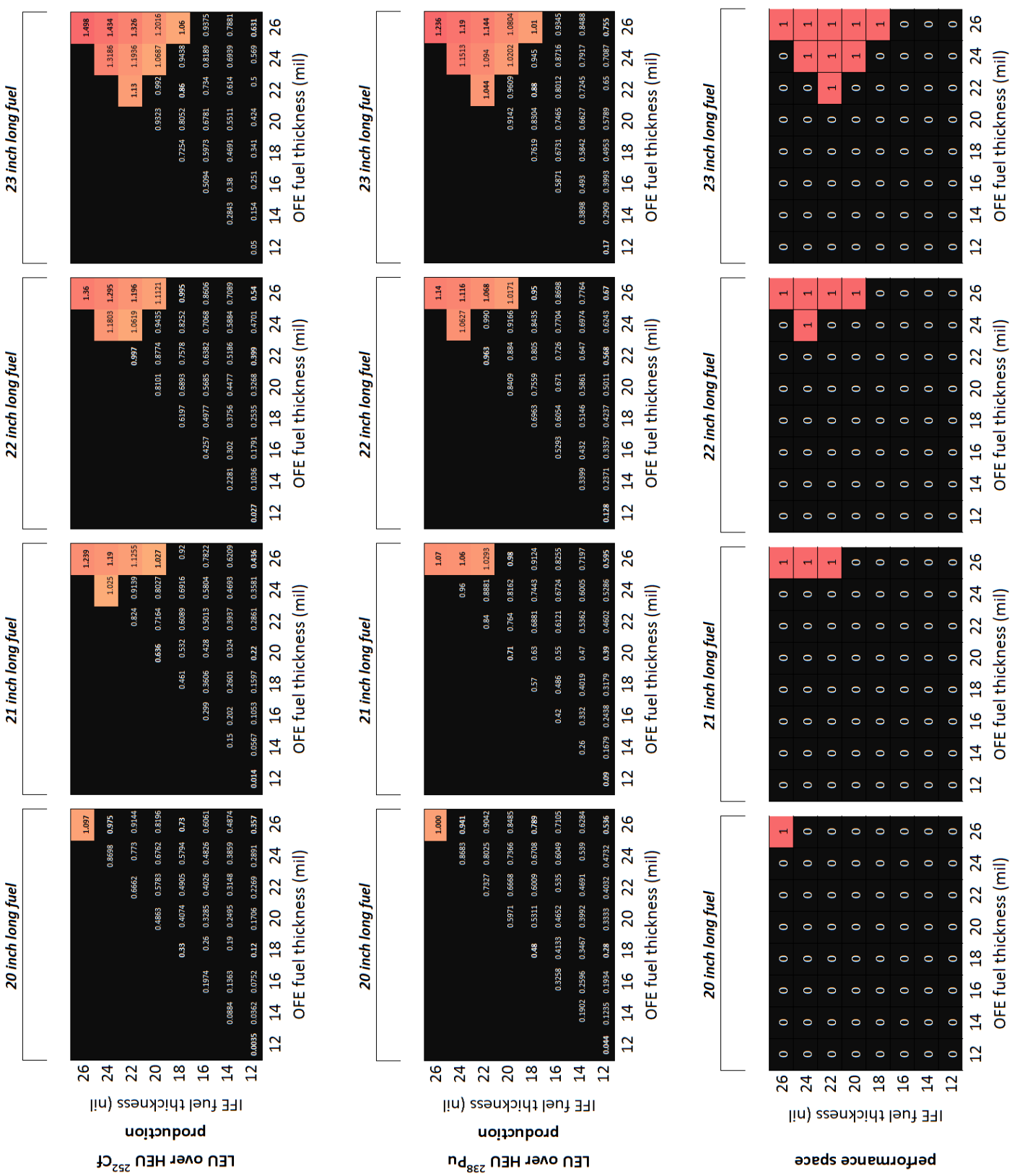

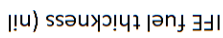

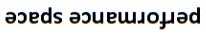

Alternate Design Concepts for the High Flux Isotope Reactor using Low-Enriched Uranium Fuel Systems - Scoping Analysis 
Table 6-5 - design space discretized for fuel length and IFE, OFE fuel thicknesses: margin to CHF in the IFE (left); margin to FE in the IFE (middle); configuration meeting IFE TH margin requirements (equal 1 if CHF and FE margins exceed 1.0, else equal 0) (right). Cells are blacken if excluded from design space or below a specific value (1.0 for the three figures)
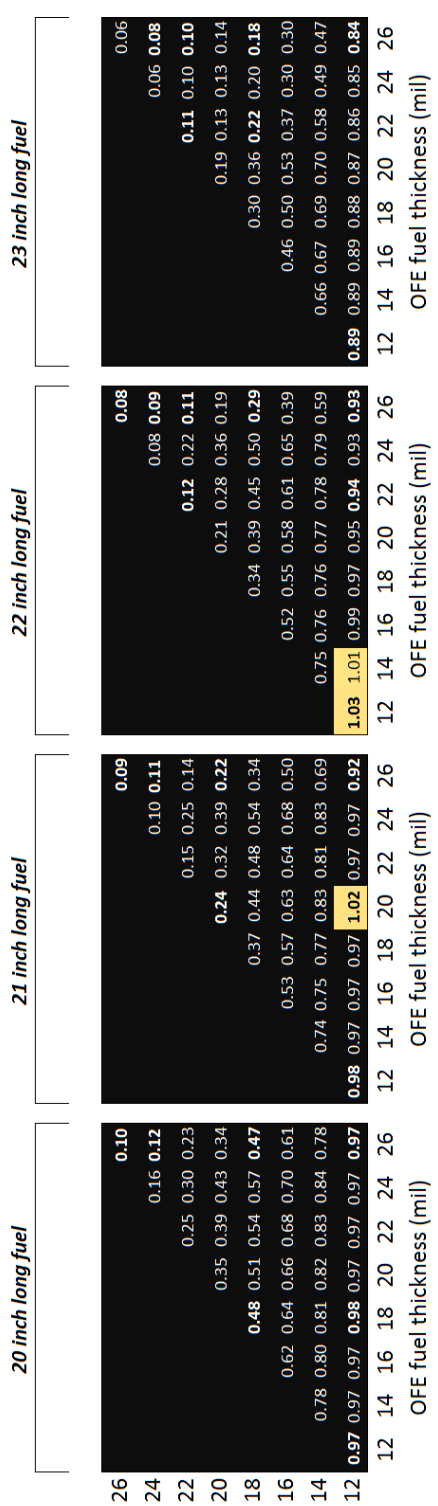

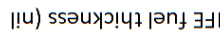

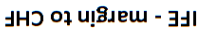
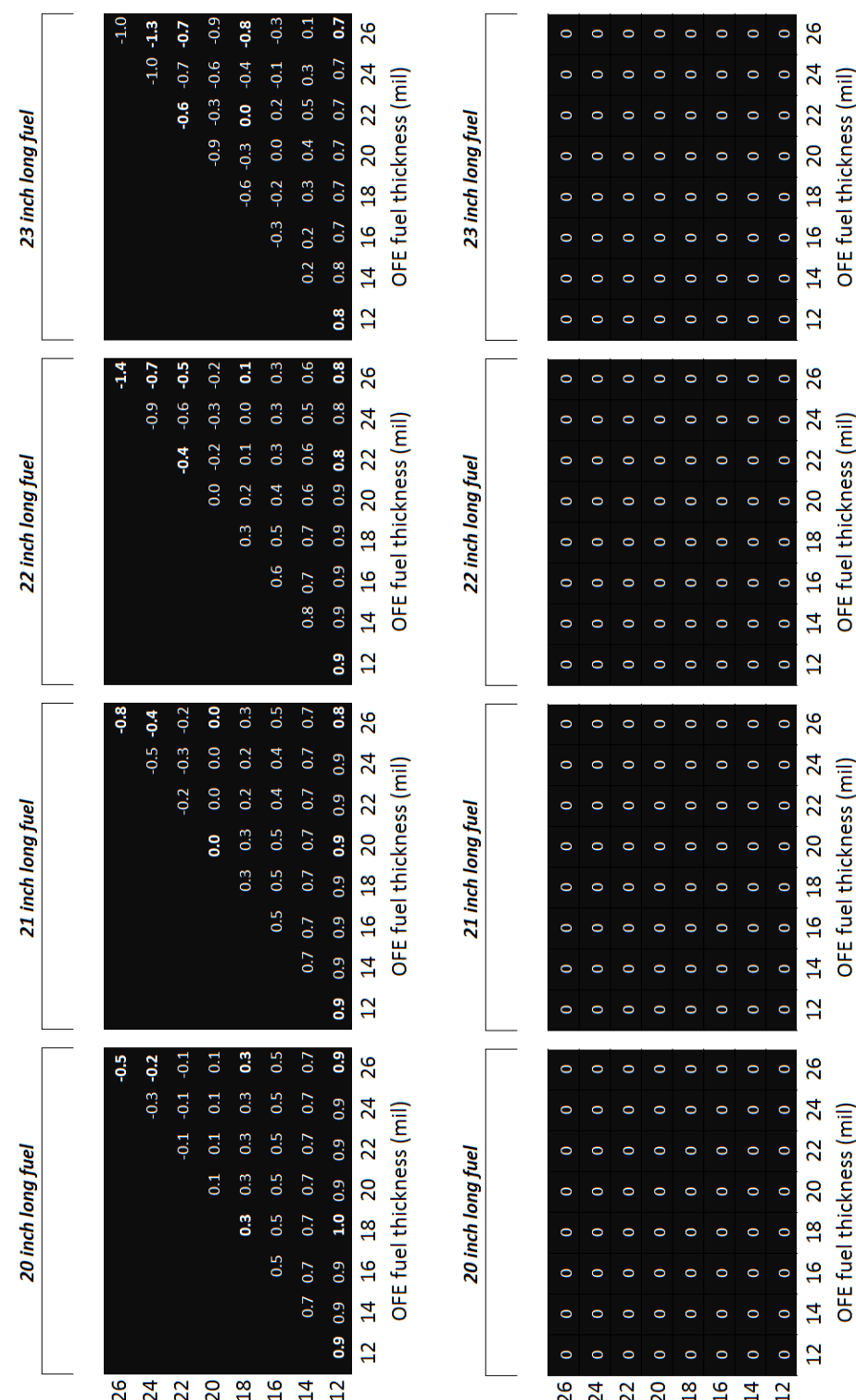

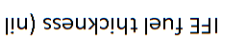

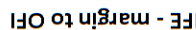

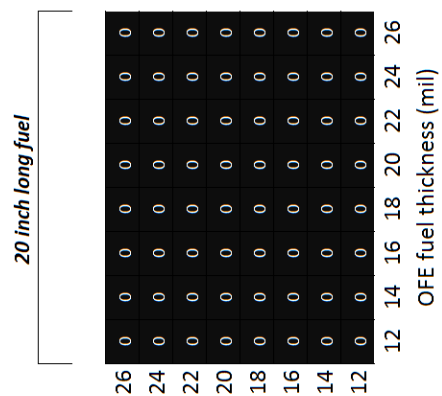

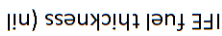

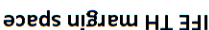

Alternate Design Concepts for the High Flux Isotope Reactor using Low-Enriched Uranium Fuel 
Table 6-6 - design space discretized for fuel length and IFE, OFE fuel thicknesses: margin to CHF in the OFE (left); margin to FE in the OFE (middle); configuration meeting OFE TH margin requirements (equal 1 if CHF and FE margins exceed 1.0, else equal 0) (right). Cells are blacken if excluded from design space or below a specific value (1.0 for the three figures)
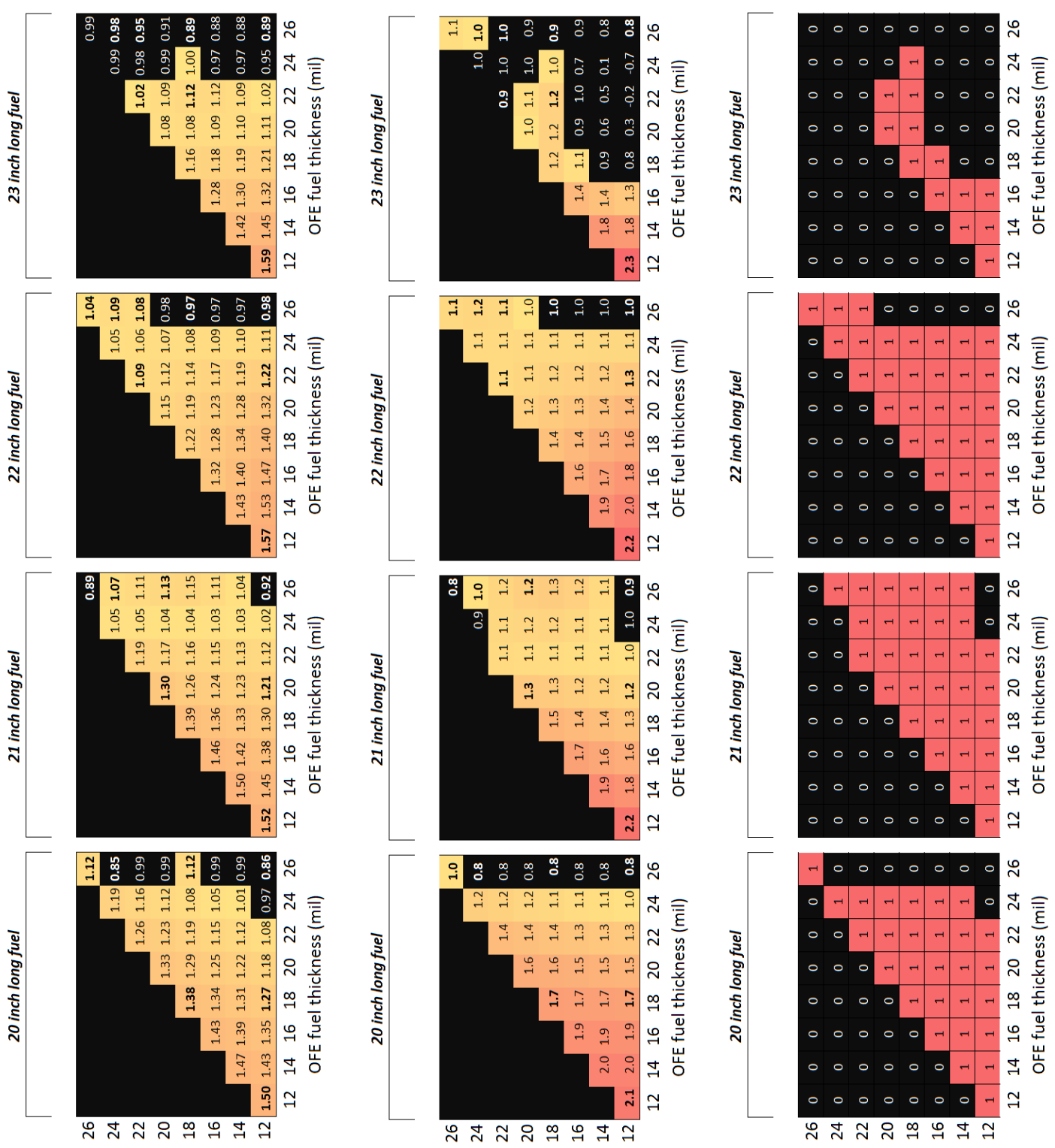

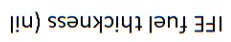

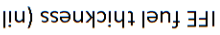

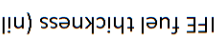

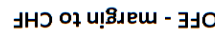

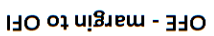

วoeds U!ßsem $\mathrm{H} \perp \exists \unlhd O$

Alternate Design Concepts for the High Flux Isotope Reactor using Low-Enriched Uranium Fuel Systems - Scoping Analysis 


\subsubsection{No Fuel Contouring, Al-B Absorber in IFE Plates}

Since no viable design could be obtained for uncontoured fuel without absorbers, complex features need to be introduced.

In a second step, we insert a layer of boron mixed with aluminum (the same composition as provided in ORNL HEU representative core [Chandler, 2015]) in the IFE plates as depicted in Figure 6-4. Unlike the HEU core design, the fuel is still un-contoured (flat) in this step. The insertion of an absorber in the IFE plates can help reduce power peaking in the IFE and balance the power more favorably between the two fuel elements.

The study focuses only on the most favorable design space:

- Fuel length: from 21 to 23 inch long fuel; based on results presented previously, 20 inch long fuel configurations cannot be viable.

- OFE fuel thickness: 26 mil

- IFE fuel thickness: varies, the range of variation depends on favorable performance design space, which depends on fuel length

- Al-B layer thickness: varies with IFE fuel thickness so that the sum of the fuel thickness and Al-B layer thickness is kept to a constant value of 26 mil (AL-B density remains constant)

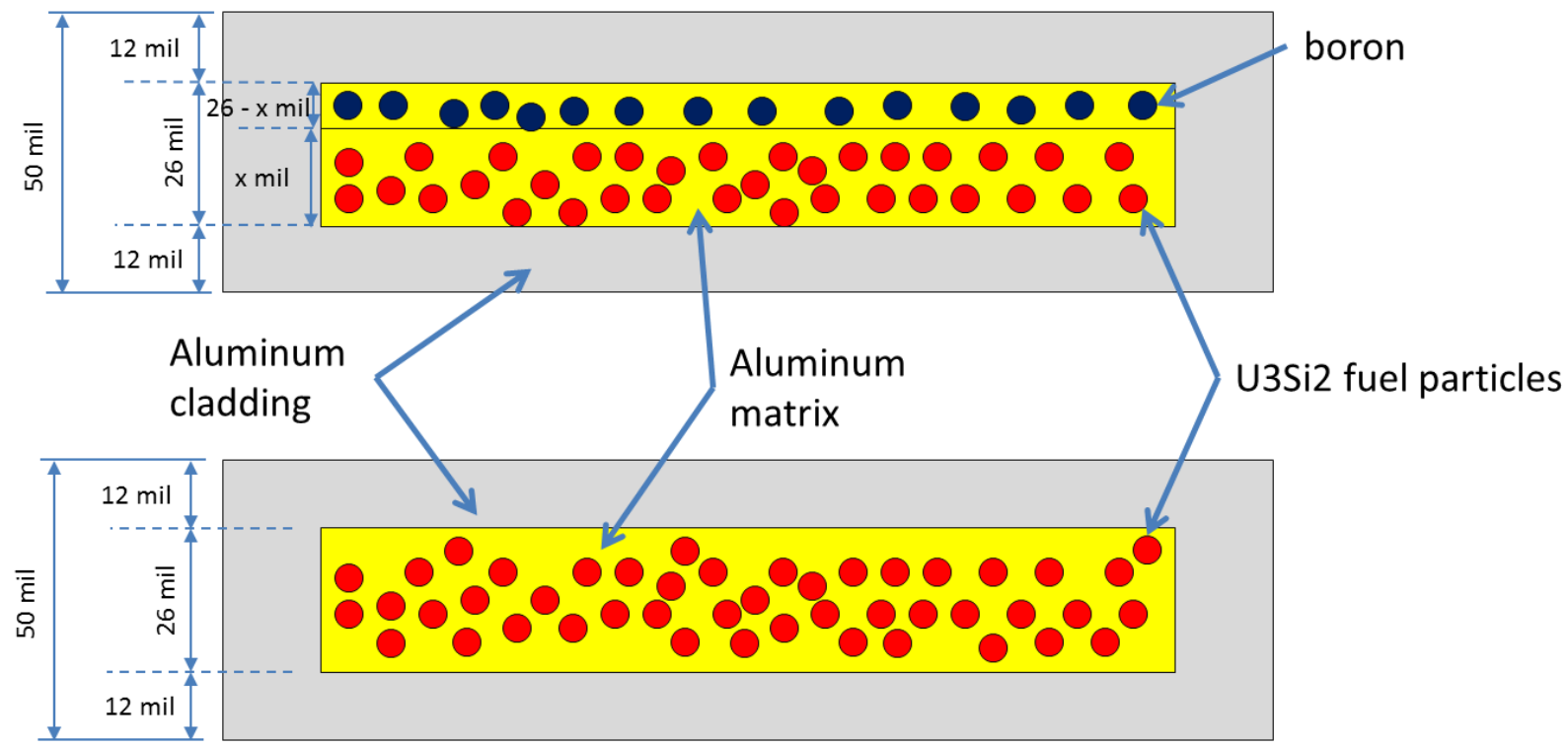

$+$

Figure 6-4 - Schematic IFE (top) and OFE (bottom) fuel plate cross-section of un-contoured (flat) fuel with Al-B layer in IFE plates 
Comparing configurations with and without Al-B layer, the following conclusions can be drawn:

- The power required to match the average HEU neutron flux in the most limiting location (typically the cold source) decreases substantially due to the presence of the Al-B layer (see Figure 6-5). This is because the presence of boron decreases the core reactivity, which forces the control elements to open more and shift the power to the OFE plates, which therefore increases the flux in the reflector (and cold source). The reduced reactor power automatically increases the TH margins.

- Despite the reduction in required operating power, in most cases, the cycle length decreases when compared to the configuration without boron (see Figure 6-6). This is an indication that the boron is not entirely burned at the end of cycle, which penalizes the cycle length and the overall performance.

- The production of ${ }^{252} \mathrm{Cf}$ and ${ }^{238} \mathrm{Pu}$ decreases slightly, due to the reduction in cycle length (see Figure 6-7 and Figure 6-8).

- Overall, in order to reach the performance requirements, the IFE fuel thickness should be at least 23, 20 and 19.5 mil-thick for configurations with an Al-B layer having a fuel length of 21,22 and 23 inch, respectively.

- Steady-state thermal-hydraulic margins to CHF and FE increase substantially in the IFE when compared to configurations without Al-B layer (see Figure 6-9 and Figure 6-10). It is however far from sufficient to meet the safety requirements, especially for the required IFE fuel thicknesses stated in the bullet above.

- Steady-state thermal-hydraulic margins to CHF and FE in the OFE plates remain relatively constant and very similar to the equivalent configurations without Al-B layer and slightly above the required value (see Figure 6-11 and Figure 6-12).

Overall, no viable configurations could be obtained using un-contoured fuel with a layer of Al-B due to significant lack of TH margins in the IFE plates. 

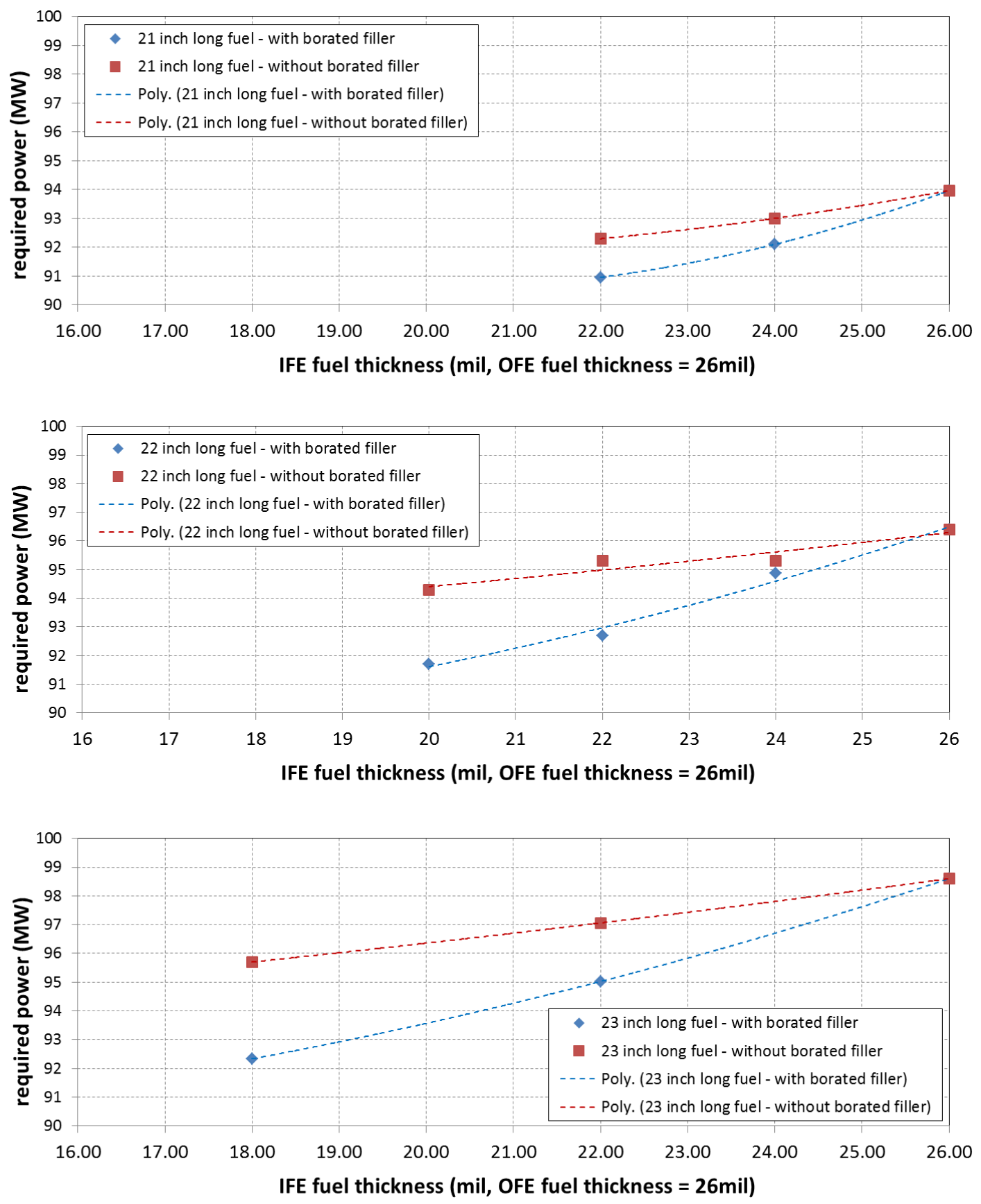

Figure 6-5 - Power required to match average HEU neutron flux in most limiting location for uncontoured fuel configuration with and without Al-B layer in IFE plates. Results are for 21 (top), 22 (middle), 23 (bottom) inch long fuel configuration. Al-B layer thickness is equal to 26 mil minus the IFE fuel thickness (mil). OFE fuel thickness is always 26 mil

Alternate Design Concepts for the High Flux Isotope Reactor using Low-Enriched Uranium Fuel Systems - Scoping Analysis 

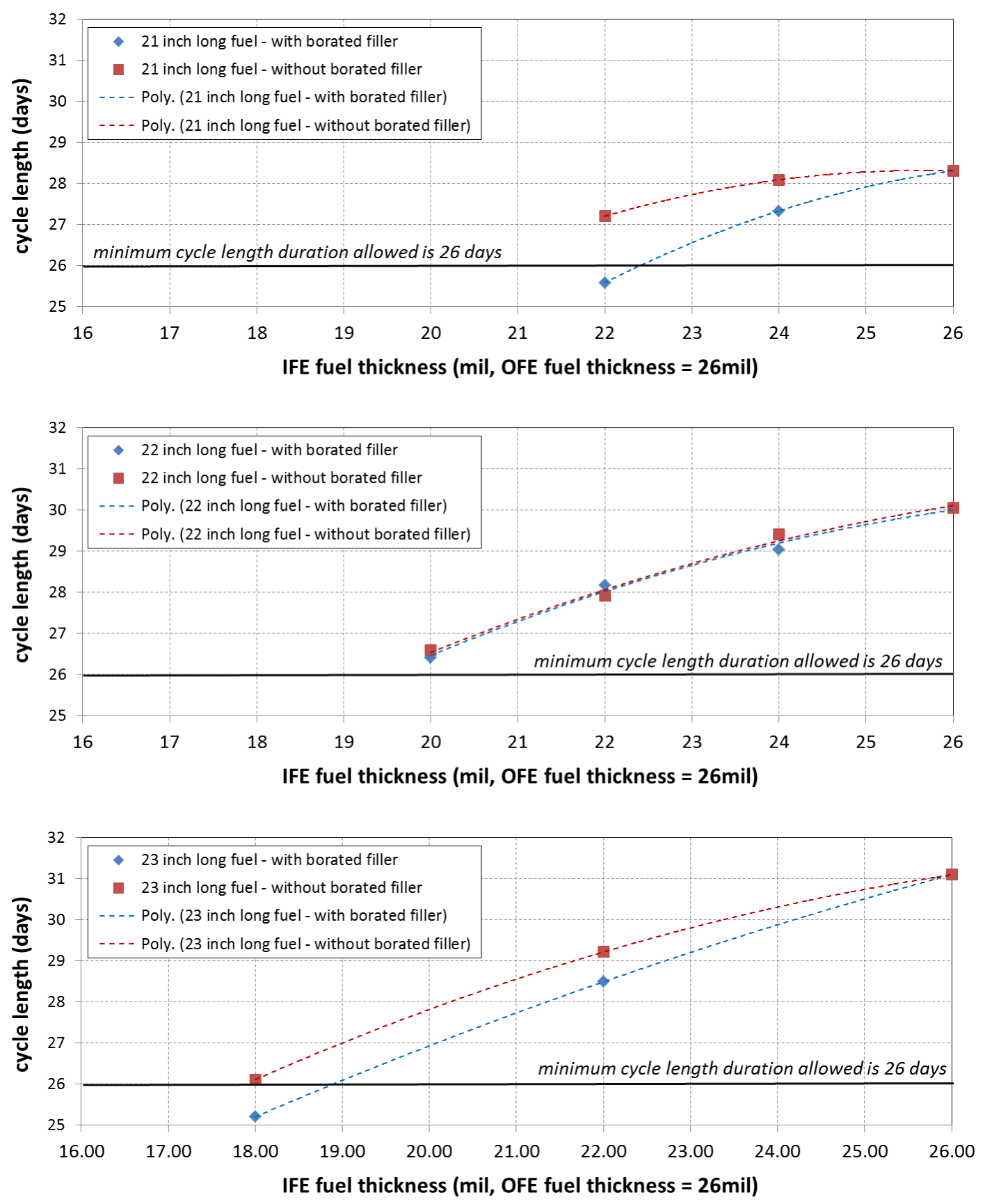

Figure 6-6 - Cycle length at required power for un-contoured fuel configuration with and without Al-B layer in IFE plates. Results are for 21 (top), 22 (middle), 23 (bottom) inch long fuel configuration. Al-B layer thickness is equal to 26 mil minus the IFE fuel thickness (mil). OFE fuel thickness is always 26 mil

Alternate Design Concepts for the High Flux Isotope Reactor using Low-Enriched Uranium Fuel Systems - Scoping Analysis 

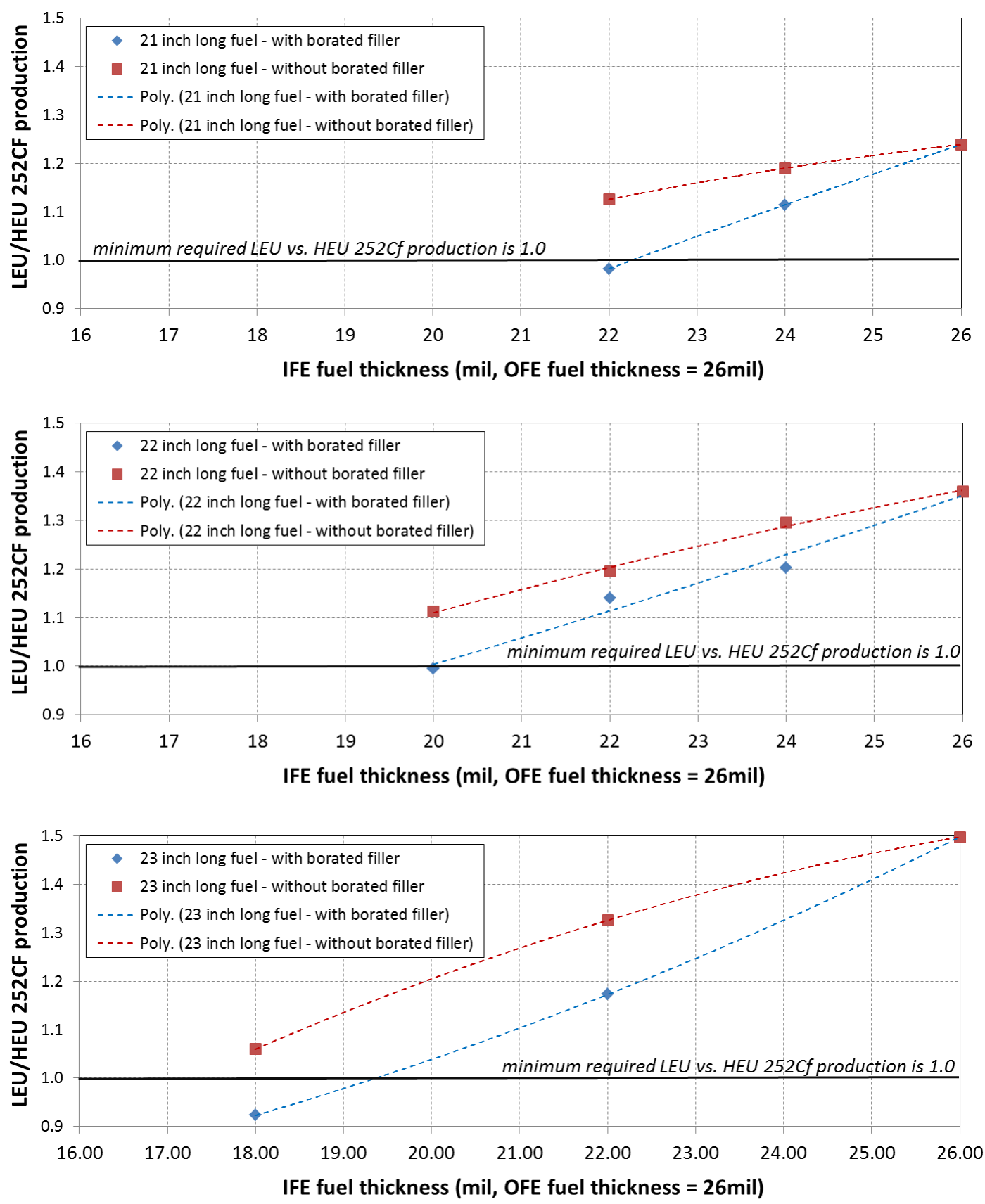

Figure 6-7 - ratio LEU vs. HEU ${ }^{252} \mathrm{Cf}$ production for configuration with and without Al-B layer in IFE plates. Results are for 21 (top), 22 (middle), 23 (bottom) inch long fuel configuration. Al-B layer thickness is equal to 26 mil minus the IFE fuel thickness (mil). OFE fuel thickness is always 26 mil 

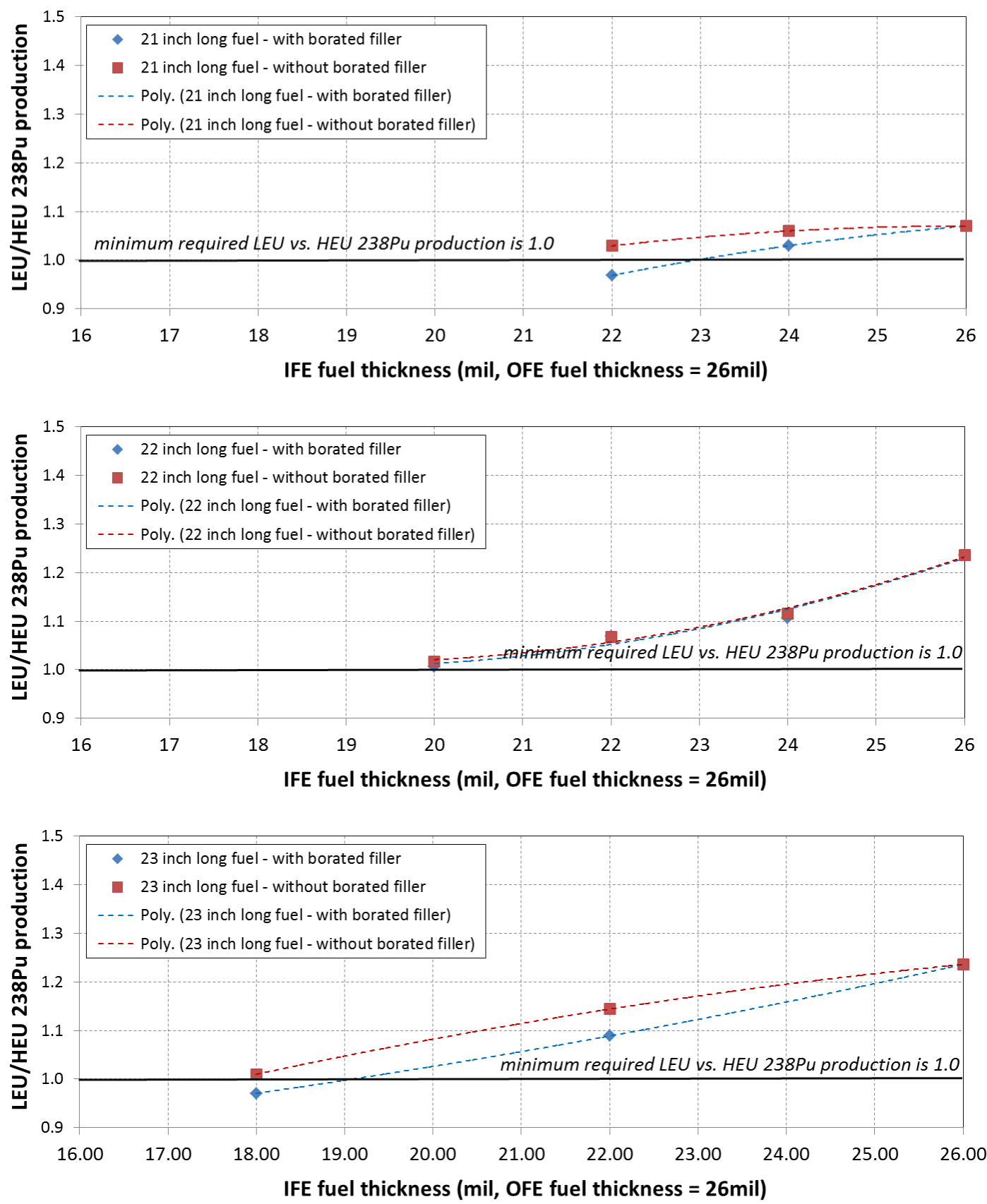

Figure 6-8 - ratio LEU vs. HEU ${ }^{238} \mathrm{Pu}$ production for configuration with and without Al-B layer in IFE plates. Results are for 21 (top), 22 (middle), 23 (bottom) inch long fuel configuration. Al-B layer thickness is equal to 26 mil minus the IFE fuel thickness (mil). OFE fuel thickness is always 26 mil 

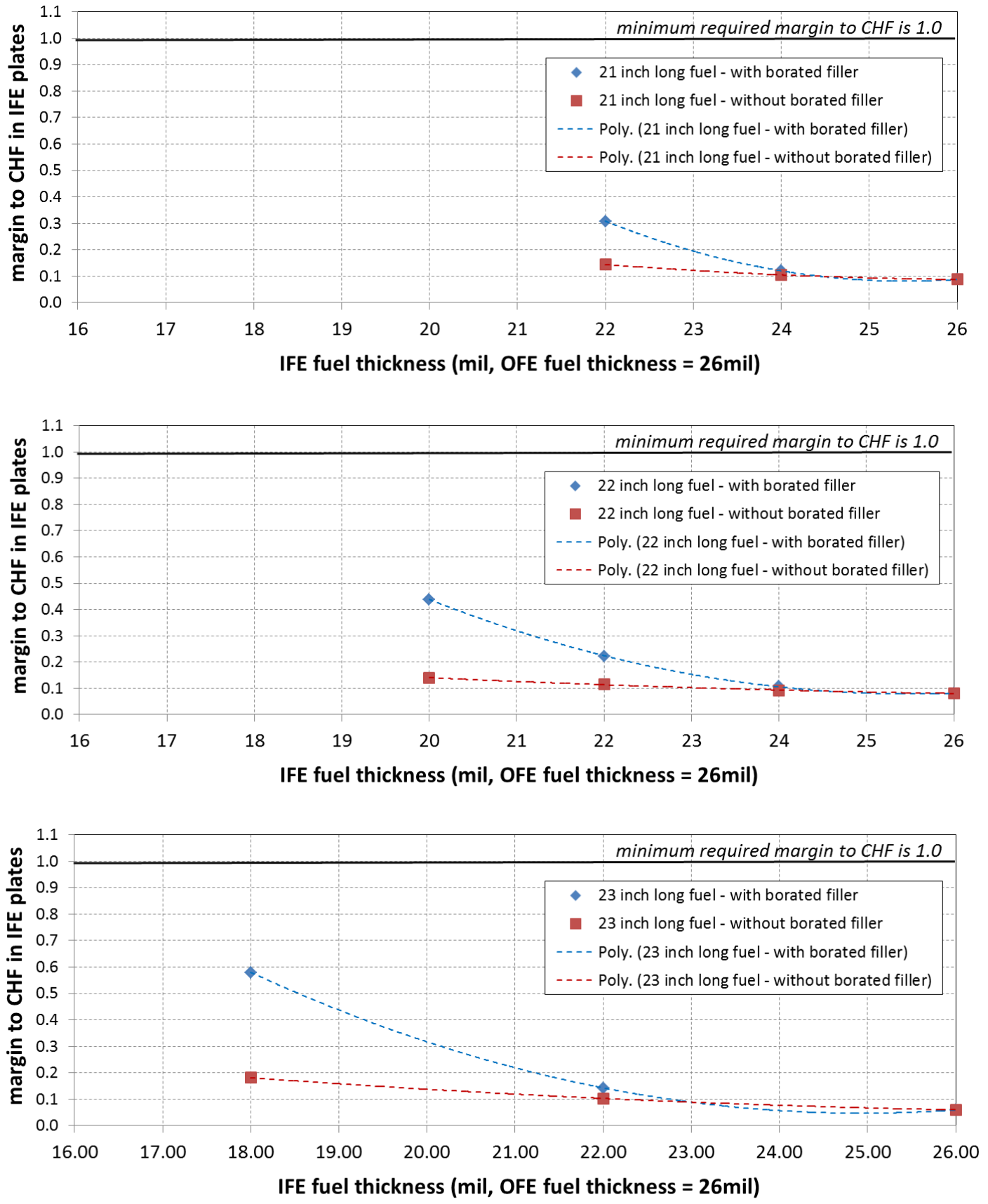

Figure 6-9 - margin to CHF in IFE plates for configuration with and without Al-B layer in IFE plates. Results are for 21 (top), 22 (middle), 23 (bottom) inch long fuel configuration. Al-B layer thickness is equal to 26 mil minus the IFE fuel thickness (mil). OFE fuel thickness is always 26 mil

Alternate Design Concepts for the High Flux Isotope Reactor using Low-Enriched Uranium Fuel Systems - Scoping Analysis 

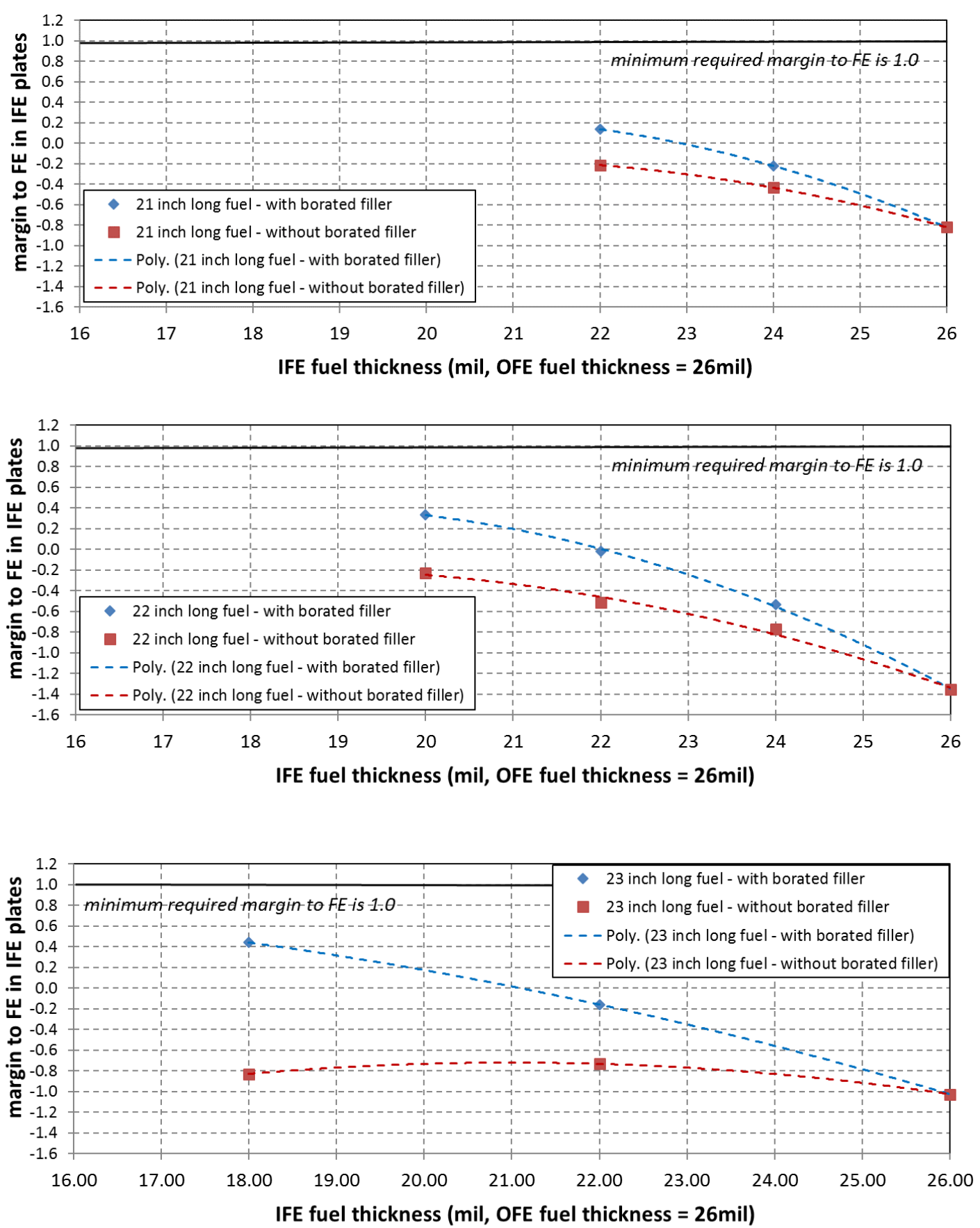

Figure 6-10 - margin to FE in IFE plates for configuration with and without Al-B layer in IFE plates. Results are for 21 (top), 22 (middle), 23 (bottom) inch long fuel configuration. Al-B layer thickness is equal to 26 mil minus the IFE fuel thickness (mil). OFE fuel thickness is always 26 mil

Alternate Design Concepts for the High Flux Isotope Reactor using Low-Enriched Uranium Fuel Systems - Scoping Analysis 

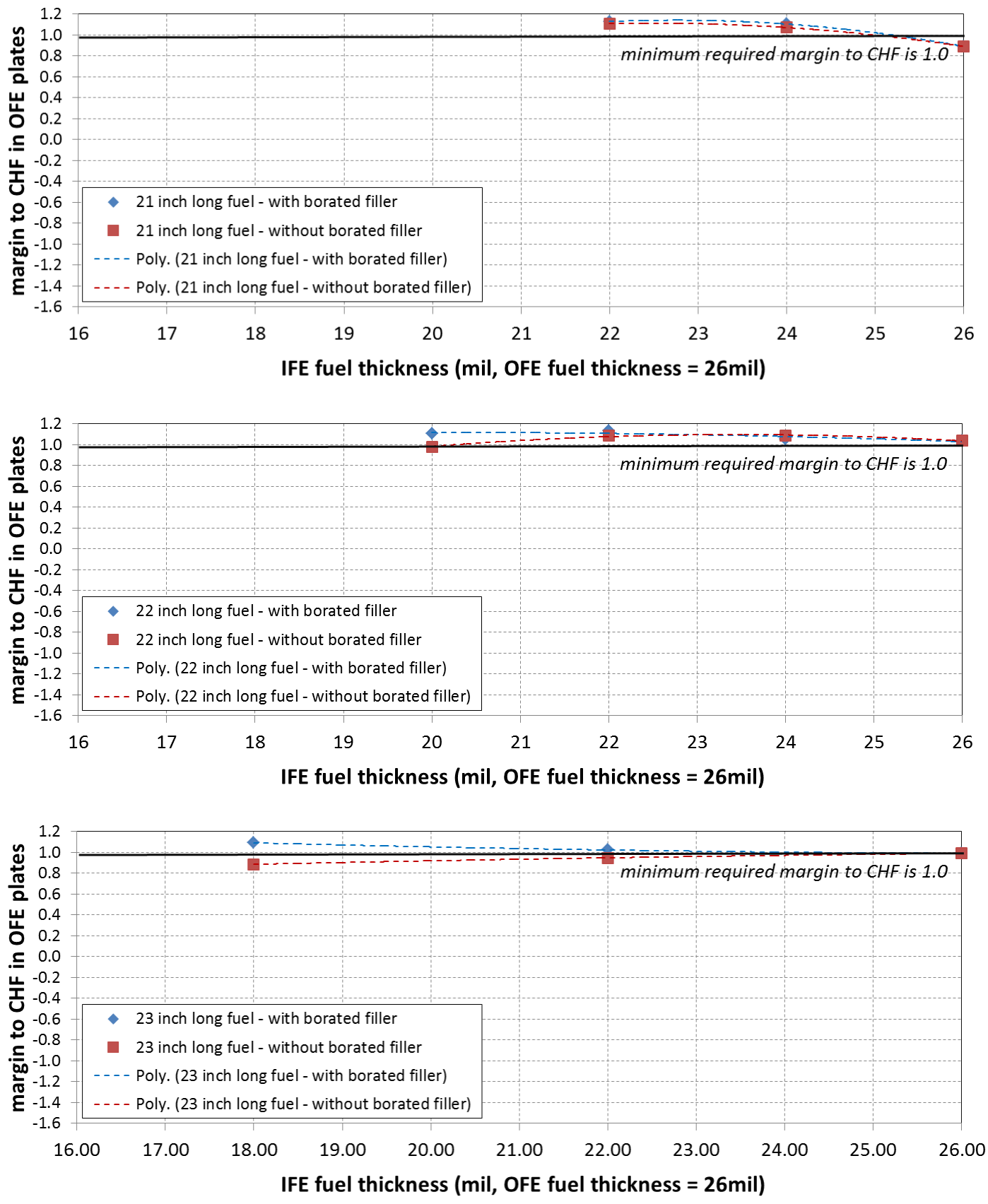

Figure 6-11 - margin to CHF in OFE plates for configuration with and without Al-B layer in IFE plates. Results are for 21 (top), 22 (middle), 23 (bottom) inch long fuel configuration. Al-B layer thickness is equal to 26 mil minus the IFE fuel thickness (mikl). OFE fuel thickness is always 26 mil

Alternate Design Concepts for the High Flux Isotope Reactor using Low-Enriched Uranium Fuel Systems - Scoping Analysis 

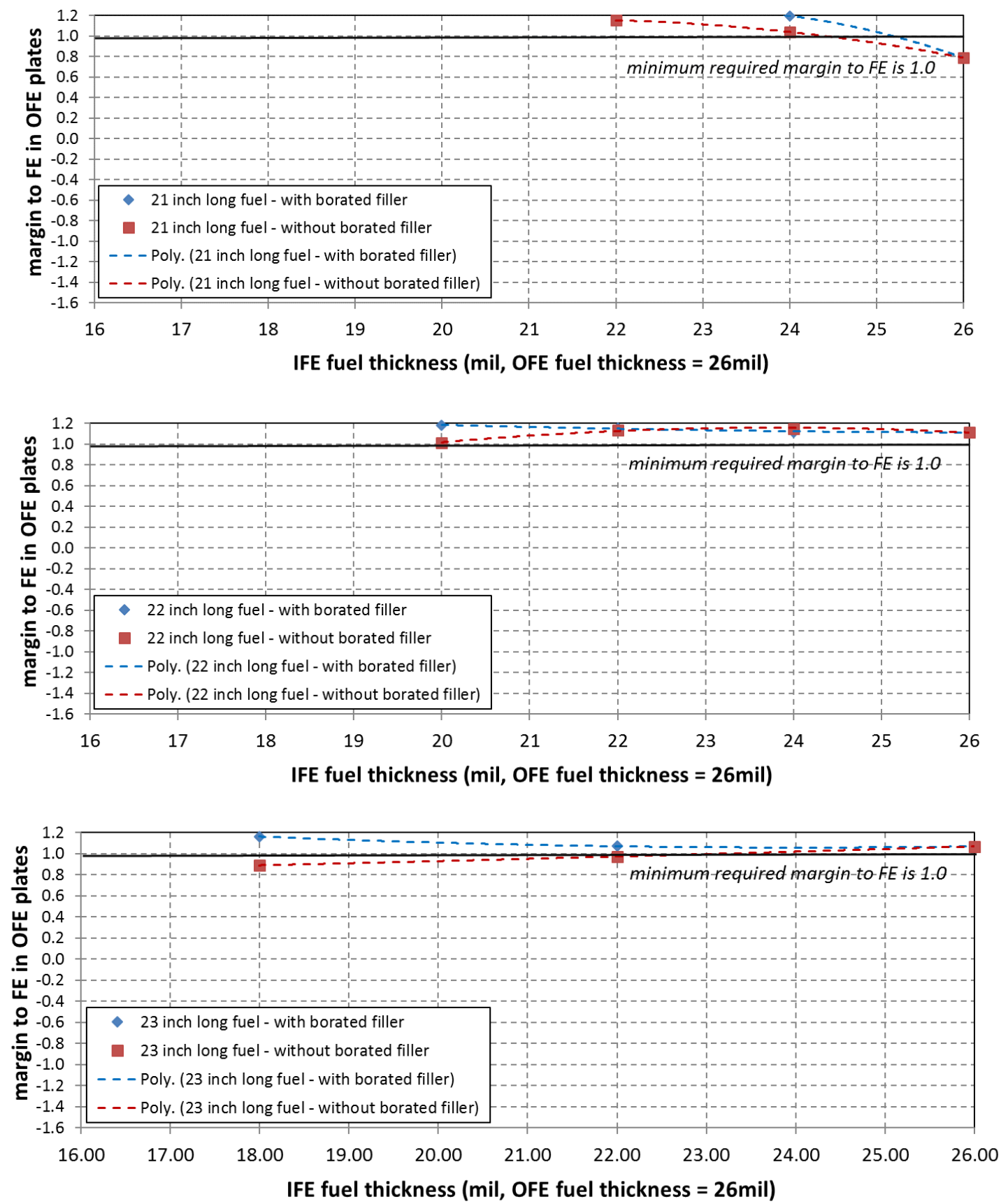

Figure 6-12 - margin to FE in OFE plates for configuration with and without Al-B layer in IFE plates. Results are for 21 (top), 22 (middle), 23 (bottom) inch long fuel configuration. Al-B layer thickness is equal to 26 mil minus the IFE fuel thickness (mil). OFE fuel thickness is always 26 mil

Alternate Design Concepts for the High Flux Isotope Reactor using Low-Enriched Uranium Fuel Systems - Scoping Analysis 


\subsubsection{Fuel Contouring, no Absorber}

From the results generated so far, it is clear that having enough TH margin in the IFE is by far the most difficult requirement to meet. So next, we try contouring the fuel in the IFE plates (the OFE fuel thickness can be kept to a constant value of 26 mil). No absorbers are present.

Regarding TH margins, all configurations studied previously are most limited at Beginning of Cycle (BOC) and the IFE inner and outer edges are where there are insufficient margins.

Since all configurations present similar problems, we try eliminating fuel on the inner and outer edges of the IFE plates, as depicted in Figure 6-13. Since the inner edge is more problematic than the outer one, more fuel needs to be removed there.

For 21, 22 and 23 inch long fuel configuration (and 26 mil thick fuel OFE plates), the IFE fuel has been progressively shaped as depicted in Figure 6-13 (shapes A, B and C) to study the impact of the fuel reduction on the metrics of interest, in particular the IFE TH margins.

IFE minimum margins in the IFE plates obtained for 22-inch long configuration are shown on Figure 6-14. It can be seen that a significant gain in TH margins can be obtained in the IFE plates when the fuel thickness on the edges is aggressively reduced. With shape $C$, it can be seen that sufficient margin could be obtained in all lateral region except for region 3, 4 and 5. Further fuel reduction would be needed in those regions to meet the IFE margin requirements.

However, additional reductions lead to a substantial drop in performance. With shape $C$, the closest one to meet the IFE safety margin requirement, the fuel mass reduction is such that the performance requirements are not achieved. Since an even larger fuel reduction is required to meet the TH margin requirement, it is concluded that it will be impossible to meet performance and safety margin requirement simultaneously. Similar conclusions are drawn for configuration having a fuel length of 21 and 23 inch (see Table 6-7 for more detailed results). While shape C offers substantial improvement, it is, by itself, insufficient. 

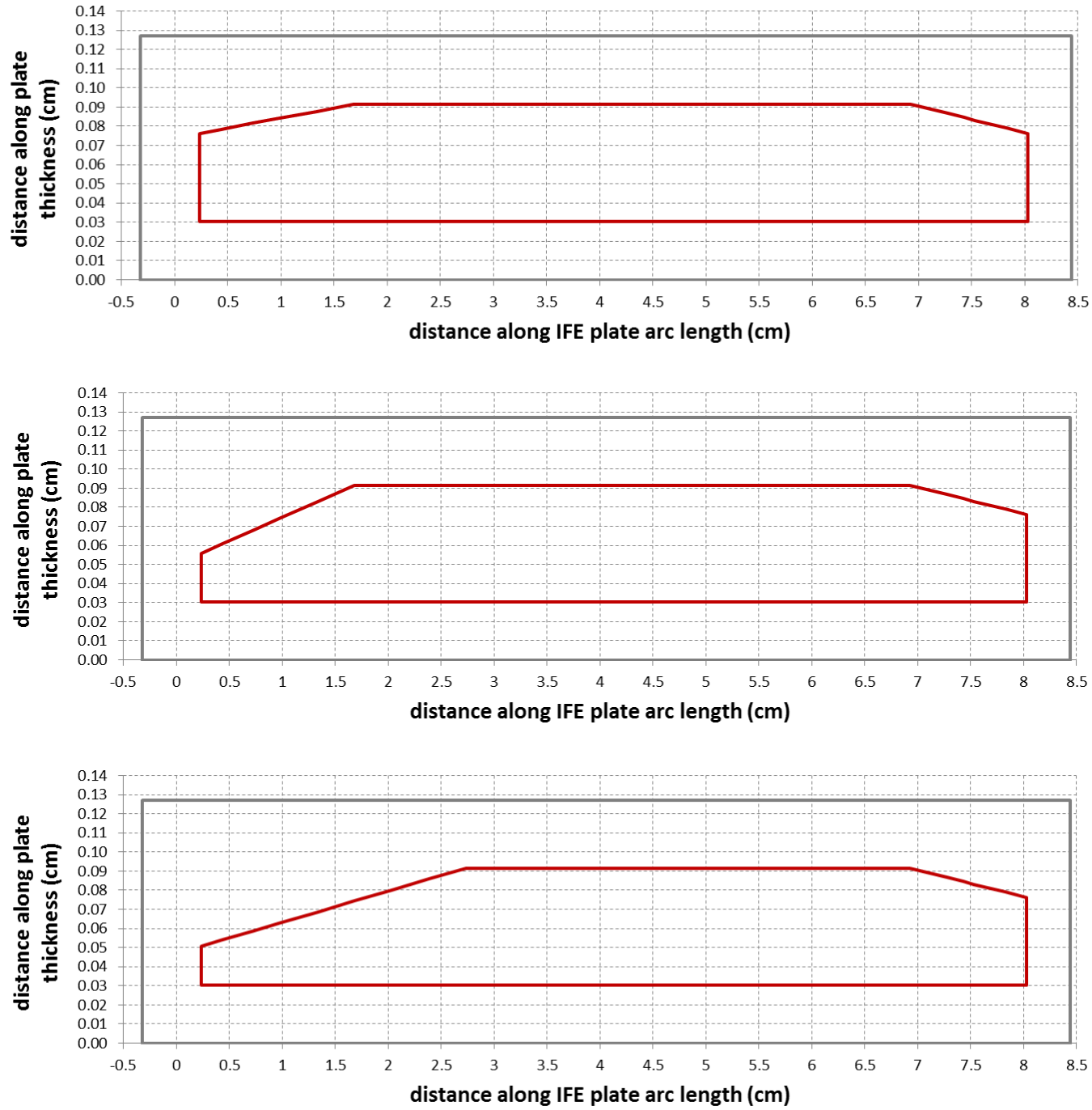

Figure 6-13 - IFE fuel shape A (top), B (middle) and C (bottom) used to study the impact of the fuel reduction on IFE margins and other metrics of interest

Alternate Design Concepts for the High Flux Isotope Reactor using Low-Enriched Uranium Fuel Systems - Scoping Analysis 


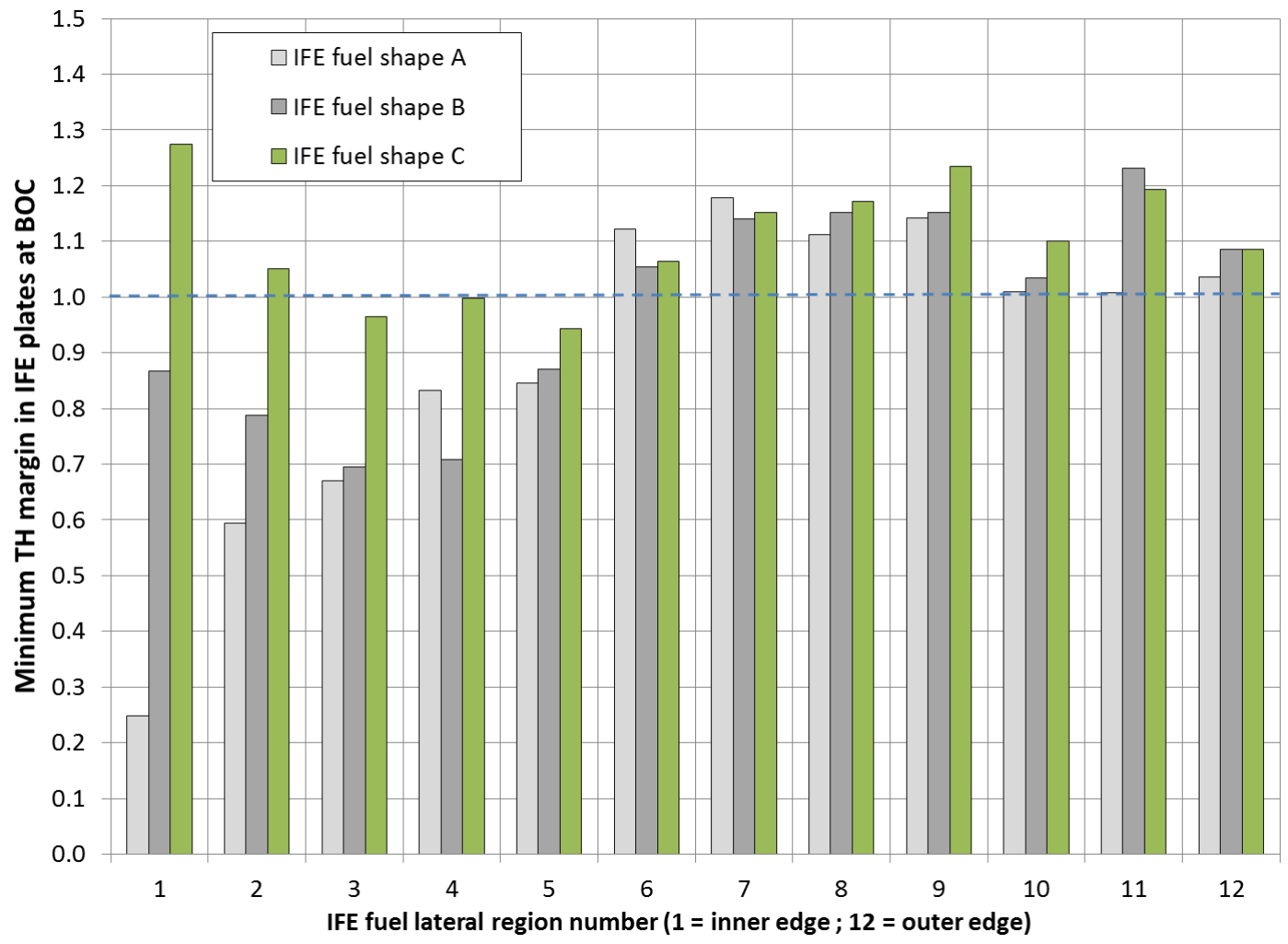

Figure 6-14 - Minimum TH margin in IFE plates at BOC per IFE lateral fuel region obtained with three different IFE fuel shapes (labeled A, B and C, depicted in figure 8). OFE fuel thickness is 26 mil, fuel length in both elements is 22 inch long and no absorbers are present. The blue dashed line represents the minimum required value (1.0)

Table 6-7 - Key results obtained for IFE shaped fuel configuration (labeled A, B and C, depicted in Figure 6-13) of fuel length 21,22 and 23 inch. Cell is black if value does not meet requirement.

\begin{tabular}{|c|c|c|c|c|c|c|c|c|c|}
\hline \multirow{3}{*}{ metrics } & \multicolumn{9}{|c|}{ fuel length (inch) } \\
\hline & \multicolumn{3}{|c|}{$\begin{array}{c}21 \\
\text { IFE fuel shape }\end{array}$} & \multicolumn{3}{|c|}{$\begin{array}{c}22 \\
\text { IFE fuel shape }\end{array}$} & \multicolumn{3}{|c|}{$\begin{array}{c}23 \\
\text { IFE fuel shape }\end{array}$} \\
\hline & $A$ & $B$ & $c$ & $A$ & $B$ & $c$ & $\boldsymbol{A}$ & B & $c$ \\
\hline required power (MW) & - & 90.54 & - & 95.07 & 93.93 & 93.17 & - & - & 95.05 \\
\hline cycle length at required power (days) & - & 23.61 & - & 27.98 & 27.31 & 25.49 & - & - & 26.49 \\
\hline LEU vs $\mathrm{HEU}{ }^{252} \mathrm{Cf}$ production ratio & - & 0.84 & - & 1.18 & 1.12 & 0.99 & - & - & 1.07 \\
\hline LEU vs HEU ${ }^{238} \mathrm{Pu}$ production ratio & - & 0.89 & - & 1.07 & 1.04 & 0.97 & - & - & 0.98 \\
\hline minimum TH margin in IFE & - & 0.74 & - & 0.25 & 0.70 & 0.94 & - & - & 0.88 \\
\hline minimum TH margin in OFE & - & 0.88 & - & 1.00 & 1.23 & 1.23 & - & - & 1.05 \\
\hline
\end{tabular}

Alternate Design Concepts for the High Flux Isotope Reactor using Low-Enriched Uranium Fuel 


\subsubsection{Fuel Contouring, with Absorber}

It has been shown that the IFE fuel contouring and the insertion of boron in the IFE plates were both effective at increasing TH safety margins in the IFE. However, it has also been shown that, alone, these features cannot lead to satisfactory designs. In this final step, we study configurations combining both features.

Starting with shapes B and C (see Figure 6-13 above), an Al-B layer is added to the IFE plates so that the total thickness of the fuel and Al-B layer is everywhere 26 mil. Based on the results obtained with these two new configurations, the fuel shape is progressively changed (and smoothed) until performance requirements are satisfied and TH margins exceed the requirements everywhere and for the entire cycle. After a few design iterations, the fuel profile shown in Figure 6-15 is found to satisfy the criteria described above for a fuel length of 22 inch long. Other satisfactory designs can certainly be obtained for longer fuel length but have not been explicitly studied.

The selected configuration for further analysis is labeled 22-NH10-26_AlB in the remainder of this paper. Evolution of the critical control rod position, thermal flux in the cold source, ratio fast/thermal flux in the cold source, ${ }^{252} \mathrm{Cf}$ and ${ }^{238} \mathrm{Pu}$ production for the 22-NH10-26_AlB and HEU configurations are presented in Figure 6-16 to Figure 6-20. Overall, it can be seen that 22-NH10-26_AlB performance are very similar to the current HEU core:

- Cycle length is slightly longer than the HEU core (27 days versus 26 days)

- On average, thermal flux in cold source is slightly larger than the HEU core $(\sim+0.3 \%)$ but the ratio fast over thermal flux is slightly less favorable $(\sim 0.22$ versus $\sim 0.21)$

- $\quad{ }^{252} \mathrm{Cf}$ and ${ }^{238} \mathrm{Pu}$ production is slightly larger than the HEU core $(\sim+3 \%)$, production rates are very similar

The evolution of the power leading to CHF (using the Gambill correlation) and FE (using the modified Saha-Zuber correlation) is presented in Figure 6-21. It can be seen that the configuration 22-NH1026_AlB is limited at BOC (CHF power is $132.3 \mathrm{MW}$ ) but remains comfortably above the safety limit (92 MW x $1.36=125.12 \mathrm{MW}$ ). Other design characteristics are presented in Table 6-8.

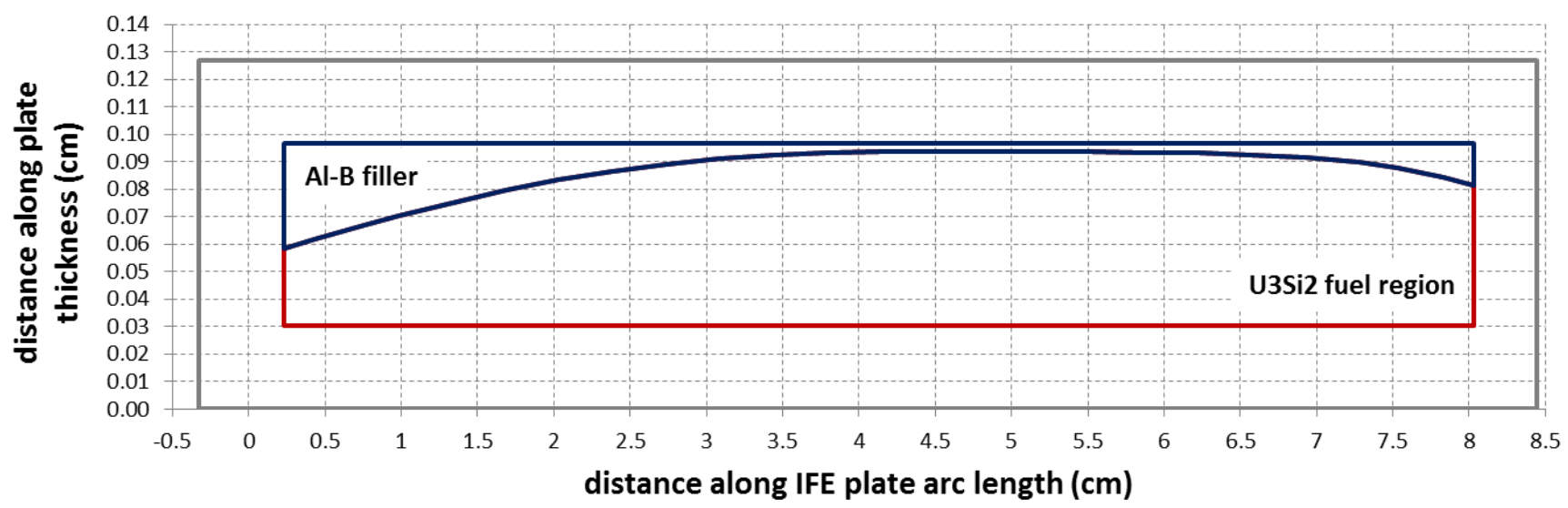

Figure 6-15 - Configuration 22-NH10-26_AlB IFE fuel profile with Al-B filler 


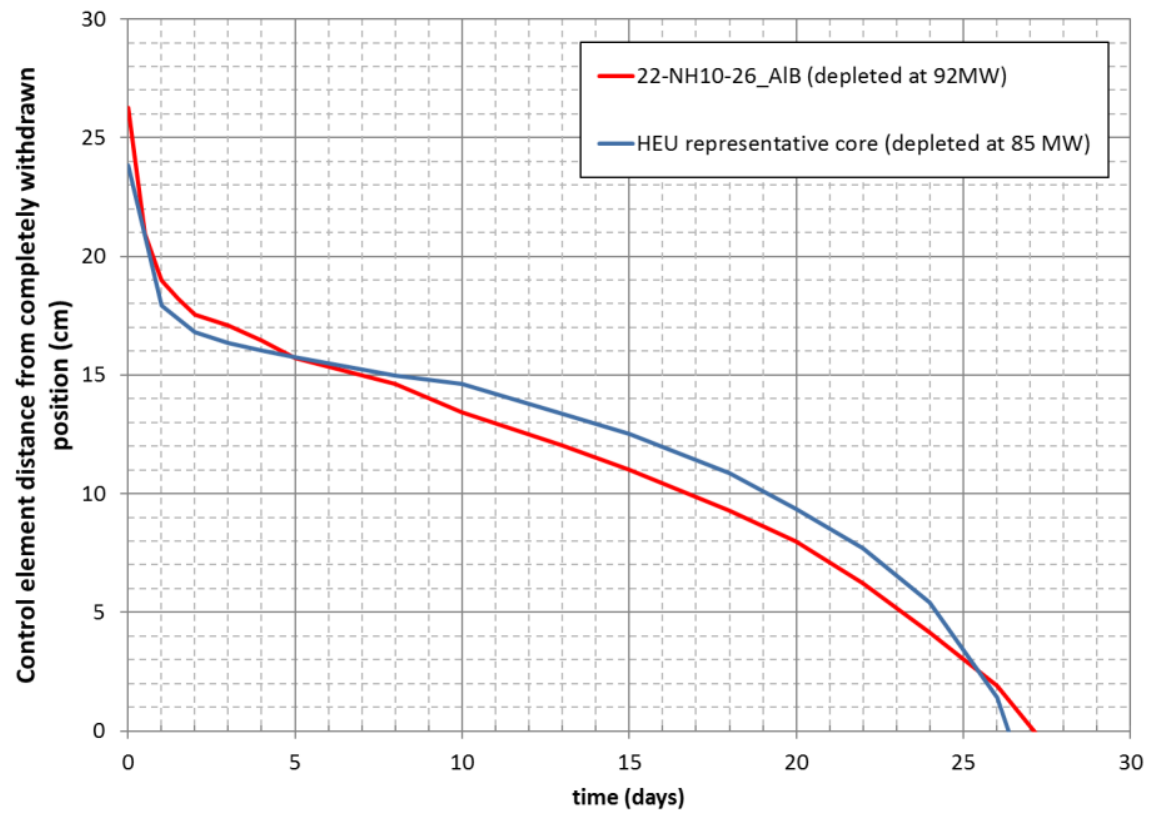

Figure 6-16 - Critical position of the control elements versus time for configuration 22-NH10-26_AlB depleted at $92 \mathrm{MW}$ and HEU depleted at 85MW

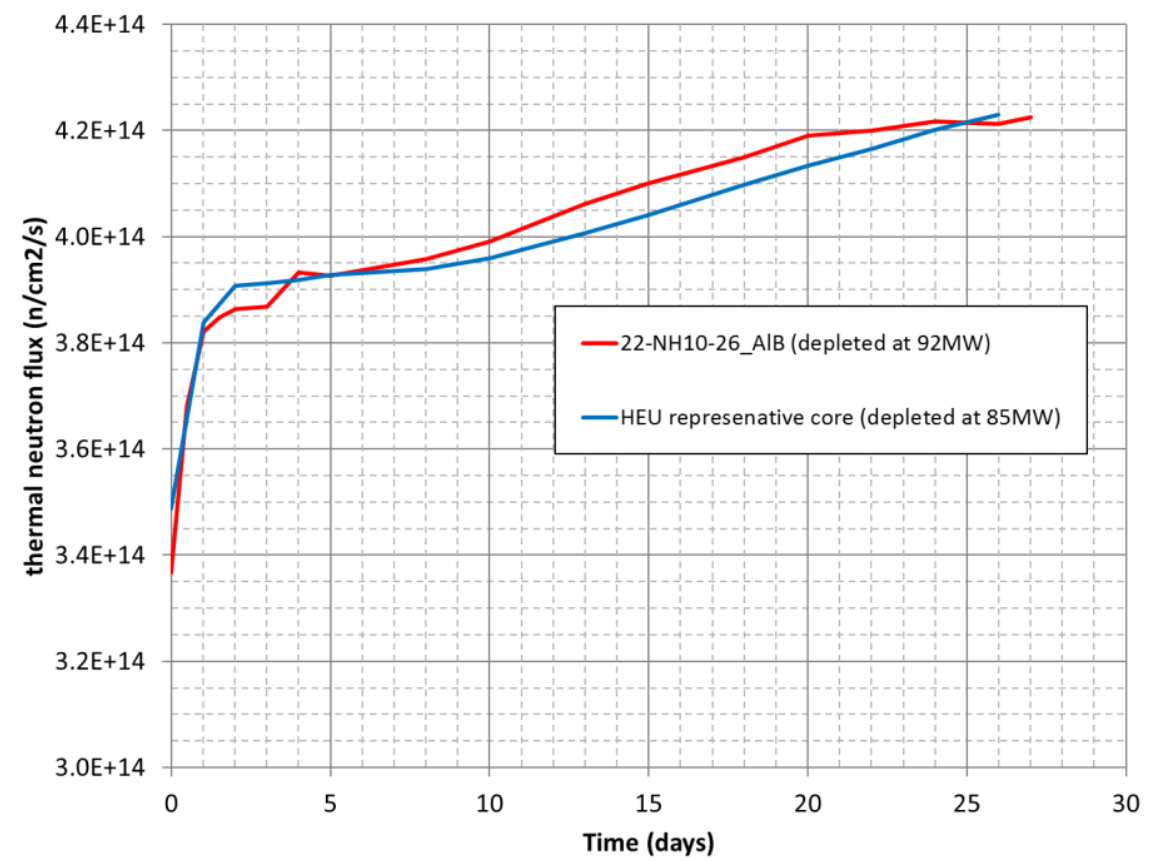

Figure 6-17 - Thermal neutron flux in cold source (limiting location) for configuration 22-NH10-26_AlB depleted at 92MW and HEU depleted at 85MW

Alternate Design Concepts for the High Flux Isotope Reactor using Low-Enriched Uranium Fuel Systems - Scoping Analysis 


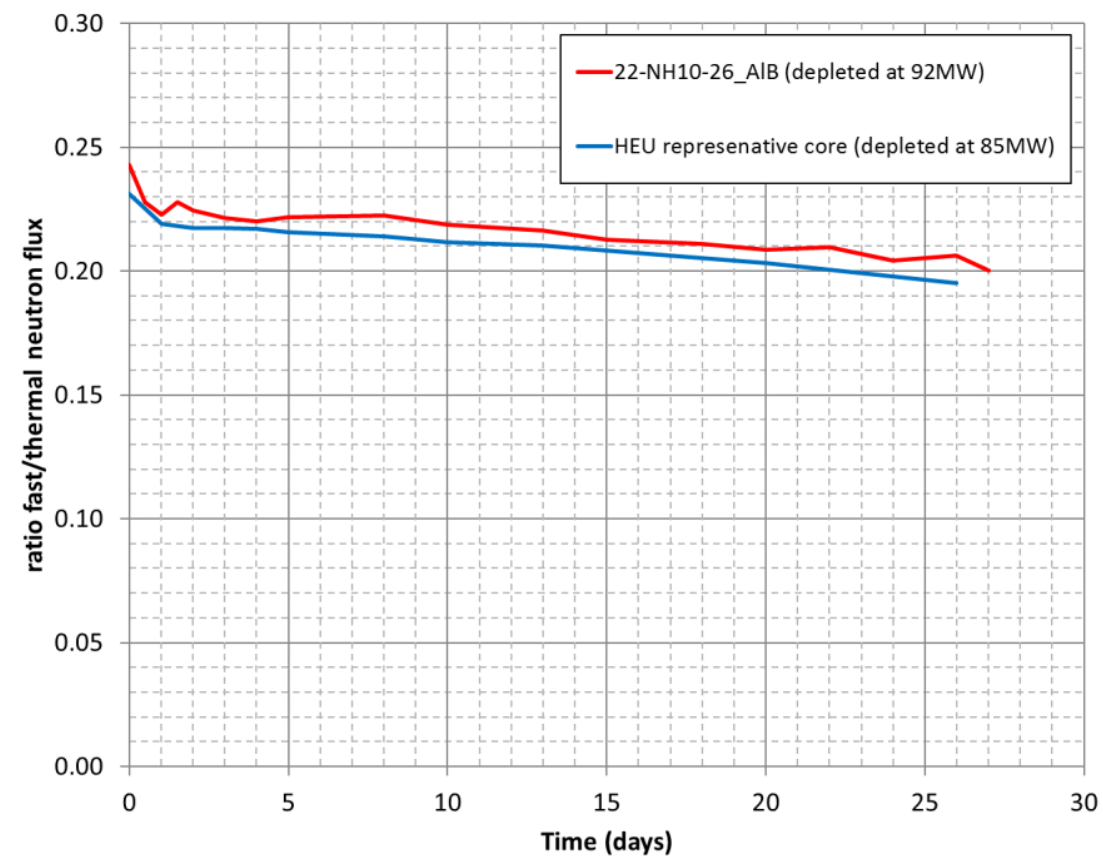

Figure 6-18 - Ratio of fast / thermal neutron flux in cold source (limiting location) for configuration 22NH10-26_AlB depleted at 92MW and HEU depleted at 85MW

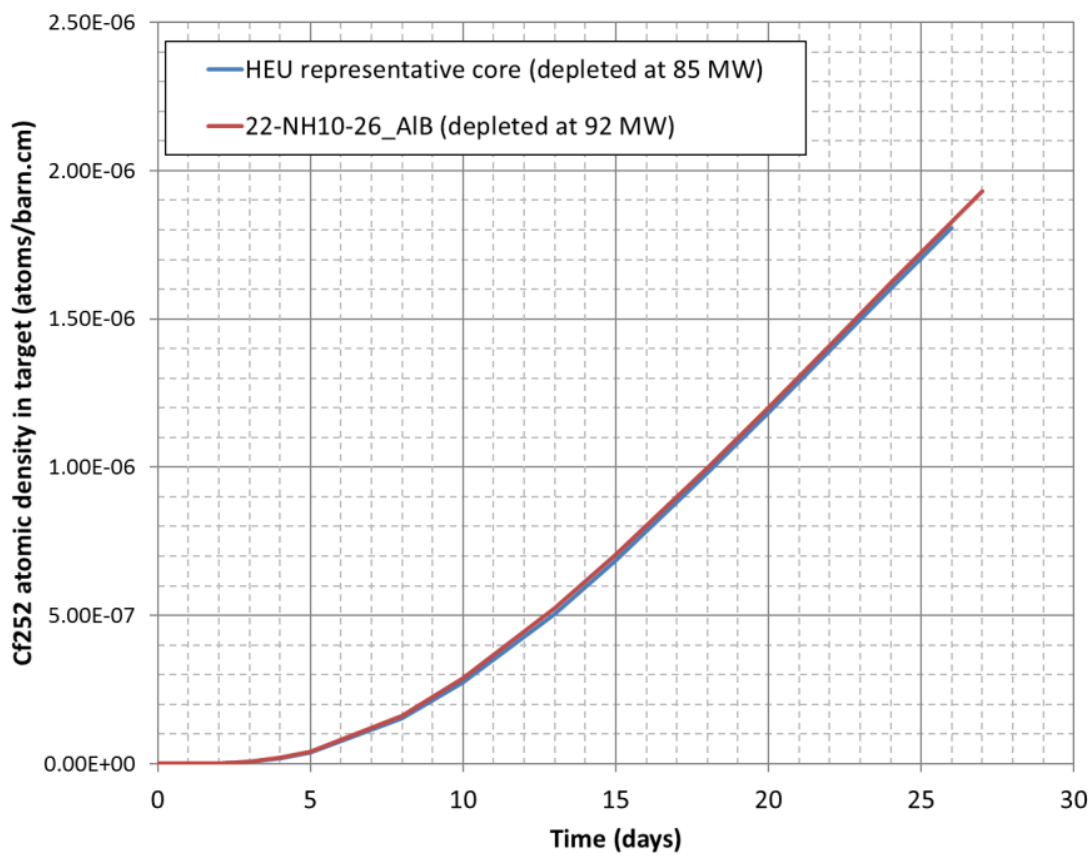

Figure 6-19 - Evolution of the ${ }^{252} \mathrm{Cf}$ atomic density in targets for configuration 22-NH10-26_AlB depleted at 92MW and HEU depleted at 85MW

Alternate Design Concepts for the High Flux Isotope Reactor using Low-Enriched Uranium Fuel Systems - Scoping Analysis 


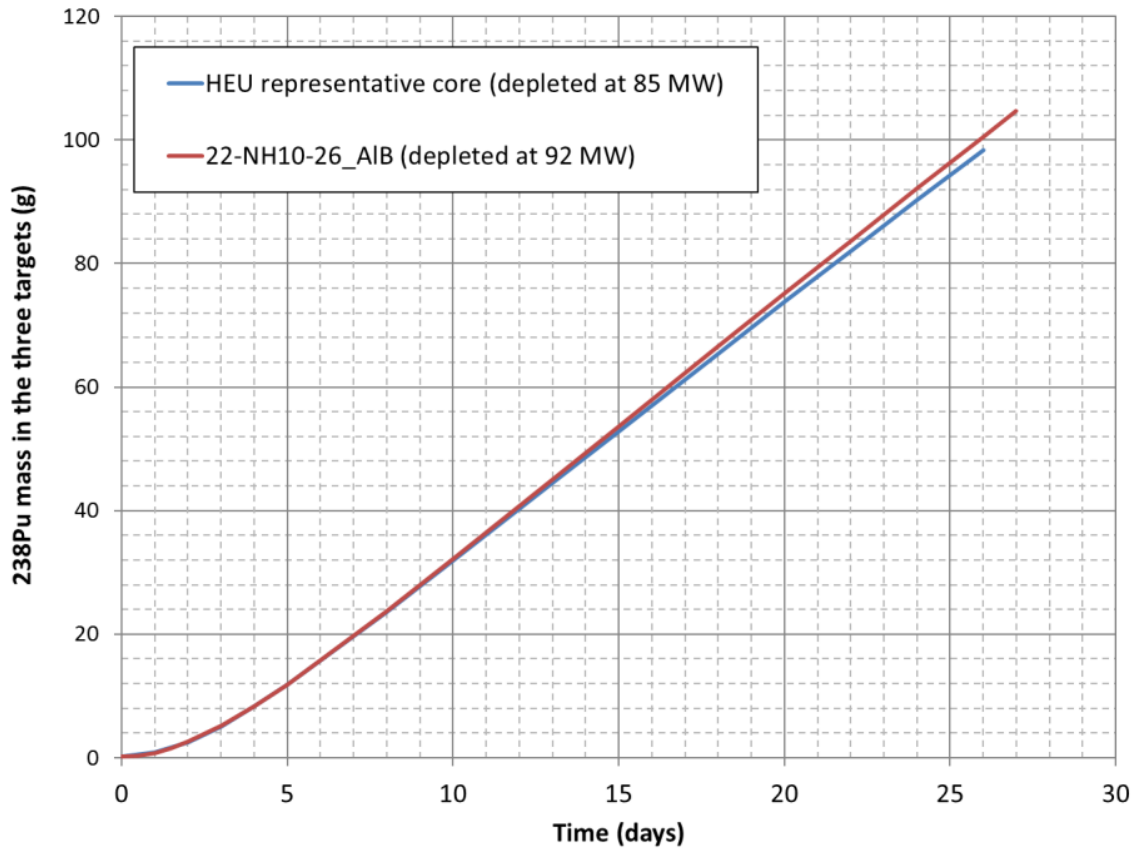

Figure 6-20 - Evolution of the ${ }^{238} \mathrm{Pu}$ mass in targets for configuration 22-NH10-26_AlB depleted at 92MW and HEU depleted at 85MW

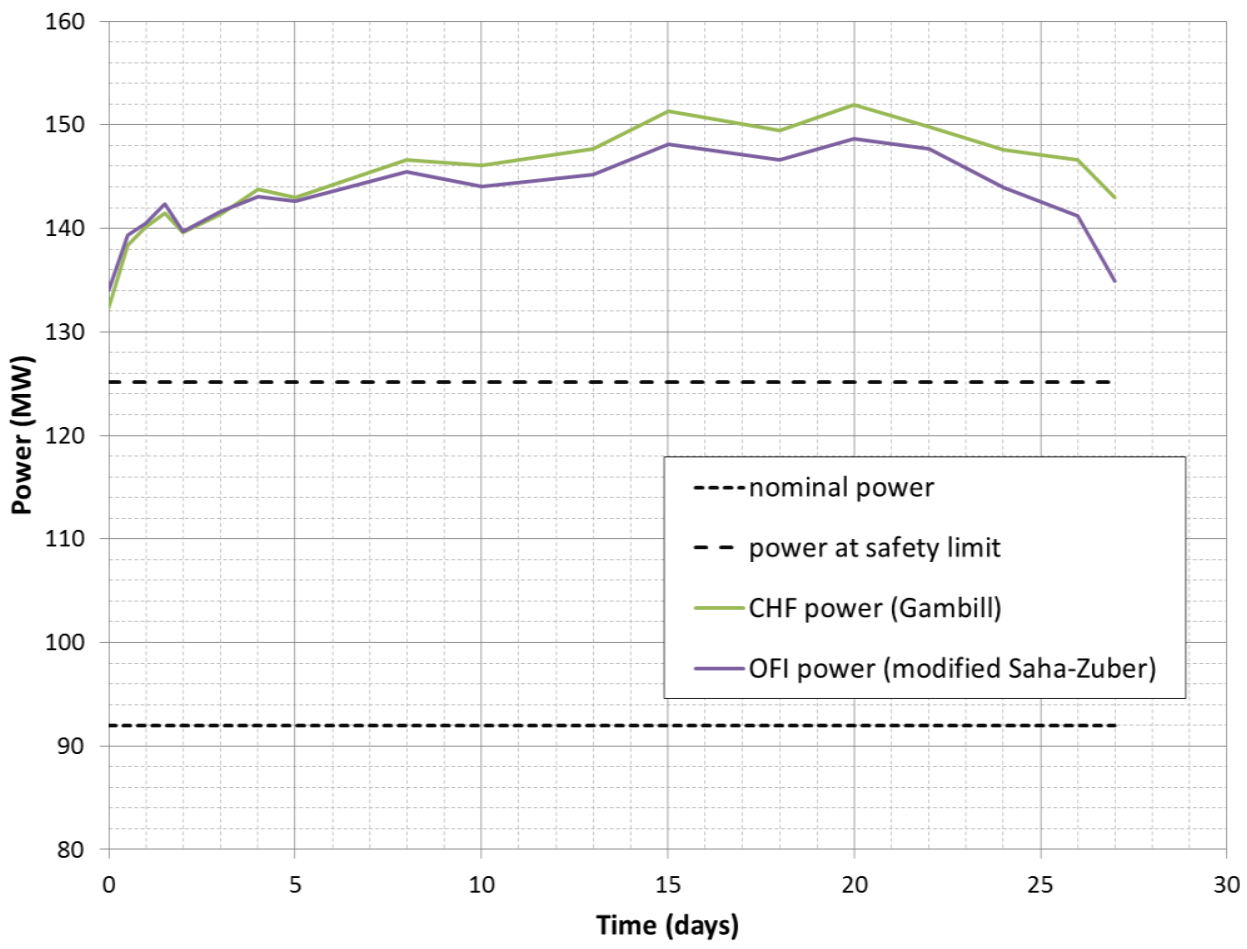

Figure 6-21 - Evolution of the power leading to CHF and OFI for configuration 22-NH10-26_AlB depleted at $92 \mathrm{MW}$ and compared to the nominal and safety limit power

Alternate Design Concepts for the High Flux Isotope Reactor using Low-Enriched Uranium Fuel Systems - Scoping Analysis 
Table 6-8 - characteristics of the silicide 22-NH10-26_AlB design and current HEU core

\begin{tabular}{|c|c|c|}
\hline Core parameters & HEU core & 22-NH10-26_AlB \\
\hline Nominal reactor power (MW) & 85 & 92 \\
\hline Number of fuel elements & 2 & 2 \\
\hline Cladding type & Al-6061 & Al-6061 \\
\hline Fuel type & $\mathrm{U} 308-\mathrm{Al}$ & U3Si2 - Al \\
\hline Fuel form & Mixed powder & Mixed powder \\
\hline 235U enrichment (wt. \%) & 93.10 & 19.75 \\
\hline${ }^{235} \mathrm{U}$ loading (IFE/OFE/total, kg/core) & $2.60 / 6.8 / 9.40$ & $3.97 / 9.15 / 13.12$ \\
\hline Uranium loading (IFE/OFE/total, kg/core) & $2.79 / 7.30 / 10.10$ & $20.10 / 46.33 / 66.46$ \\
\hline Number of plates (IFE / OFE) & $171 / 369$ & $171 / 369$ \\
\hline Plate length (in) & 24 & 24 \\
\hline Plate thickness (mil) & 50 & 50 \\
\hline Channel thickness (mil) & 50 & 50 \\
\hline Fuel length (in) & 20 & 22 \\
\hline Fuel width (IFE, OFE, in) & $3.07 / 2.79$ & $3.07 / 2.79$ \\
\hline $\begin{array}{l}\text { IFE fuel thickness: } t=f(s) \text {, where } t \text {, fuel thickness } \\
\text { (mil) is function of } s \text {, distance along involute arc } \\
\text { length (in) }\end{array}$ & Not communicated & $\begin{array}{c}\mathrm{t}=-5.046269 \mathrm{E}-02 \mathrm{~s}^{6}- \\
2.107159 \mathrm{E}-01 \mathrm{~s}^{5}+ \\
3.357662 \mathrm{E}+00 \mathrm{~s}^{4}- \\
9.407684 \mathrm{E}+00 \mathrm{~s}^{3}+ \\
4.124355 \mathrm{E}+00 \mathrm{~s}^{2}+ \\
1.517110 \mathrm{E}+01 \mathrm{~s}+ \\
9.606028 \mathrm{E}+00\end{array}$ \\
\hline IFE fuel + filler thickness (mil) & 30 & 26 \\
\hline IFE fuel volume / plate (cc) & 21.0 & 24.5 \\
\hline IFE filler volume / plate (cc) & 9.18 & 4.28 \\
\hline${ }^{10} \mathrm{~B}$ density in IFE filler $(\mathrm{g} / \mathrm{cc}$ ) & 0.001752 & 0.001752 \\
\hline${ }^{10} \mathrm{~B}$ mass in IFE filler ( $\mathrm{g} /$ plate) & 0.0161 & 0.0075 \\
\hline${ }^{10} \mathrm{~B}$ mass in IFE element $(\mathrm{g})$ & 2.75 & 1.28 \\
\hline OFE fuel thickness (mil) & Not communicated & 26 (constant value) \\
\hline OFE fuel volume (cc/plate) & 18.77 & 26.2 \\
\hline 235U maximum consumption (\%) & Not communicated & 61.3 \\
\hline Estimated peak fission density (f/cc fuel particle)* & Not communicated & $3.5 \times 10^{21}$ \\
\hline Peak power density (kW/cc meat) & Not communicated & 25.3 \\
\hline Peak power density (kW/cc fuel particle) & Not communicated & 59.6 \\
\hline Peak heat flux $\left(\mathrm{W} / \mathrm{cm}^{2}\right)$ & Not communicated & 469 \\
\hline
\end{tabular}

* Based on ${ }^{235} \mathrm{U}$ consumption only (excludes other fissile isotope contribution such as ${ }^{239} \mathrm{Pu}$ but includes ${ }^{235} \mathrm{U}$ consumption induced by other reactions such as $[n, \gamma]$. Reported value is therefore expected to be slightly conservative 


\section{Conclusions}

The present report investigated alternate design concepts for the HFIR reactor using LEU fuel systems. The designs presented here were based on the assumptions that some of the geometric constraints could be relaxed, the fuel length in particular.

For both fuel systems considered in this analysis - UMo monolithic and silicide namely - it appears clearly that a longer fuel would be beneficial for safety margins as it tends to reduce power peaking. Unfortunately, this is insufficient to eliminate the need for complex features: If it is relatively easy to find designs meeting the performance criteria, it remains excessively difficult to find configurations satisfying the safety criteria, especially in the inner element.

The UMo design presented here would not require contouring the fuel but would need a substantial re-design of the inner element (fuel plates and side-plate) with an absorbing sleeve.

The complex features required for the proposed silicide design are remarkably similar to the current HEU core: fuel contour, presence of B4C in the IFE plate's filler.

Both concepts would certainly present fabrication challenges and would require a substantial fabrication development effort. In addition, for silicide, the lack of burnup-dependent thermal conductivity and blister data would need to be addressed.

The difficulty of meeting the safety criteria in the inner element plates is related to the particularly conservative safety basis implemented in the HSSHTC code (heat transfer modeled only in one dimension and cumulative combination of hot channel factors). The current effort lead by ORNL to replace HSSHTC by the code COMSOL - able to model heat transfer in three dimensions - should be pursued and encouraged as it could be a way to alleviate some of the conservatisms inherent with the use of HSSHTC. Safety criteria evaluated with COMSOL could lead to simpler designs, which could be necessary if the current fabrication development effort fails to produce the complex features proposed by the design team. 


\section{Acknowledgements}

This work was sponsored by the U.S. Department of Energy, Office of Material Management and Minimization in the U.S. National Nuclear Security Administration Office of Defense Nuclear Nonproliferation under Contract DE-AC02-06CH11357. This report would not have been possible without the close collaboration, professionalism and availability of the ORNL conversion team.

Alternate Design Concepts for the High Flux Isotope Reactor using Low-Enriched Uranium Fuel 


\section{References}

[Anselmet, 2013]

[Bergeron, 2012]

[Bojanowski, 2018]

[Chandler, 2015]

[Cheverton, 1960]

[Cheverton, 1962]

[Cheverton, 1971]

[Croff, 1980]

[Gouat, 2011]

[Haeck, 2007]

[HFIR SAR, 2009]

[Hilvety, 1967]

[IAEA, 1992]

[Ilas, 2011]
M-C. Anselmet et al. "Dimensioning the EVITA semi-open loop at BR2 for qualification of full size JHR fuel elements", RRFM 2013, http://www.euronuclear.org/meetings/rrfm2013/transactions.htm

A. Bergeron, "Review of the Oak Ridge National Laboratory (ORNL) Neutronic Calculations Regarding the Conversion of the High Flux Isotope Reactor (HFIR) to the Use of Low Enriched Uranium (LEU) Fuel", ANL/RERTR/TM-12/49, Argonne National Laboratory, 2012

C. Bojanowski et al., "Influence of Multi-Dimension Heat Conduction on Heat Flux Calculation for HFIR LEU Analysis", ANL/RTR/TM-17/18, Argonne National Laboratory, 2018

David Chandler, private communication. Email sent to A. Bergeron $04 / 23 / 2015$

R.D. Cheverton, “HFIR Preliminary Physics Report”, ORNL-3006, October 1960.

R. D. Cheverton, "Preliminary Report on Experimental Power and Flux Distribution in HFCE-2", ORNL-TM-90, January 1962.

R.D. Cheverton, T.M. Sims, “HFIR Core Nuclear Design”, ORNL-4621, July 1971.

A. G. Croff, "ORIGEN-2 - A revised abd Updated Version of the Oak Ridge Isotope Generation and Depletion Code", ORNL-5621, 1980

P. Gouat, "Dimensioning the EVITA semi-open loop at BR2 for qualification of full size JHR fuel elements", Nuclear Engineering and Design, vol. 241 (2011), Issue 2, pp. 925-941

http://www.sciencedirect.com/science/article/pii/S0029549311000306

W. Haeck, "An Optimum Approach to Monte Carlo Burnup", Nuclear Science and Design, Vol. 156, pp. 180-196, 2007.

HFIR Safety Analytic Report, ORNL/HFIR/USAR/2344/Rev. 6B, approved $01 / 2009$.

N. Hilvety et al. "HFIR Fuel Element Steady State Heat Transfer Analysis", ORNLTM-1903, Oak Ridge National Laboratory, 1967

"Research Reactor Core Conversion Guidebook Volume 4 : Fuels (Appendices IK)”, International Atomic Energy Agency [IAEA], IAEA-TECDOC-643, 1992, http://www-pub.iaea.org/MTCD/publications/PDF/te 643v4 prn.pdf

G. Ilas, R.T. Primm III, "Low Enriched Uranium Fuel Design with TwoDimensional Grading for the High Flux Isotope Reactor", ORNL/TM-2010/318, March 2011.

Alternate Design Concepts for the High Flux Isotope Reactor using Low-Enriched Uranium Fuel Systems - Scoping Analysis 
[Jaluvka, 2016]

[Kalcheva, 2012]

[Koonen, 2009]

[Lane, 1958]

[Lane, 1959]

[McLain, 1967]

[Meyer, 2017]

[NIST, 2018]

[NRC, 1988]

[ORNL, 2017]

[Renfro, 2014]

[Rothrock, 2008]

[Stillman, 2012]
D. Jaluvka et al., Argonne National Laboratory, unpublished information, 2016

S. Kalcheva et al. "Reactivity Performances of Two Prototypes HEU Fuel Elements with Cadmium Wires Irradiated In the BR2 Reactor", European Research Reactor Conference, RRFM/IGORR 2012, Prague, March 18-22, 2012, Czech Republic

E. Koonen et al. "EVITA: a semi-open loop in BR2 for RJH fuel qualification", RRFM 2009, http://www.euronuclear.org/meetings/rrfm2009/transactions.htm

J. A. Lane et al., "Ultra High Flux Research Reactors", ORNL CF-58-7-117, July 1958.

J. A. Lane et al., "High Flux Isotope Reactor Preliminary Design Study", ORNL CF59-2-65, March 1959.

H. A. McLain "HFIR Fuel Element Steady State Heat Transfer Analysis Revised Version", ORNL-TM-1904, December 1967

M. Meyer et al. "Preliminary Report on U-Mo monolithic Fuel for Research Reactors", INL/EXT-17-40975, Rev. 0, September 2017.

NIST database website, http://www.nist.gov/pml/data/comp.cfm

"Safety Evaluation Report Related to the Evaluation of Low-Enriched Uranium Silicide-Aluminum Dispersion Fuel for Use in Non-Power Reactors",

U.S. Nuclear Reactor Regulation [NRC], NUREG-1313, 07/1988, http://www.osti.gov/scitech/servlets/purl/6830338

ORNL website, http://neutrons.ornl.gov/facilities/HFIR/, visited June 13 2017.

D. Renfro et al. "Preliminary Evaluation of Alternate Designs for HFIR LowEnriched Uranium Fuel", ORNL/TM-2014/154, 10/2014

R. B. Rothrock, "HFIR Safety Limits Calculations", ORNL RRD Calculations, CHFIR-2007-005, approved 04/30/2008

J. Stillman et al., "Technical Basis in Support of the Conversion of the University of Missouri Research Reactor (MURR) Core from Highly-enriched to LowEnriched Uranium - Core Neutron Physics", ANL/RERTR/TM-12/30, Argonne National Laboratory, 2012

Alternate Design Concepts for the High Flux Isotope Reactor using Low-Enriched Uranium Fuel Systems - Scoping Analysis 



\section{Argonne $\mathbf{A}$}

\section{Nuclear Science and Engineering Division}

Argonne National Laboratory

9700 South Cass Avenue, Bldg. 208

Argonne, IL 60439

www.anl.gov

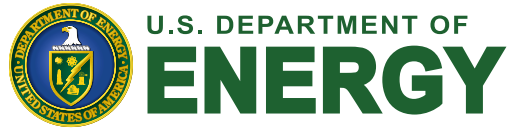

Argonne National Laboratory is a U.S. Department of Energy laboratory managed by UChicago Argonne, LLC 